Erster Beratungsgegenstand:

\title{
Die Finanzverfassung im Rahmen der Staatsverfassung
}

1. Bericht von Professor Dr. Karl M. Hettlag e, Mainz

I.

Die deutsche Finanzverfassung ist seit der Verabschiedung des Gmundgesetzes eine offene Frage. Der Verfassungsgeber von 1949 sah sich aus äußeren und inneren Gründen nicht in der Lage, für den Bereich der Finanzen eine Zwischenverfassung so festzulegen, wie es im übrigen geschehen ist. In Art. 107 GG wurde der einfache Bundesgesetzgeber verpflichtet, diesen vorläufigsten Teil einer vorläufigen Ordnung bis zum Ende des Jahres 1952 durch eine vorläufig endgültige Regelung zu ersetzen. Seit 4 Jahren erörtern nun die gesetzgebenden Körperschaften, die Wissenschaft und die öffentliche Meinung Mittel und Wege zu einer besseren Finanzverfassung. Auch die Staatsrechtswissenschaft hat dazu einiges zu sagen.

Unsere heutige Finanzverfassung genießt keinen guten Ruf, obwohl die Finanzen nicht in schlechter Verfassung sind. Die bisherige Entwicklung hat eindeutig dargetan, daß die derzeitigen Verfassungsgrundlagen der Finanzpolitik je länger je mehr ein Hemmnis der großen Politik nach innen und außen sind. Utber den hohen Rang der Frage nach einer besseren und richtigeren Finanzverfassung braucht kein Wort verloren zu werden. Die vom Verfassungsgeber selbst aufgegebene Neuordnung ist die erste größere Revision des Grundgesetzes und rührt an seine tragenden Grundgedanken.

Die besonderen finanzpolitischen und finanzwissenschaftlichen Fragen, die vor allem der bundesstaatliche Finanzausgleich aufgibt, werde ich nicht erörtern, obwohl gerade von dort her die gestaltenden Kräfte der Finanzverfassung kommen. Eine Betrachtung der Finanzverfassung in erster Linie unter staatsrechtlichen Gesichtspunkten tut den Problemen notwendig Gewalt an. Dieser gewollten Einseitigkeit der Betrachtungsweise müssen wir uns bei unserem Gedankenaustausch bewußt bleiben.

Mein Bericht bringt zunächst einige grundsätzliche Ubberlegungen über die Finanzverfassung überhaupt, ihr Ziel, ihren Gegenstand und ihre normative Eigenart; er wendet sich dann der Finanzgewalt und ihren Grenzen zu, insonderheit der Stel- 
lung der Finanzgewalt im Rechtsstaat, in der Gewaltenteilung und im Bundesstaat.

\section{Wesen und Aufgabe einer verfassungs-} rechtlichen Finanzordnung

Unter der Finanzverfassung im staatsrechtlichen Sinne ist der Inbegriff jener Verfassungsnormen zu verstehen, die sich mit der Ordnung des Geldwesens und dem Ablauf der Finanzvorgänge in der staatlichen Haushalts-, Vermögens- und Schuldenwirtschaft und insbesondere der Grundordnung des Steuerwesens beim Staat und den eingegliederten Gemeinwesen befassen. Mit Recht hat Strickrodt in einer weit ausholenden Untersuchung über die Möglichkeiten eines allgemeinen Systems der Finanzverfassung hervorgehoben, daß dieser Begriff bisher allzu eng gehandhabt worden ist, indem man unter Finanzverfassung hauptsächlich die verfassungsrechtliche Ordnung der Finanzgewalt im Bundesstaat, den Finanzausgleich, verstanden hat. Tatsächlich schafft aber die Finanzverfassung erst den sicheren Rechtsboden, auf dem das ganze Wirtschaftsund Sozialgefüge ruht. Vorgänge des Geldwesens sind zwar immer nur Spiegelungen bestimmter güterwirtschaftlicher Sachverhalte. Diese Spiegelhaftigkeit nimmt ihnen aber nicht ihre eigene und unmittelbare Wirksamkeit in der Wirtschaftsordnung. Dieser untrennbare Zusammenhang von Wirtschaftsordnung und Fianzverfassung gipfelt in der Abhängigkeit des Wertes fast aller Rechtsbeziehungen vom Wert des Geldes. Ihren letzten Sinn nimmt die Finanzverfassung aus dieser Hinordnung auf die Sicherheit der Währung und die Beständigkeit aller geldwerten Rechtsverhältnisse.

Von der Finanzverfassung kann im gleichen Sinne wie von der Wirtschaftsverfassung gesprochen werden. Beide sind zwei Seiten der gleichen Münze. Soweit die Grundlagen des Wirtschaftslebens verfassungsrechtlich überhaupt normiert werden, wird damit zugleich immer auch etwas über die Verfassung des Geldwesens ausgesagt. So wird die Grundentscheidung einer Verfassung für ein liberales Wirtschaftssystem im Geldwesen nur eine Funktion der freien Wirtschaft und im Finanzrecht nur ein Organisationsmittel der Gesellschaft sehen, wie sie z. B. in bestimmten Autonomievorstellungen für die Notenbank oder in der gesetzlich offenen Kreditschöpfung der Banken sich ausdrückt. Eine liberale Wirtschaftsverfassung wird die Finanzgewalt des Staates gegenüber dem Bürger anders ausgestalten als etwa eine sozialistische oder totalitäre Ordnung. Eine Verfassung, die - wie das Grundgesetz - über die verfassungsmäßige Wirtschaftsordnung nichts Besonderes aus- 
sagt, könnte an den Grundlagen der Finanzordnung ebenso schweigend vorübergehen. Sie könnte sich gegenüber Änderungen des Geldwertes als einem gesellschaftlichen Vorgang ebenso neutral verhalten wie gegenüber Fehlbeträgen im Staatshaushalt oder gegenüber Art und Ausmaß der staatlichen Verschuldung. Auch die Organisation der Finanzgewalt im Bundesstaat mit ihren Bestimmungen über die Zuteilung von Steuerquellen oder Steuererträgen könnte sie der einfachen Gesetzgebung nach der allgemeinen Kompetenzordnung überlassen, wie es die Weimarer Reichsverfassung im wesentlichen getan hat. Sie brauchte auch nichts über die innere Ordnung des Staatshaushaltes oder über die staatliche Verschuldung auszusagen.

Die tragenden Leitgedanken auch der Finanzverfassung gründen sich auf bestimmte politische Ideale, nicht zuletzt auf einer bestimmten Vorstellung von der sozialen Gerechtigkeit. Auch darin unterscheidet sie sich nicht von der Wirtschaftsverfassung. $\mathrm{Ob}$ man sie wegen dieser letzten Rechtfertigung in ihren Hauptsätzen, z. B. hinsichtlich der Stabilität des Geldwertes, mit dem Range überpositiven Rechts und der Geltungskraft ungeschriebenen Verfassungsrechts ausstatten darf, wie es gelegentlich geschieht, erscheint mir allerdings zweifelhaft. In welchem Maße aber ihre Kernsätze von den verfassungspolitischen Grundentscheidungen berührt werden, mag in bezug auf den Rechtsstaatsgedanken, die Gewaltenteilungslehre und das bundesstaatliche Prinzip näher dargetan werden.

\section{Rechtsstaat und Finanzverfassung}

Die rechtsstaatliche Grundordnung will die menschliche Persönlichkeit gegenüber staatlichen und sozialen Gewalten schützen. Damit muß sie auch der Finanzgewalt bestimmte Grenzen setzen und das natürliche ungeregelte Finanzgeschehen, durch das der Sozial- und Rechtsordnung schwere Gefahren drohen können, normativ umhegen. Sie muß vor allem auch den staatlichen Steueranspruch grundsätzlich der gleichen rechtsstaatlichen Begrenzung und Formalisierung wie sonstige Eingriffe der Staatsgewalt unterwerfen, wenn die rechtsstaatliche Grundordnung vollständig und widerspruchsfrei sein soll. Mit Recht aber hat Herr Forsthoff in seinem Bericht über Begriff und Wesen des sozialen Rechtsstaates vor diesem Kreise 1953 betont, daß der Rechtsstaat als Steuerstaat auf einer spezifischen, in der rechtsstaatlichen Verfassung enthaltenen Voraussetzung beruhe, nämlich der Abgrenzung der Finanzhoheit von dem grundrechtlichen Schutz des Eigentums. Der Steueranspruch ist seiner Natur nach niemals Enteignung 
im staatrechtlichen Sinne mit ihren Schranken und ihren Rechtsfolgen. Diese Herausnahme des Steueranspruchs aus dem Verfassungsschutz gegen enteignende Eingriffe bedeutet eine wesentliche Durchbrechung des ganzen rechtsstaatlichen Schutzsystems. Tatsächlich ist sie auch das trojanische Pferd des Sozialismus im bürgerlichen Rechtsstaat, wie uns die englische Entwicklung der letzten Jahrzehnte und unsere eigene auch beweisen. Wir allerdings haben dazu noch einen anderen Mißbrauch der staatlichen Finanzgewalt in der Stabilisierungsgesetzgebung nach zwei großen Inflationen mit ihren enteignenden Folgen gründlich kennengelernt. Was bleibt aber von der freiheitlichen Grundordnung und dem Schutz des Eigentums bestehen, wenn der Staat alle Geldbesitzer um 93,5 vH und alle Gläubiger um $90 \mathrm{vH}$ und seine eigenen sogar um $100 \mathrm{vH}$ ohne Verfassungsbruch enteignen darf?

Die Herausnahme der Finanzgewalt des Staates aus dem grundrechtlichen Enteignungsschutz gibt schwere Probleme auf. Es ist offenbar unsinnig und unmöglich, die Finanzgewalt unter die Grenzen und Rechtsfolgen von sonstigen enteignenden Eingriffen zu stellen. Auf ihr beruht die gesamte materielle Ordnung des Staatslebens. Die Finanzgewalt allein ermöglicht es, das Bekenntnis der Verfassung zum Sozialstaat zu verwirklichen. Das Spannungsverhältnis zwischen dem rechtsstaatlichen und sozialstaatlichen Ideal ist durch eine materielle Einschränkung der Finanzgewalt nicht aufzuheben. Eine solche Schutzklausel wäre ein Fremdkörper im System des sozialen Rechtsstaates. Sie wäre auch rechtsinhaltlich kaum vorstellbar und vollziehbar und würde günstigenfalls den Katalog unbestimmter Verfassungsrechtsbegriffe um eine weitere Umschreibung des Angemessenen und seiner Grenzen vermehren. Der gesetzgebenden Gewalt und auf der Grundlage der Gesetze auch der vollziehenden Gewalt ist hier ein breites Tor des Interventionismus ohne verfassungsrechtliche Schranken eröffnet, worauf schon Herr Scheuner in seinem vorjährigen Referat hingewiesen hat.

Inwieweit die Würde des Menschen und das allgemeine Persönlichkeitsrecht durch ein Utbermaß enteignender Besteuerung ader durch bestimmte Formen dieser Enteignung verletzt sein könnten, mag hier dahingestellt bleiben. Diese äußersten Werte der grundrechtlichen Ordnung begrenzen selbstverständlich auch die Finanzgewalt. Das gleiche muß von dem rechtsstaatlichen Fundamentalsatz der Gleichheit vor dem Gesetz gesagt werden. Aber wegen Verletzung des Gleichheitssatzes ist meines Wissens noch nie ein Steuergesetz für ver- 
fassungswidrig erklärt worden, auch nicht das Investitionshilfegesetz, dem Herr Ipsen unter diesem Gesichtspunkt eine so tiefgründige Kritik angedeihen ließ. Der Gleichheitssatz bedeutet für die Handhabung der Finanzgewalt, daß, wie es Art. 134 der Weimarer Reichsverfassung ausdrückte, die Staatsbürger ohne Unterschied im Verhältnis ihrer Mittel zu allen öffentlichen Lasten nach Maßgabe der Gesetze beitragen. Eine solche Formel relativiert den verfassungsrechtlichen Schutz gegen abgaberechtliche Willkür fast bis zur Unwirksamkeit.

Die merkwürdige Sonderstellung der Finanzgewalt in der rechtsstaatlichen Schutzordnung betrifft natürlich nur Art und Außmaß des Steueranspruchs, nicht seine rechtsstaatliche Formalisierung durch den Vorbehalt und den Vorrang des Gesetzes; sie beschränikt insbesondere auch nicht die Zulässigkeit des Rechtsweges Eine Finanzgerichtsbarkeit nach den allgemeinen rechtsstaatlichen Grundsätzen verstände sich aus der Generalklausel des Art. 19 GG bei uns von selbst, auch wenn sie nicht in Art. 108 GG noch ausdrücklich vorgesehen wäre. Diese Finanzgerichtsbarkeit bedeutet die richterliche Utberprüfung der Gesetzesanwendung im vollen Umfange der sonstigen Verwaltungsgerichtsbarkeit. Sie nimmt an allen verfassungsrechtlichen Garantien der rechtsprechenden Gewalten, die unabhängigen Richtern anvertraut ist, teil. Insoweit kann von einer Sonderstellung der Finanzgewalt im Rechtsstaat nicht gesprochen werden.

Die Finanzverfassung wird auch von einem anderen allgemeinen Verfassungs-Prablem berührt, dem von Verfassungsrecht und Verfassungswirklichkeit. Dieses Spannungsverhältnis, das alle Bereiche der Verfassung durchzieht, wird bei der Finanzverfassung besonders deutlich. Die Kategorien des Geldlichen pflegen höchst real zu sein. Wenn die Verfassung darüber etwas zuverlässig normieren will, ist ihr der bequeme Weg eines dilatorischen Formelkompromisses oder eines bloßen Programmsatzes zwar nicht verwehrt, aber doch aus der Natur der Sache erschwert. Die Finanzverfassung ist sozusagen der Schwurpunkt des ganzen Verfassungswerkes, was Rechtsstaat, Gewaltenteilung und vor allem die bundesstaatliche Ordnung angeht. Man hat den Finanzausgleich nicht zu Unrecht die deutsche Gretchenfrage genannt. In ihr wird die Ernsthaftigkeit und Realisierbarkeit wesentlicher Teile des übrigen Verfassungswerkes auf die Probe gestellt. Daraus mag sich auch die große Zurückhaltung der meisten Verfassungen zu Finanzfragen erklären, die die Entwicklung im wesent- 
lichen der künftigen Entscheidung des einfachen Gesetzgebers überlassen.

Die Anforderungen an eine angemessene, materiell richtige Finanzverfassung wechseln ständig. Es gibt praktisch keinen Grundsatz einer guten Finanzondnung, der nicht heute richtig und notwendig, morgen aber unter veränderten Verhältnissen falsch und unangemessen sein kann. Selbst die goldene Finanzregel des jährlich auszugleichenden Haushalts, die unter normalen Voraussetzungen uneingeschränkt gelten soll und deshalb bei uns in Art. 110 GG mit Verfassungskraft ausgestaltet worden ist, wird in einer Wirtschaftskrise unvernünftig. Die Macht der Verhältnisse würde über sie hinweggehen. Die Normen der Finanzverfassung ermangeln vielfach tatsächlich der Vollziehbarkeit und Durchsetzbarkeit in jedem Fall. So sind z. B. Art. 109, 110 und 113 GG heute schon unwirksame, weil unwirkliche Gesetze. Der Verfassungsgeber sollte sich deshalb gerade im Bereich der Finanzen große Zurückhaltung und äußerstes $\mathrm{MaB}$ auferlegen.

Die rechtsstaatliche Ordnung stetzt eine bestimmte gesellschaftliche Wirklichkeit voraus, die sie schützen und deren Entwicklung sie mehr oder weniger lenken will. Diese Ordnung in Gesellschaft und Wirtschaft beruht auf einer bestimmten Güterondnung mit einem festen Wertmaßstab aller geldwerten Rechtsbeziehungen, den wir Währung nennen. Wenn eine rechtsstaatliche Ordnung ihren Sinn behalten soll, so kann sie an diesem höchsten Rechtsgut, das die Grundlage der gesamten Wirtschafts- und Sozialordnung bildet, nicht achtlos vorübergehen. Veränderungen des Geldwertes sind weithin Folgen der Gesetzgebung, sie können aber auch durch bloße Regierungsmaßnahmen ganz legaler Art ausgelöst werden. Änderungen des Geldwertes brauchen nicht einmal vom Staat auszugehen. Der bloße Ablauf des freien Wirtschaftsgeschehens führt ständig zu Veränderungen der Kaufkraft durch Veränderungen der Preise und Löhne, des Kreditvolumens und anderer automatischer Vorgänge. Hier laufen Ereignisse höchsten politischen Ranges außerhalb der rechtsstaatlichen Grundordnung ab. Auf diesem Wege können Revolutionen sich abseits aller staatsrechtlichen Kategorien vollziehen. Mit anderen Worten: die Währung ist ein Schutzgut jeder rechtsstaatlichen Ordnung, das die Verfassung grundrechtlich oder institutionell, unmittelbar oder mittelbar, geschrieben oder ungeschrieben zu wahren hat.

Wie die Finanzverfassung die Währung normativ schützen sollte und könnte, ist schwer zu sagen. Meist geschieht dies mittelbar durch Gebote oder Verbote oder Verfassungsinsti- 
tutionen, die letztlich dem Schutz der Währung und der Stabilität der wirtschaftlichen und sozialen Verhältnisse dienen. Dazu rechnet beispielsweise schon die verfassungsrechtliche Festlegung der Gesetzesform für den Haushaltsplan und die staatliche Verschuldung und insbesondere natürlich das - sachlich problematische - Verfassungsgebot des Haushaltsausgleichs. $\mathrm{Zu}$ diesem mittelbaren Währungsschutz in der Finanzverfassung gehören weiter etwaige institutionelle Sicherungen für die Unabhängigkeit der Notenbank oder die Sonderrechte der Regierung und des Finanzministers in Finanzfragen oder die Ausdehnung der richterlichen Unabhängigkeit auf die Rechnungsprüfungsbehörden. Diese verschiedenartigen Verfassungsnormen sichern die Währung aber nur mittelbar und unvollständig. Sie sind auch durchweg nicht zu diesem Ziele aufeinander abgestimmt. Dennoch darf ihre Bedeutung nicht unterschätzt werden. In unserer Verfassung könnten sie wesentlich erweitert und vertieft werden $\mathrm{z}$. B. durch eine verfassungsrechtliche Sicherung der Unabhängigkeit der Notenbank, deren Rechtsstellung ursprünglich auf Besatzungsrecht beruhte, heute aber der einfachen Bundesgesetzgebung überlassen ist. $\mathrm{Zu}$ diesem Ziele sagt Art. 88 GG nichts aus.

Einzelne Bestimmungen einfacher Gesetze, die der guten Ordnung der Finanzen und dem Währungsschutz dienen, haben tatsächlich den Rang materieller Verfassungsnormen. Das gilt z. B. von $\S 21$ Abs. 3 der Reichshaushaltsordnung und $\$ 26$ der Geschäftsordnung der Bundesregierung, wonach die Mehrheit der Bundesregierung den Finanzminister nur überstimmen kann, wenn der Bundeskanzler mit der Mehrheit stimmt. Das gleiche galt von $\$ 96$ der Geschäftsordnung des Bundestags, der das Initiativrecht der Abgeondneten bei Finanzvorlagen einschränkte, leider aber durch ein Urteil des Bundesverfassungsgerichts für unzulässig und verfassungswidrig erklärt worden ist. Das Außerordentliche solcher von der Verfassungsregel abweichenden Bestimmungen zum Schutze von Finanzen und Währung bringt sie in die Nähe des Ausnahme- und Notstandsrechts. Sie sind nicht selten autoritäre Abweichungen von den demokratischen Verfassungsgrundsätzen, wie denn die Finanzverfassung aus diesen hier nur angedeuteten Sachzusammenhängen weithin Ausnahmerecht von der allgemeinen Verfassungsregel ist.

Für das Ideal des sozialen Rechtsstaates könnte ein Grundrecht auf stabile Währung, auf Werterhaltung des Erarbeiteten und Gesparten, ebenso gerechtfertigt erscheinen, wie ein Grundrecht auf Arbeit mit dem Ziele der Vollbeschäftigung. Es braucht nicht gesagt zu werden, wie problematisch ein 
solches Grundrecht wäre. Seinem Wesen nach könnte es sich nur als Programmsatz an den Gesetzgeber und die Regierung richten, ohne subjektive Sozialrechte des Einzelnen gegen währungsgefährdende Staatsmaßnahmen zu begründen. Eine aktuelle Rechtswirkung gegen Schwankungen der Kaufkraft, etwa im Sinne einer Richtlinie für Preis- und Lohnbewegungen, würde ein solcher Programmsatz der Verfassung praktisch nicht erwerben können. Lassen wir deshalb diesen abwegigen Einfall aus der Traumfabrilk des Staatsrechts auf sich beruhen. Wir müssen feststellen, daß es für den Wert des Geldes keinen Verfassungsshutz und keine wirkliche Rechtssicherheit gibt. Das letzte Ziel einer Finanzverfassung ist insoweit nicht erreichbar. Das rechtsstaatliche Grundanliegen des Schutzes gegen staatliche Willkür zerschellt hier an der rauhen Wirklichkeit.

Um so bedeutender ist der mittelbare Schutz der Währung durch verfassungsrechtliche Einzelbestimmungen. In dieser Beziehung ist unsere Finanzverfassung wie die der meisten Staaten recht unvollkommen, wie denn überhaupt das Staatsrecht aus den neueren gesicherten Erkenntnissen der Staatswissenschaften, der Wirtschafts- und Finanzwissenschaften, kaum Folgerungen gezogen hat. Die wesentlichen Rechtsstützen einer geordneten Geldverfassung und öffentlichen Finanzgebarung sind durchweg der einfachen Gesetzgebung überlassen, wie z. B. das Notenprivileg und die Stellung der Notenbank gegenüber Gesetzgeber und Regierung oder die - kaum entwickelte - Staatsaufsicht über die Kreditschöpfung der Banken. Andere währungsgefährdende Maßnahmen, wie die staatliche Geldschöpfung durch die Ausgabe von Kassenscheinen mit Annahmezwang oder staatliche Wechselreiterei nach Art der berühmten Mefo-Wechsel oder Kippen und Wippen bei der Münzprägung, sind gesetzlich ungeregelt und nicht verboten.

Unser Grundgesetz kennt einen mittelbaren Währungsschutz in Art. 110 mit dem Gebot des Haushaltsausgleichs, in Art. 112, der Haushaltsüberschreitungen von einem unvorhergesehenen und unabweisbaren Bedürfnis abhängig machen will, in Art. 113 durch die vorbehaltene Zustimmung der Bundesregierung zu Mehrausgabebeschlüssen von Bundestag und Bundesrat gegenüber dem Voranschlag, in Art. 114 in der Entlastung der Bundesregierung durch Bundestag und Bundesrat als einen Akt mehr formeller Kontrolle und in der richterlichen Unabhängigkeit der Mitglieder des Rechnungshofes, und schließlich in Art. 115, der die Aufnahme von Krediten auf einen außerordentlichen Bedarf und in der Regel auf werbende 
Zwecke beschränken will. Wie gering die Rechtssubstanz dieser Klauseln ist und wie wirkungslos sie in der politischen Praxis vielfach sind, wird uns zum Teil noch beschäftigen und braucht im einzelnen hier nicht dargetan zu werden. Als verfassungsrechtlicher Schutzdamm für die Stabilität der Währung können sie kaum gewertet werden. Soviel über die Bedeutung der Finanzverfassung für die rechtsstaatliche Grundordnung.

IV. Die Finanzgewalt in der Gewaltenteilung

Auch ein anderer tragender Grundgedanke unserer Verfassung, der Grundsatz der Gewaltenteilung, gibt für die Finanzverfassung eigene Probleme auf. Wesentliche Durchbrechungen des Trennungsgrundsatzes sind für die Finanzverfassung geradezu typisch. Nicht zu Unrecht hat Herr Wacke die Finanzverfassung der Bundesrepublik als einen Katalog von Verfassungsausnahmen bezeichnet. Diese Abweichungen von der sonstigen Kompetenzordnung betreffen die Zuständigkeit zur Steuergesetzgebung, das Verhältnis von Legislative und Exekutive bei der Feststellung des Staatshaushalts und insbesondere die Aufteilung der Finanzgewalt im Bundesstaat. Die Abweichungen von der allgemeinen Verfassungsordnung berühren sogar die Gerichtsbarkeit, wenn man die einheitliche Regelung der Finanzgerichtsbarkeit durch Bundesgesetz, die Art. 108 Abs. 5 GG vorschreibt, abweichend von Art. 92 GG dahin versteht, daß die Finanzgerichte aller Instanzen als Bundesgerichte eingerichtet werden können. Ich halte diese Auffassung mit den Herren Friesenhahn und Klein nicht für zutreffend, will darauf aber auch im einzelnen nicht eingehen.

Für die grundsatzwidrige Ausübung tron funktioneller Verwaltung durch Organe der Gesetzgebung bietet die Finanzverfassung die bekannten Beispiele der Feststellung des Haushaltsplans oder der Erteilung von Kreditermächtigungen durch ein formelles Gesetz, die einen eindeutigen Vorrang der Legislative begründen. Das erklärt sich aus der geschichtlichen Entwicklung des vordemokratischen Steuerbewilligungsrechts zum volldemokratischen Haushaltsbewilligungsrecht.

Auch hier bestätigt sich die Feststellung der Herren Drath, Forsthoff, Weber u. a., daß der Grundsatz der Gewaltenteilung seine umfassende Funktion des Hemmens und Ausgleichs der Gewaltenträger in der modernen Demokratie einzubüßen beginnt und mehr ein technisches Mittel zur Organisation der Staatsgewalt zugunsten der individuellen Freiheit geworden ist. Der Einbruch der gesetzgebenden Gewalt in den Funktionsbereich von Regierung und Verwaltung ist breit: von der Enteignung durch Gesetz über parlamentarische Mitwirkungs- 
rechte beim Gesetzesvollzug bis zur unmittelbaren Einflußnahme auf die Durchführung des gesetzlich festgestellten Haushaltsplanes. Die Ursachen und Probleme dieser Entwicklung gehören nicht hierher, ihre Auswirkungen auf die Finanzverfassung, insbesondere auf die Rechtsnatur des Haushaltsplans und die tragenden Grundgedanken des öffentlichen Haushaltsrechts, sollen aber kurz hervorgehoben werden.

Das Haushaltsgesetz ist keine Norm, die Ansprüche oder Verbindlichkeiten Dritter begründet ( $\$ 24 \mathrm{RHO}$ ); das gilt gleichermaßen für öffentliche und private Rechte und Pflichten. So kann z. B. eine Steuer nicht schon deshalb erhoben werden, weil sie im Haushaltsgesetz vorgesehen ist. Umgekehrt muß eine Verbindlichkeit gegenüber dem Staat selbstverständlich erfüllt werden, auch wenn sie nicht im Haushaltsplan als Einnahme veranschlagt ist. Die Rechtswirkung des Haushaltsgesetzes wird zutreffend als Autorisation, als Ermächtigung an die Regierung zur Leistung bestimmter Ausgaben für bestimmte Zwecke gekennzeichnet. Für die Einnahmeseite des Haushaltsplans begnündet das Haushaltsgesetz keine Pflicht der Regierung, die veranschlagten Beträge zu erheben. Eine Rechtspflicht dazu kann nur durch besondere Gesetze, vor allem die Abgabengesetze, begründet werden; das gleiche gilt für eine etwaige Verpflichtung der Regierung zur Leistung bestimmter Ausgaben. Die vollziehende Gewalt ist bei der Durchführung des Haushaltsplans kein Vollzugsausschuß der gesetzgebenden Gewalt. Diese Selbständigkeit und alleinige Verantwortung der Regierung entspricht dem Verfassungsgrundsatz der Gewaltentrennung in Art. 20 Abs. 2 GG. Die Befugnisse der gesetzgebenden Organe beschränken sich auf die politische Haushaltsüberwachung, die sich in der formalen Genehmigung von Haushaltsabweichungen, in der Utberprüfung der Rechnung und der abschließenden Entlastung äußert. Einmischungen von Gesetzgebungsorganen, z. B. des Finanzausschusses oder eines Fachausschusses der Vollksvertretung, in den Vollzug des Haushaltsplans sind verfassungswidrig. So ist ein Haushaltsvermerk, der die Leistung einer Ausgabe oder die Besetzung einer Planstelle von der vorherigen Zustimmung eines Ausschusses der Volksvertretung abhängig machen will, rechtsunwirksam und für die Regierung unbeachtlich. Nach Art. 79 Abs. 3 GG würde eine Mitwirkung von Gesetzgebungsorganen beim Vollzug des Haushaltsplans nicht einmal durch verfassungsänderndes Gesetz begründet werden können. Ich bin der Meinung, daß diese Verfassungsschranke auch außerhalb des Haushaltsvollzuges unübersteighar ist und eine Mitwirkung von Ausschüssen oder Mitgliedern der gesetzgebenden 
Körperschaften in Regierungs- und Verwaltungsangelegenheiten auf Grund besonderer Gesetze verbietet.

Für den Bereich des Haushaltsvollzuges muß ich aber leider hinzusetzen, daß diese verfassungsrechtlichen Feststellungen über die alleinige Entscheidungskompetenz der Regierung tatsächlich nur einen geringen praktischen Wert haben, denn die politische Abhängigkeit der Regierung vom Parlament läßt sie ein ständiges Einvernehmen mit diesem suchen und Auseinandersetzungen über ihre alleinigen Entscheidungsbefugnisse nach Möglichikeit vermeiden.

Diese politische Abhängigkeit der Regierung vom Parlament ist auch geeignet, die tragenden Grundgedanken unseres Haushaltsrechts mehr und mehr zu verändern und auszuhöhlen. Alle Haushaltsordnungen gehen von der Annahme aus, daß die Volksvertretung der natürliche Hüter einer guten Finanzordnung gegenüber einer ausgabefreudigen Regierung sèi, die unzweifelhaft auch heute einer Bindung und Uberwachung zur Wahrung von Sparsamkeit und Wirtschaftlichkeit bedarf. Das Lebensigesetz der Massendemokratie, das ist der Wettbewerb der Parteien um die Stimme der Wähler, hat diese Interessenlage wesentlich verschoben. Das Parlament ist keineswegs mehr der geborene Hüter von Sparsamkeit und Wirtschaftlichkeit. Die Regierung beim Vollzug des Haushaltsplans auch rechtlich noch dem Willen des Parlaments zu unterwerfen, hieße den natürlichen Hang der Demokratie zum Selbstmord noch verstärken. Gegen diese immer drohende Dunchibrechung der Gewaltenteilung muß in der Finanzverfassung ein autoritäres Gegengewicht geschaffen werden. Ansätze dazu sind im Grundgesetz enthalten z. B. in dem Zustimmungsvorbehalt der Bunderegierung $\mathrm{zu}$ Mehrausgabebeschlüssen von Bundestag und Bundesrat in Art. 113 GG, der aber unklar und unvollständig ist und seinen Zweck bisher nicht erfüllt hat, oder in dem alleinigen Recht des Finanzministers zur Zustimmung zu Haushaltsüberschreitungen nach Art.112 GG, das die nachträgliche Genehmigung durch Bundestag und Bundesrat aus \$83 der Reichshaushaltsordnung bedeutungslos gemacht hat. Auch die Unabhängigkeit des Rechnungshofes nach Art. 114 GG enthält ein solches autoritäres Element, das sich aber nur in "Erinnerungen“ und nicht in Maßnahmen äußern darf. Der Rechnungshof ist bisher verfassungsrechtlich nur der sachverständige Grehilfe des Parlaments zur Vorbereitung der Entlastung geblieben. Ein künftiges Finanzverfassungsgesetz wird aus diesen Ansätzen ein System gegenseitiger Kontrollen von Parlament und Regierung zur Sicherung von Haushalt und Währung mit dem Rechnungshof als unabhängigem insti- 
tutionellen Hüter einer geordneten und wirtschaftlichen Finanzgebarung entwickeln müssen. Dabei sollte auch die Sonderstellung des Finanzministers innerhalb und außerhalb der Regierung verfassungssechtlich gewährleistet werden. In anderen Ländern, insbesondere in Großbritannien, hat die politische Tradition seit Jahrhunderten zu solchen autoritären Einrichtungen der demokratischen Verfassung geführt, die ihre ungeschriebene Verfassungskraft bis heute behalten haben.

Diese Abweichungen von dem sonstigen Verfassungsbild im Bereich der Finanzordnung sind so bedeutend, da $B$ die Frage nach einer in ihrer Art eigenen Finanzfunktion der Staatsgewalt gestellt werden kann. So meint z B. Herr Wacke, daß für diese Abrweichungen im Bereich von Gesetzgebung und Verwaltung, vor allem von der bundesstaatlichen Grundordnung, besondere innere Gründe maßgebend sein müssen; sie führten zu einer eigenen Finanzunktion, die von allen anderen Bereichen des Staatslebens deutlich abgrenzbar sei. Mit der materiellen Verwaltung, die die Interessen der Bürger betreue und Daseinsvorsorge treibt, sei sie nicht vergleichbar. Die Finanzfunktion laufe quer durch das gesamte Staatsgefüge und bestehe in der Selbstausstattung des Staates, in der Beschaffiung der Mittel, in der Intendantur. Tatsächlich ist ja auch die Finanzverwaltung in Preußen aus der Heeresverwaltung der Kriegs- und Domänenkammern hervorgegangen, und diesen militärischen Zug, gepaart mit Nüchternheit und Ordnungssinn, hat sie bis heute im Typ zu bewahren sich bemüht. Der antiparlamentarische Affekt ist überall bei den Finanzministerien am größten. Sein Amt und die Finanzverfassung überhaupt leben immer ein wenig in der Nähe des Ausnahmezustandes. Man könnte Abschnitt 10 des Grundgesetzes über das Finanewesen als die Traditionskompanie Preu.ßens im liberal-demokratischen Verfassungsstaat rheinisch-bayerischen Gepräges bezeichnen, und es ist wohl auch kein Zufall, daB der geistige Vater dieser Finanzverfassung ein früherer preuBischer Finanzminister war.

Ähnliche Ausnahmezüge zeigt im übrigen auch das Finanzrecht anderer Staaten, z. B. Frankreichs mit dem berühmten Inspecteur des Finance, der auf allen Stufen der Verwaltung fast ihr Vormund mit weiten Zustimmungs- und Mitzeichnungsrechten ist. So weist die Natur der Sache dem Hüter der öffentlichen Finanzen tatsächlich überall die Funktion zu, ein objektives und objektivierendes Prinzip im Verfassungsbau und in der politischen Entwicklung der Parteiendemakratie zu sein. $\mathrm{Ob}$ man die Finanzgewalt wegen dieser Eigenart und Eigengesetzlichkeit staatrechtlich als eine besondere Finanz- 
funktion bezeichnen soll, lasse ich dahingestellt. Eine vierte Gewalt ist damit nicht anerkannt. Gesetzgebung, Verwaltung und Rechtsprechung behalten auch im Finanzbereich ihre funktionelle Eigenart und ihre typische Ausprägung.

\section{Die Finanzgewalt im Bundesstat}

Die ganze Eigenart der Finanzverfassung und der komplexe Charakter ihrer Probleme wird bei ihrer Einordnung in das bundesstaatliche Verfassungssystem offenbar. Man bezeichnet diese Frage meist als die des Finanzausgleichs, der nicht minder ein staatsrechtliches: wie ein finanzwirtschaftliches und finanzwissenschaftliches Problem ist. Es ist oft gesagt worden, daß die bundestaatliche Aufteilung der Gewalten und die politische Bedeutung des bündischen Gedankens wirkungslos bleiben, wenn ihnen nicht die Finanzverfassung in Gesetzgebung, Verwaltung und Rechtsprechung entspricht. Wo die finanziellen Voraussetzungen für das verfassungsmäßige Zusammenwirken von Bund und Gliedern fehlen, ist der Wille der Verfassung nur beschränkt oder überhaupt nicht vollziehbar. Diese Inkongruenz von Staatsverfassung und Finanzverfassung kann sich gleichermaßen gegen den Bund wie gegen die Länder richten. Das zentrale Problem der bundesstaatlichen Finanzordnung besteht nun aber darin, daß die allgemeinen Grundsätze für das Zusammenwirken und die Trennung $z$ wischen Bund und Ländern $f \ddot{r}$ die Finanzgewalt nicht unverändert angewandt werden können. Ältere Verfassungen haben das versucht, indem sie keine Sonderregeln für die Handhabung der Finanzgewalt aufstellten. Heute enthalten die Verfassungen wohl aller Bundesstaaten Sonderbestimmungen über die Aufteilung der Steuergesetzgebung und der Besteuerungshoheit. Bereits die Verfassung der Vereinigten Staaten von 1787 verlieh der Union eine umfassende Finanzgewalt, die von der sonstigen Gewichtsverteilung der Verfassung erheblich abwich. Durch die 16. Verfassungsnovelle von 1913 erhielt der Bund das Recht, eine eigene Einkommensteuer neben der Einkommensteuer der Einzelstaaten zu erheben. Immerhin blieben die Steuerquellen unbeschadet des Vorranges der Bundesfinanzgesetze einer getrennten Gesetzgebung und Verwaltung von Bund und Einzelstaaten überlassen, wobei der Bund neben den Zöllen, die ihm allein zustehen, sawohl indirekte als auch direkte Steuern nach eigenem Ermessen erheben kann. In der Schweiz wies die Bundesverfassung von 1848, deren Finanzartikel kennzeichnenderweise 1874 und später mehrfach ge- 
ändert wurden, dem Bund zunächst die Zölle und Monopolerträge von Bahn und Post sowie die Verkehr- und Verbrauchsteuern zu. 1915 wurde dann zur Deckung des militärischen Bedarfes eine Bundeseinkommensteuer erhoben, die seitdem alljährlich unter wechselnden Bezeichnungen als direkte Bundessteuer weiter erhoben wird. $\mathrm{Zu}$ ihrer Rechtfertigung außerhalb der verfassungsmäßigen Gesetzgebungskompetenz erfand man eine wohlbegriüdete Theorie des fiskalischen Notrechts. Der Kampf um die verfassungsrechtliche Legalisierung der Bundeseinkommensteuer dauert in der Schweiz noch an. Die deutsche Entwicklung von der Bismarckschen Reichsverfassung bis heute ist bekannt. Sie weist die gleichen Entwicklungstendenzen auf. Es geht uns hier nicht um die finanzpolitische Generallinie dieser Erscheinungen, sondern lediglich um den Bedeutungswandel, den die staatsrechtlichen Probleme der Finanzgewalt im Bundesstaat unter ihr erfahren haben.

Unter $\mathbf{F}$ in a $\mathbf{z}$ g e w a $1 \mathrm{t}$ ist die Ausübung der Staatsgewalt zur Deckung des staatlichen Bedarfs durch öffentliche Zwangsabgaben zu verstehen. Diese Finanzgewalt ist ein Ausfluß der allgemeinen Staatsgewalt, die im Bundesstaat wie diese auf Bund und Länder aufgeteilt werden muß. Sie ausschließlich dem Bund oder den Gliedstaaten vorzubehalten, hieße das bündische Prinzip beseitigen. Gewiß wäre eine Finanzverfassung denkbar, die die gesamte Finanzgesetzgebung und die Erhebung aller Steuern dem Bund vorbehielte und die Länder wie die übrigen Gebietskörperschaften an dem Aufkommen der Bundessteuern entsprechend ihren Aufgaben beteiligte. Eine solche Finanzverfassung würde man aber nicht mehr bundesstaatlich nennen dürfen, selbst wenn den Ländern im übrigen eine ausschließliche oder konkurrierende Gesetzgebung und ein eigener weisungsfreier Verwaltungsbereich eingeräumt würden. Man würde diese Länder wegen des Fehlens einer eigenen Finanzgewalt nur noch als hochpotenzierte Selbstverwaltungskörper mit einer weitgehenden autonomen Rechtsetzungsbefugnis und mit eigenen und übertragenen Verwaltungsaufgaben bezeichnen können, nicht aber als Gliedstaaten eines Bundesstaates.

Es ist eine viel erörterte Erscheinung, daß die ständig zunehmenden Aufgaben des modernen Verwaltungsstaates in Bundesgesetzen einheitlich geregelt wenden und dem stärkeren Finanzträger, das ist der Bund, angelastet werden. Die äußeren und inneren Gründe dafür sind bekannt. Diese Ungleichmäßigkeit in der Zunahme des Finanzbedarfes bei Bund und Ländern erfordert eine ständige Anpassung ihrer Finanzkompetenzen. Die förderale Theorie, die unserer Verfassung zugrunde liegt. 
ist ein Kind des christlich-naturrechtlichen Subsidiaritätsprinzips und des Idealismus und der Romantilk Sie ist nicht nur ein zweckmäßiges, sandern ein unentbehrliches Gegenstück zur demakratischen Staatsform und zum rechtsstaatlichen Anliegen. Der Zuwachs an gesamtstaatlicher Verantwortung und öffentlichen Aufgaben und Lasten beim Bund hat die Labilität jeder bundesstaatlichen Ordnung durch den Kampf um einen möglichst großen Anteil an der Finanzgewalt erheblich vergrößert. Die Entwicklung hat den Bund überall zum angreifenden Teil gemacht. Die angegriffenen Länder nehmen ihre Zuflucht zum Verfassungsrecht, weshalb die neueren Finanzverfassungen sich überwiegend mit dem Finanzausgleich in Artikeln befassen, die ihrer Tendenz nach Schutzklauseln zugunsten des bisherigen Besitzstandes der Länder sind. Weitgehende Zustimmungsvorbehalte der Länder bei der Finanzgesetzgebung des Bundes sollen dieses Verteidigungssystem bis in die Grundsatzfragen der Verfassung hinein vertiefen. Gegenstände und Gehalt der Finanzartikel wenden weniger durch ihren Rang für das Verfassungsleben als vielmehr durch das Ziel taktischer Vollkommenheit dieses staatsrechtlichen Verteidigungswerkes bestimmt. So werden dann schließlich sogar bestimmte Bedarfsgrößen und feste Quoten an einem ungewissen künftigen Steueraufkommen verfassungsrechtlich festgelegt, u.m sie tunlichst unentziehbar zu machen. Alles dieses ist in seiner Tendenz durchaus verständlich.

Worin liegt nun aber der tiefere Grund für diese Erscheinungen? Das Problem beginnt mit der Zuteilung der öffentlichen Aufgaben und des Finanzbedarfes auf Bund und Länder. Eine sinnvolle Zuordniung der Deckungsmittel, sei es aus eigenen Steuern, sei es aus Steueranteilen anderer Steuergläubiger, setzt eine bestimmte und in der großen Linie beständige, wenn auch nicht endgültige $\mathrm{Zu}-$ weisung der finanziellen Lasten an alle Träger öffentlicher Aufgaben voraus. Uber diese Aufgaben- und Ausgaben-Verteilung pflegen die Verfassungen der Bundesstaaten nichts besonderes zu bestimmen, so auch das Grundgesetz nicht. Sie unterstellen, daß durch die Zuweisung der Verwaltungsaufgaben bei der Durchführung der Gesetze zugleich über die Kostenträgerschaft entschieden werde, wobei der verfassungsrechtliche Unterschied zwischen einer eigenen Landesverwaltung und einer Bundesauftragsverwaltung der Länder keine Bedeutung für die Lasten haben soll; sie rechtfertige es lediglich, daß der Bund ausnahmsweise die Kosten einer Auftragsverwaltung durch Bundeszuschüsse mittrage, weil es sich hier um Gemeinschaftsaufgaben von Bund und Ländern handele. 
Der Entwurf der Bundesregierung zu einem Finanzverfassungsgesetz, das den bisherigen Art. 106 GG in sieben neue Verfassungsartilkel auflösen und erweitern wollte, versuchte in dieser Art, die Finanzverantwortung aus der Verwaltungsverwaltung abzuleiten. Die Deckungsmittel, die bisher nicht nach dem Finanzbedarf auf Bund und Länder aufgeteilt sind, sollen nunmehr nach dem besonderen „finanziellen Kampetenzbereich" erneut aufgeteilt werden. Bundesaufgaben sollen aus Bundesmitteln, Länderaufgaben aus Ländermitteln finanziert werden, so lautet die eindrucksvolle Formel. Eine solche Richtlinie verschiebt das Problem nur von der Deckung des Istbedarfes, wie er nach der jeweiligen und vielfach grundsatziosen Entscheidung des Gesetzgebers entsteht, hin zu der Ermittlung eines Sollbedarfes, zur „richtigen“ Zuordnung der Aufgaben und Lasten an Bund und Länder. Der innere $\mathrm{Zu}$ sammenhang zwischen Aufgabenverantwortung und Ausgabenverantwortung soll das lastenzuteilende Prinzip sein. Dieser Leitgedanke entspricht dem förderalen Prinzip, mit dessen Sinn und Zweck die Ausweitung hoheitlicher Gewalt eines Partners auf Kosten eines anderen, sei es im Verhältnis Bund - Länder, sei es der Länder untereinander, grundsätzlich nicht vereinbar ist.

An den Begriffen "Aufgabenvenantwortung", „Ausgabenverantwortung" und "Finanzverantwortung" hat sich eine lebhafte Diskussion entfacht. Wer trägt die Aufgabenverantwortung bei der Durchführung eines Bundesgesetzes durch die Länder in eigener Verwaltung nach Art. 30 und 84 GG? Besteht nicht eine selbständige Deckungsverantwortung des Bundes dergestalt, daß ihm verfassungsrechtlich die Verantwortung für die Deckung aller Lasten auferlegt wird, die seine Gesetzgebung verursacht? Es ist ein allgemeiner Rechtsgedanke, da $B$ Tätigwerden im fremden Auftrag grundsätzlich auch für fremde Rechnung geschieht, was sicherlich auch für die Bundesauftragsverwaltung der Länder gelten muß. Diesen Grundsatz aber auch auf die weisungsfreie eigene Verwaltungstätigkeit der Länder bei der Durchführung von Bundesgesetzen auszudehnen ist schon deshallb nicht gerechtfertigt, weil die Länder Art und Ausmaß der Aufgabenerfüllung im Rahmen der Bundesgesetze allein bestimmen. Diese $\mathrm{L}$ ä $\mathrm{n}$ de $\mathrm{r}$ aufgaben bedingen $\mathrm{L}$ ä $\mathrm{n}$ di $\mathrm{T}$ rausgaben und sollen deshalb nach der Meinung der Bundesregierung auch deren alleinige Finanzverantwortung begründen.

Dieser Streit um die Verantwortungen ist deshalb so unfruchtbar, weil jeder Partner dem anderen die Finanzverantwortung für eine Aufgabe zuzuschieben versucht, bei der jener 
in irgendeiner Form über die Durchführung der Aufgabe und damit über die Höhe ihrer Kosten mitbestimmt. Dieses politische Beteiligtsein soll zu einer entsprechenden finanziellen Beteiligung führen. Art und Ausma $B$ dieser wechselseitigen Interessen im weiten Bereich der öffentlichen Aufgaben sind so verschiedenartig und weitgespannt, $\mathrm{da} B$ daraus brauchbare Grundsätze für die Deckungs- oder Finanzverantwortung kaum mehr zu entwickeln sind. Schließlich bleibt es bei der Tautologie der vorgeschlagenen Neufassung des Art. 106 Abs. 2 GG, nach der "der Bund die zur Ausübung der staatlichen Befugnisse und zur Erfüllung der staatlichen Aufgaben erforderlichen Ausgaben trägt, soweit die Wahrnehmung dieser Befugnisse und Aufgaben Sache des Bundes ist; alle übrigen Kosten sollen die Länder tragen". Die Begründung erläutert diese Umschreibung des suum cuique dahin, daß die Länder die Kosten ihrer Verwaltung grundsätzlich allein zu tragen haben, und daß bei der Wahrnehmung bestimmter Aufgaben durch mehrere Gebietskörperschaften - gemeint ist vor allem die Auftragsverwaltung - diese Gemeinschaftsaufgaben auch gemeinschaftlich finanziert werden müßten. Der Bund solle aber nicht das Recht haben, fremde Aufgaben, an denen er nur politisch interessiert ist, durch Zuschüsse mitzufinanzieren. Diese Ausführung eigener Länderaufgaben ganz für Rechnung des Bundes, wie sie Art. $120 \mathrm{GG}$ für die Besatzungslasten und die Kriegsfolgelasten mit einem Block von rund 5 Milliarden DM als Ausnahme von der Regel vorschreibt, solle es künftig nicht mehr geben. Bis dahin soll eine Pauschalierung der Kostenerstattung oder eine wirklich spürbare Interessenquote der Länder von mindestens $30 \mathrm{vH}$ (bisher $15 \mathrm{vH}$; nach der beschlossenen Neuregelung für ein Teilgebiet des Art. 120 GG künftig $20 \mathrm{vH}$ ) das finanzielle Interesse des Verwalters fremder Mittel erhalten.

Technische Einzelheiten interessieren hier nicht. Wichtig ist nur die Erkenntnis, daB a us der $\mathrm{Natur}$ einer bestimmten Aufgabe kaum ein brauchbares Zuordnungsprinzip für die Kostenbelastung entnommen werden kann. Selbst dort, wo eine Aufgabe ihrer Art nach als typische Länderaufgabe $z u$ bezeichnen ist, besteht möglicherweise noch eine Ausgleichsfunktion des Bundes, die in Art. 28 Abs. 3 GG als Grundsatz verkündet wird. Diese Ausgleichsfunktion kann in einer ziemlich breiten Grenzzone dem sonst die Aufgabenzuteilung beherrschenden Subsidiaritätsprinzip widersprechen. Föderalismus bedeutet Verschiedenheit der öffentlichen Aufgaben nach Art und Ausmaß ihrer Verwirklichung von Land zu Land aus Selbstentscheidung. 
Für die rechtsstaatliche Freiheit und für die politischen Werte des echten Föderalismus ist es kein zu hoher Preis, wenn sich dieser Unterschied der Aufgabenerfüllung in maßvollen Grenzen hält. Um diese Grenzen geht es aber gerade bei der Lastenzuweisung. Die politische Grundanschauung hierüber hat sich in den letzten 50 Jahren gewandelt. Die öffentliche Meinung nimmt schon geringfügige Leistungs- oder Belastungsunterschiede nicht mehr widerspruchslos hin. Ein gleichmäßiger Verwaltungsstandard und eine gleichmäßige Steuerbelastung sind auch im Bundesstaat ein Ideal geworden. Der Kreis der Aufgaben, deren Vollzug keine regionale Mannigfaltigkeit mehr erträgt, wird immer größer. Selbst die Zitadelle der Eigenstaatlichkeit, die kulturellen Aufgaben, werden davon erfaßt. Sollen die Schulen in Schleswig-Holstein oder in Bayern deswegen weniger gut ausgestattet sein als in Nordrhein-Westfalen, weil dias Aufkommen an Landessteuern je Einwohner 1955 in Schleswig-Holstein 170,- DM, in Bayern 230,- DM und in Nordrhein-Westfalen 316,- DM betrug? Soll die Universität in Hamburg dreimal so reich ausgestattet sein wie die Landesuniversität in Schleswig-Holstein, weil das Steueraufkommen in Hamburg je Kopf 480,- DM und in Schleswig-Holstein nur $170,-D M$ beträgt? Hier fließt dem Bund ganz von selbst auch ohne den Verfassungshinweis in Art. 28 Abs. 3 GG eine Ausgleichsfunvtion zu, deren Ausmaß heute mit den ursprünglichen Anschauungen der Verfassung kaum mehr in Einklang steht. Die Länder pflegen als Kollektiv allen Durchbrechungen der verfassungsmäßigen Aufgabentrennung zu widersprechen, sie einzeln vielfach aber selbst durch das Nachsuchen von Bundeszuschüssen herbeizuführen. Während sonst das Geld der Aufgabe folgen soll, zieht hier das Geld die Aufgabe nach sich.

Nach der Begründung zum Finanzverfassungsgesetz scheint die Bundesregierung aus dieser Entwicklung eine neue verfassungsrechtliche Theorie der Gemeinschaftsauf$\mathrm{g}$ a b e $\mathrm{n}$ von Bund und Ländern entwickeln $z u$ wollen, die ,auf der Grundlage der verfassungsrechtlichen Kompetenznormen, gegebenenfalls des ungeschriebenen Verfassungsrechts, durch die staatspolitische Praxis bestimmt werden“. Für diese Gemeinschaftsaufgaben, deren Kern die Bundesauftragsverwaltung ist, soll der Bund den Sachaufwand ganz oder teilweise tragen und sogar Zuschüsse zu den persönlichen und sachlichen Verwaltungskosten der Länder leisten dürfen, während sonst gegenseitige Verwaltungskostenzahlungen grundsätzlich ausgeschlossen sein sollen. Ich übergehe die finanzpolitische und technische Seite dieser Verwaltungskostenfrage hier. Sie hat 
ein erhebliches finanzielles Gewicht. In der großen Linie hat das inzwischen in Kraft getretene Vierte Uberleitungsgesetz, v.orher Finanzanpassungsgesetz genannt, dergleichen Verwaltungskostenzuschüsse beseitigt, vor allem für die Auftragstätigkeit der Finanzämter als Landesbehörden für den Bund bei der Einziehung der Umsatzsteuer, der Beförderungsteuer und des Bundesanteils an der Einkommensteuer.

Ich muß es mir auch versagen, in die innere Problematik des Versuches einer Zuordnung der finanziellen Lasten nach Verantwortungsbereichen einzugehen. Herr Köttgen hat das in einer gründlichen und gedankenreichen Form schon getan. Ich stimme ihm darin zu, daß aus der formalen Erklärung einer Aufgabe zur Länderaufgabe im Sinne von Art. 30 und $84 \mathrm{GG}$ allein die Finanzverantwortung nicht begründet werden kann. Die Sachverantwortung bemiBt sich nach anderen Gesichtspunikten, beispielsweise nach dem Ausmaß der bundesgesetzlichen Regelung von der Rahmenregelung bis in die technischen Einzelheiten hinein, die wegen des angedeuteten Bedürfnisses nach einheitlicher Aufgabenerfüllung mehr und mehr zunimmt. Umgekehrt besteht wegen der formellen Weisungsgebundenheit der Länder bei ihrer Bundesauftragsverwaltung nach Art. 85 GG unter dem Gesichtspunkt der Sachverantwortung keine verfassungsrechtliche Notwendigkeit, sie deshalb aus Bundesmitteln zu finanzieren. Die Entscheidung über die Kostentragung ist aus der verfassungsrechtlichen Kategorie des Gesetzesvollzugs durch bestimmte Verwaltungsträger nicht zu treffen. Der einfache Bundesgesetzgeber hat freie Hand für sachgerechte Regelungen und Unterscheidungen. Ich stimme Herr Köttgen insbesondere $\mathrm{zu}$, wenn er meint, daß sich hinter der Idee der Rechts- und Wirtschaftseinheit, deren Bedeutung Art. 72 Abs. 2 Ziff. 3 GG bestätigt, für die Gegenwart - mehr oder minder unverhüllt - die Idee einer Verwaltungseinheit verberge. Ich bin der Meinung, da $B$ e in moderner $B$ u desstaat, der ein sozialer Rechtsstat sein will, a uf die Dauer nicht umhinkommt, diese Verwaltungseinheit in ihren wesentlichen $\mathrm{Z}$ weigen $z$ u verwirklichen. Der unaufhaltsame Utbergang vom bürgerlichen Rechtsstaat zum Verwaltungsstaat hat auch die traditionelle Scheidung der Verwaltungsbereiche im Bundesstaat entscheidend verändert und keine restaurativen Verfassungsbemühungen können diese Entwicklungstendenz aufhalten. Hier setzt die Macht der Entwicklung und die Natur der Dinge der konservativen Haltung Grenzen, die man bedauern muß, aber nicht ignorieren kann. 
Auch die besondere Eigenart der Finanzgewalt erzwingt eine einheitlichere Betrachtung und eine verfassungsrechtliche Zusammenfassung, vielfach abweichend von der sonstigen $\mathrm{Ge}-$ waltenteilung zwischen Bund und Ländern. Das Objekt der Finanzgewalt, die Vielzahl der Steuergegenstände und Steuerschuldner, bildete seinerseits eine große Einheit. Aus dieser einen Steuerkraft der Wirtschaft entspringen schließlich alle Steuerquellen gemeinsam. So unausgewogen das Steuersystem auch sein mag, alle Wirtschaftsvorgänge wirken irgendwie in alle Steuerverhältnisse hinein. Umgekehrt wirkt jede Veränderung der Besteuerung bei einer Steuerart in irgendeiner Form auf alle übrigen zurück. Dieser unteilbare große Zusammenhang zwischen Wirtschaft und Steuer erheischt eine ständige Anpassung des gesamten Steueraufkommens an den Gesamtbedarf aller Bedarfsträger. Nationale Aufgaben, nationaler Finanzbedarf, Nationaleinkommen und nationales Steueraufkommen sind letztlich einheitliche und korrespondierende Größen. Unbeschadet der Vielzahl ihrer Teilhaber ist die Finanzgewalt eine einheitliche, wie die Staatsgewalt eine einheitliche ist, unbeschadet ihrer Funktionsformen und ihrer zahlreichen Wirkungsbereiche.

Gleiche öffentliche Lasten und gleiche Verwaltungsleistungen sind auch die Voraussetzung für eine möglichst weitgehende Wettbewerbsgleichheit, für gleiche wirtschaftliche Startbedingungen. Eine freiheitliche Wirtschaftsverfassung muß die prinzipielle Gleichheit der Wettbewerbsbedingungen unter demSteuergesetz fordern. Sieverlangt zwar nicht Gleichheit und Gleichartigkeit der Besteuerung, aber doch Gleichmäßigkeit, d.h. gleiches $\mathrm{Maß}$ unter gleichartigen Voraussetzungen. Sie duldet grundsätzlich keine regionalen Steuerunterschiede, die sich aus einer unterschiedlichen Handhabung der gliedstaatlichen Finanzgewalt ergeben, obwohl die regionalen Verschiedenheiten von Finanzbedarf und Steuerkraft sich doch im Bundesstaat von selbst verstehen müßten. Dieser eifersüchtige Gleichheitsdrang der Wirtschaft nivelliert sogar die Hebesätze der örtlichen Gewerbe- und Grundsteuern und beschränkt damit die gemeindliche Selbstverwaltung in ihrer schon begrenzten Finanzautonomie nicht weniger als die föderale der Länder.

Es ließen sich noch weitere typische wirtschaftliche $\mathrm{Zu}$ sammenhänge aufzeigen, die einen linientreuen Föderalismus in der Finanzverfassung heute unmöglich machen. Sie alle lassen sich auf die Unvereinbarkeit einer föderalen Finanzautonomie in Steuergesetzgebung und Ertragshoheit mit der wirtschaftlichen und sozialen Einheit des modernen Verwal- 
tungsstaates - gleich welcher Verfassungsform - zurückführen. Dieses Spannungsverhältnis kann die Finanzverfassung nur dadurch lösen, daß sie die Finanzordnung dem einheitlichen Wirtschafts- und Sozialgefüge anpaßt, nicht umgekehrt dadurch, daß sie die Wirtschafts- und Sozialordnung entsprechend den natürlichen gliedstaatlichen Verschiedenheiten zu differenzieren versucht. Ein solcher Versuch würde alsbald bei der Wiedereinführung von unsichtbaren Binnenzöllen durch unterschiedliche Belastungen von Gütererzeugung, Verkehr und Verbrauch enden.

Welche Folgerungen hat unsere Verfassung aus dieser unentrinnbaren Gewalt des Einheits - und Gleichheitsgedankens im Bereich des Wirtschaftlichen und Sozialen bei der Aufteilung der Finanzgewalt gezogen? Für die Gesetzgebung begründet Art. 105 GG eine ausschließliche Zuständigkeit des Bundes nur für die Zölle und die Finanzmonopole. Die große Masse der übrigen Abgaben soll der konkurrierenden Gesetzgebung von Bund und Ländern unter den allgemeinen Voraussetzungen einer Bedarfsgesetzgebung nach Art. 72 GG unterliegen. Die drei Voraussetzungen einer Bedarfsgesetzgebung gelten alternativ und sind so weit gefaßt, daß praktisch alle Steuern wegen ihrer Bedeutung für die Rechts- und Wirtschaftseinheit darunter fallen. Art. 105 fügt diesen Voraussetzungen noch eine weitere hinzu, nämlich die Inanspruchnahme einer Steuer - ganz oder teilweise - zur Deckung der Bundesausgaben. Damit ist aus der formell konkurrierenden Bedarfsgesetzgebung praktisch eine ausschließliche Bundeszuständigkeit für alle Steuern geworden, mit Ausnahme der in Art. 105 ausdrücklich vorbehaltenen Steuern mit örtlich bedingtem Wirkungskreis. Die Finanzverfassung hat also den erwähnten Entwicklungstendenzen ohne förmliche Änderung der allgemeinen Gesetzgebungszuordnung etwa durch eine erweiterte ausschließliche Bundesgesetzgebung bereits Raum gegeben.

Mit einem kurzen Wort nur sei auf die ausdrücklich ausgenommenen Steuern mit örtlich bedingtem Wirkungskreis eingegangen. Dieser neue Begriff ist wiederholt kritisiert und als ungerechtfertigt und unbrauchbar bezeichnet worden. Zwischenzeitliche Verwaltungsgerichtsurteile können diese Meinung nur bestätigen. In unserem Zusammenhang ist kritisch anzumerken, daß die Beispiele, die die Verfassung selbst für solche Steuern mit örtlich bedingtem Wirkungskreis gibt, nämlich die Grunderwerbsteuer, die Wertzuwachssteuer und die Feuer- 
schutzsteuer, typische Verkehrssteuern sind, die zwar an eine örtliche Belegenheit anknüpfen, tatsächlich aber wegen ihrer wirtschaftlichen Bedeutung heute wie früher einer bundeseinheitlichen Gesetzgebung bedürfen. Hier widerruft die Finanzverfassung ihre eigenen Grundsätze, um mit dem Kunstbegriff der Steuern mit örtlich bedingtem Wirkungskreis die Autonomievorstellungen der allgemeinen Staatsverfassung wenigstens noch in einem stillen Winkel wirksam werden zu lassen. Dieser innere Widerspruch der Finanzverfassung sollte dadurch beseitigt werden, da $B$ sogenannte Steuern mit örtlich bedingtem Wirkungskreis künftig nicht mehr aus der allgemeinen Zuständigkeitsordnung ausgeklammert werden.

Das Grundgesetz hat die Zuständigkeit zur Finanzgesetzgebung endgültig zwischen Bund und Ländern aufgeteilt. Die Vorläufigkeit der Finanzverfassung aus Art. 107 erfaßt nicht die Gesetzgebungszuständigkeit. Zur Verwirklichung dieser Verfassungsentscheidung bedarf es keiner ausfüllenden Bundesgesetzgebung mehr wie unter der Weimarer Verfassung. Die Zuständigkeitsordnung ergibt sich mit unmittelbarer Rechtswirkung aus der Verfassung selbst. Der Anspruch des Grundgesetzes auf Vollständigkeit und Endgültigkeit seiner Regelungen ist in diesem Teil der Finanzverfassung nicht so bedenklich wie die gleichgerichteten heutigen Tendenzen für die Aufteilung der Ertnagshoheit. Die Weimarer Reichsverfassung (Art. 8 und 11) regelte die Gesetzgebungszuständigkeit teils weiter, teils enger. Sie war scheinbar enger, insaweit sie eine konkurrierende Bundesgesetzgebung nur zuließ, wenn eine Abgabe - ganz ader teilweise - zur Deckung von Bundesausgaben in Anspruch genommen wurde; sie war weiter, weil das Reich nach Art. 11 durch einfaches Bundesgesetz Grundsätze über die Zulässigkeit und die Erhebungsart von Landesabgaben aufstellen konnte, was der einfache Bundesgesetzgeber heute für die Steuern mit örtlich bedingtem Wirkungskreis nicht mehr kann. Die Aufteilung der Gesetzgebungszuständigkeit ist verfassungsfest und tatsächlich unabänderlich, weil die Zustimmung von zwei Drittel der Stimmen des Bundesrates zu einer etwaigen Änderung zugunsten des Bundes kaum zu erreichen wäre. Praktische Bedeutung hat diese Frage für die Grunderwerbsteuer, für eine etwa wieder einzuführende Wertzuwachssteuer, für die Vergnügungssteuer und für die Feuerschutzsteuer, die für die bundeseinheitlichen Belange des Städtebaues, des Wohnungsbaues und der Filmwirtschaft keineswegs gering ist. 
VI. Spaltung der Einkommensteuer?

Im Rahmen dieser Utberlegungen sei der Plan einer S p a ltung der Einkommensteuer kurz verfassungsrechtlich gewürdigt. Danach soll dem Bund auch künftig die Gesetzgebung über die allgemeinen Rechtsgrundlagen der Einkommensteuer einschließlich eines Meßbetragstarifes vorbehalten bleiben. Jedoch soll jedes Land innerhalb bestimmter Grenzen einen Hebesatz als Landestarif der Einkommensteuer durch Gesetz festsetzen können. Auf diesem modernen Wege zur Lösung politischer Probleme durch Spaltung würde der alljährliche Finanzkrieg um die Höhe des Bundes- und Länderanteils an der heute einheitlichen Einkommensteuer vermieden werden, indem nicht das Aufkommen, sondern der Tarif geteilt wird. Die Länder wollen auch künftig bei der Gesetzgebung über die Bundeseinkommensteuer unter Beibehaltung ihres Zustimmungsrechts im Bundesrat mitwirken, während der Bund bei der Festsetzung des Tarifes der Landeseinkommensteuer nicht mitwirken würde. Heute haben wir e in e Einkommensteuer mit zwei Bruchteils-Steuergläubigern unter einer gespaltenen Verwaltung, die die Finanzämter für den Landesanteil in eigener Verwaltung als Landesbehörden, für den Bundesanteil aber in Bundesauftragsverwaltung tätig werden läßt. Das ist wahrlich schon kurios genug. Künftig würden in jedem Lande zwei Einkommensteuern von zwei Steuergläubigern erhoben nach der Art, wie z. B. in den Vereinigten Staaten von 49 Einzelstaaten etwa 35 eine eigene Einkommensteuer neben der Bundeseinkommensteuer erheben. Auf das Rückschrittliche und wirtschaftlich Bedenkliche einer solchen doppelten und ungleichen Besteuerung des Einkommens gehe ich hier nicht ein. In diesem Kreise erhebt sich aber die Frage, ob dergleichen Lösungen überhaupt im Rahmen des Art. 107 GG durch einfaches Bundesgesetz eingeführt und für die Zukunft verfassungsfest gemacht werden können. Die Festsetzung des Tarifes oder des Hebesatzes einer Steuer durch Landesgesetz ist nicht bloß formell, sondern auch materiell ein Akt der Gesetzgebung. Ein Steuergesetz, das die Höhe der Abgaben nicht normiert und keinen unmittelbar anwendbaren Steuersatz oder Tarif enthält, ist kein Gesetz; es ist unvollziehbar und als Eingriffsgesetz im rechtsstaatlichen Sinne noch nicht vorhanden. Es bedarf einer ergänzenden Gesetzgebung, um vollziehbar und in seiner Anwendung gerichtlich nachprüfbar zu werden. Die Gesetzgebung über die Steuern vom Einkommen ist aber in Art. 105 unabänderlich dem Bund vorbehalten. $\mathrm{Daß}$ eine Länder-Einkommensteuer mit selbständiger Festsetzung der Hebesätze der Zuständigkeitsordnung 
des Art. 105 nicht entsprechen würde, ergibt sich auch aus der besonderen Ausnahmeermächtigung für die Realsteuern in Art. 105 Abs. 2 Ziff. 3, wo die Festsetzung von Hebesätzen ausdrücklich der Landesgesetzgebung und auf ihrer Grundlage der Gemeindeautonomie überlassen ist. Es könnten also wohl begründete $\mathrm{Zweifel}$ darüber geäußert werden, ob die Einkommensteuer durch einfaches Bundesgesetz auf der Grundlage des Art. 107 gespalten werden kann. Allerdings muß zugegeben werden, daß die vorbehaltene Gesetzgebungszuständigkeit des Bundes für die Einkommensteuer aus Art. 105 nur eine konkurrierende ist, die es in die Entscheidung des Bundesgesetzgebers stellt, in welchem Umfang er Teile seiner bisher umfassenden Gesetzgebung künftig den Ländern überlassen will. Die wirtschaftlichen Bedenken gegen zwei Einkommensteuern mit unterschiedlicher Höhe der Länder-Einkommensteuer überragen aber bei weitem diese staatsrechtlichen therlegungen.

\section{Die S teuerertragshoheit}

Auch hinsichtlich der Aufteilung der Steuere rträge im heutigen Art. 106 GG will ich mich auf einige grundsätzliche Bemerkoungen im Rahmen der allgemeinen Problematik der Finanzverfassung beschränken. Vorweg eine begriffliche Klarstellung: Wir sprechen von der Finanzgewalt als Besteuerungsgewalt, die sich in Gesetzgebung und Verwaltung äußert. Für den Vollzug der Steuergesetze bezeichnen wir sie auch als die Ertragshoheit eines bestimmten Steuergläubigers. Die Ertragshoheit ist rechtlich mit dem Steueranspruch gegenüber dem Abgabepflichtigen identisch, weshalb man früher einfach von Bundessteuern einerseits und Landessteuern andererseits sprach Für Steuern, deren Aufkommen nicht dem abgabeberechtigten Steuergläubiger, sondern einer anderen Gebietskörperschaft zufließt, hat man eine gesonderte Ertragshoheit dieser Körperschaft begründen wollen. Ich halte eine solche besondere „Ertragshoheit" für mißverständlich, denn sie ist kein Bestandteil der Finanzgewalt als Besteuerungsgewalt. Der Anspruch eines Partners im Finanzausgleich auf Beteiligung am Aufkommen einer Steuer eines anderen Steuergläubigers ist selbständiger und eigenartiger Natur. Er entsteht aus der gesetzlichen Zuweisung des Aufkommens und ist begrifflich kein Bestandteil der Finanzgewalt als Abgabenhoheit. Das Grundgesetz ist einer Aufteilung der Finanzgewalt auf Bund und Länder in Bundessteuern und Landessteuern ausgewichen, indem es nur vom „Zufließen“ bestimmter Steuern an Bund oder Länder spricht. 
Bedeutsam ist diese rechtsbegriffliche Feinheit praktisch nur für die Einkommensteuer.

Die bisherige Verteilung des Steueraufkommens auf Bund und Länder in Art. 106 GG ist von keinem klaren Zuteilungsprinzip beherrscht, weder von der früheren Scheidung nach indirekten und direkten Steuern, noch von der Unterscheidung der Reichsabgabeordnung in Besitz- und Verkehrsteuern einerseits und Verbrauchsabgaben und Zölle andererseits. Ein schlechter Kompromiß führte dazu, daß Steuern mit entscheidender Bedeutung für die gesamtwirtschaftlichen Zusammenhänge den Ländern allein in Verwaltung und Aufkommen überlassen wurden. Hierzu gehören die Vermögensteuer, die Erbschaftsteuer und die Kapitalverkehnsteuern, wie die Versicherungsteuer und die Wechselsteuer, und unter den Verbrauchsabgaben als einzige Ausnahme natürlich die Biersteuer. Der kürzliche Versuch des Bundestages, wenigstens für die Verkehrsteuern sowie für die Vermögensteuer und die Erbschaftsteuer klarere Grundsätze zu schaffen und die natürliche Finanzhoheit des Bundes dafür wieder herzustellen, ist am Widerspruch des Bundesrats gescheitert. Alle diese Steuern sind wegen ihrer übergebietlichen Belastung nicht auf ein bestimmtes Land radizierbar. Sie sollten deshalb dem Bund zufließen und von den Finanzämtern der Länder in seinem Auftrage verwaltet werden. Ähnliches gilt für die Kraftfahrzeugsteuer, die nach richtiger Auffassung eine Aufwandsteuer, d.h. eine Verbrauchsteuer im Sinne des Art. 106 GG ist, die dem Bund zusteht und keine Verkehrsteuer, d.h. eine Steuer vom Rechtsverkehr, die heute den Ländern zufließen. Die Verfassung selbst sagt nichts über das Aufkommen der Kraftfahrzeugsteuer. Die Finanzpraxis vor und nach 1949 hat sie kurzerhand zu einer Verkehrsteuer erklärt und damit den Ländern vorbehalten, während die Mineralölabgaben dem Bund zustehen. Dieser Begriffskrieg zwischen Bund und Ländern erinnert an die Meinungsverschiedenheiten von 1906 über die Reichserbschaftsteuer, deren Zulässigkeit als Reichssteuer nach der alten Reichsverfassung sich danach richtete, ob man sie als direkte oder indirekte Steuer ansah.

Aus diesen staatsrechtlichen Vorfragen über die Finanzhoheit, d. h. die Steuergläubigerschaft, ergeben sich keineswegs automatisch auch die Entscheidungen über die Verteilung des S teu era ufkommens. Seit jeher sind die Länder an dem Aufkommen bestimmter Reichssteuern im Rahmen des Finanzausgleichs beteiligt worden. Solche Steueranteile im Rahmen eines Utberweisungssystems läßt Art. 107 GG auch für die Neurordnung $z u$, wenn den Begünstigten darauf nur ein 
bestimmter Rechtsanspruch eingeräumt wird. So könnte beispielsweise die Kraftfahrzeugsteuer als Bundessteuer selbstverständlich ganz oder anteilig den Ländern zufließen.

Matrikularbeiträge der Länder an den Bund sind heute ebenso verfassungswidrig wie Ermessenszuwendungen des Bundes aus zentralen Ausgleichsstocks an die Länder.

VIII. Der Lasten- und Steuerkraftausgleich

Als vorletzte Einzelfrage im Rahmen der besonderen Fragestellung meines Themas möchte ich noch die staatsrechtliche Problematilk des Lasten- und Steuerkraftausgleichs zwischen den Ländern behandeln. Man bezeichnete diesen Teil des allgemeinen Finanzausgleichs früher zutreffend als den Lastenausgleich und meinte damit sowohl den Ausgleich unterschiedlicher Belastungen durch organisatorische Maßnahmen, z.B. durch Ausgleichskassen, wie vor allem die gesetzliche Berücksichtigung der Unterschiede von Finanzbedarf und Finanzkraft zwischen den Ländern in dem Verteilungsschlüssel für ihren Anteil an bestimmten Reichssteuern. Auch innerhalb der Länder, vor allem Preußens, gab es diesen besonderen Lastenausgleich für bestimmte Sachgebiete, vor allem die Fürsorgelasten, die Schullasten, die Straßenbaulasten und die Polizeilasten.

Der Steuerkraftausgleich zwischen den Ländern von Reichs wegen hielt sich ursprünglich in mäßigen Grenzen, wurde aber im Laufe der Jahre zu einem ausgeklügelten System von Rechnungseinheiten für Finanzzuweisungen, die sich möglichst weitgehend dem Bedarf jedes einzelnen Verwaltungsträgers bis zur kleinsten Gemeinde anpaßten, um eine überall gleichwertige Aufgabenerfüllung zu sichern. Ein solches System von allgemeinen Bedarfszuweisungen wäre heute verfassungswidrig, weil Art.107 GG nur Anteile an bestimmten Steuern für jeden Teil zuläßt. Ebenso wäre eine Finanzausgleichsregelung, die auch für die Gemeinden und Gemeindeverbände bundesrechtlich Beteiligungsansprüche schaffen würde, verfassungswidrig, weil die Gesetzgebung über Gemeindeangelegenheiten aller Art ausschließlich den Ländern vorbehalten ist, obwwohl Art. 28 GG, worauf Herr Köttgen kürzlich erneut hingewiesen hat, durchaus eine verfassungsrechtliche $\mathrm{Be}-$ ziehung zwischen Bund und Gemeinden herstellt. Die Gemeinden und Gemeindeverbände fordern den Steuerverbund zwischen Bund, Ländern und Gemeinden, der durch ein verfassungsänderndes Initiativgesetz aus der Mitte des Bundestages widerhergestellt werden soll, aber wohl an der un- 
erreichbaren Zustimmung von zwei Drittel der Stimmen des Bundesrats scheitern wird.

Der Finanzausgleich zwischen den Ländern wurde früher nicht nur durch Reichsgesetz geregelt, er wurde auch bei der Uberweisung der Länderanteile an den Reichssteuern von Reichs wegen verwirklicht. Auf Befehl der Besatzungsmächte wurde ein solcher Steuerkraftausgleich im Grundgesetz verboten. Daraus entstand in Art. 106 Abs. 3 und 4 GG ein höchst widerspruchsvolles Gebilde von Bundeszuschüssen zu Länderaufgaben aus dem Bundesanteil an der Einkommensteuer und Ausgleichszahlungen der finanzstärkeren an die finanzschwächeren Länder. Aus dem väterlichen Finanzausgleich von Reichs wegen wurde ein brüderlicher der Länder untereinander, bei dem der Bund nur als Gesetzgeber und beim rechnungstechnischen Vollzug, nicht aber als zahlender Finanzausgleichspartner beteiligt ist. Einzelheiten dieses horizontalen Finanzausgleichs interessieren hier nicht, obwohl sie finanzwissenschaftlich und statistisch wahre Leckerbissen darstellen. Hier interessiert nur, ob ein solcher brüderlicher Finanzausgleich der Länder untereinander dem Grundgedanken der bundesstaatlichen Verfassungsordnung überhaupt und dem Grundgesetz im besonderen entspricht. Der Beschluß des Bundestags über ein neues Finanzverfassungsgesetz will sowohl einen väterlich-vertikalen wie einen brüderlich-horizontalen Ausgleich in der Verfassung zulassen, der Bundesrat dagegen erklärt allein den letzteren für verfassungsmäßig.

Zugleich sei bemerkt, daß ein solcher Ausgleich, gleich welcher Form, immer nur die Folgen, nicht aber die Ursachen der ungleichen Aufgabenlast und Steuerkraft angleichen kann. Die Steuerkraft eines Landes deckt sich regelmäßig nicht mit seinem Finanzbedarf. Dieses Mißverhältnis ist durch die Kriegsfolgen und die hohen sozialen und technischen Anforderungen in den Großstädten und den dicht bevölkerten Gebieten heute noch größer als die früheren Unterschiede zwischen industriellen und ländlichen Gebieten. Solche Leistungsunterschiede innerhalb eines modernen Sozialstaates entbehren jeder inneren Berechtigung und verfassungsrechtlichen Legitimität. Sie sind von Bundes wegen, wenn nicht zu beseitigen, so doch wesentlich zu verringern. Die Gewährleistungspflichten des Bundes als Sozialstaat aus Art. 20 Abs. 1 und 28 Abs. 3 GG wurden in anderem Zusammenhang bereits hervorgehoben. Unzureichende Leistungen eines Landes, die binter den Leistungen aller übrigen Länder zurückbleiben, sind deshalb von Bundes wegen auszugleichen. Dieser Gedanke der bündischen Gemeinschaftshilfe findet zwar eine gewisse 
Grenze an der Subsidiarität der Bundesaufgaben und der Selbstbestimmung der Länder über ihre Finanzgebarung. Auch darf ein steuerschwaches Land nicht eine aufwendige Haushaltspolitik auf Kosten des Bundes oder anderer Länder treiben. Das Problem heißt deshalb nicht Ausgleich aller Finanzkraftunterschiede der Länder, sondern ihre Angleichung. Es geht dabei um das AusmaB des Finanzausgleichs als Bundespflicht. Der Unterschied der Steuerkraft betrug in 1955 - bezogen auf 100 als Bundesdurchschnitt - 63 beim steuerschwächsten Land und 116 beim steuerstärksten. Er soll ab 1955 auf etwa 85 zu 112 verringert werden. Die dazu erforderliche Verteilungsmasse ist von rund DM 250 Mill. auf nur etwa DM 400 Mill. erhöht worden; das sind noch nicht $5 \mathrm{vH}$. der Ländersteuereinnahmen. Es ist eine politische Frage, ob das genügt. Es ist aber auch eine Rechtsfrage, ob dieser Ausgleich nicht eine echte Bundesaufgabe des ungeschriebenen Bundesstaatsrechts ist, die er mit eigenen Mitteln zu erfüllen hat und nicht bloß als schiedsrichterlicher Gesetzgeber für eine gemeinschaftliche Ländersache wie heute. Für Einzelfälle, die aus dem Rahmen jeder durchschnittlichen Betrachtung fallen, wie Schleswig-Holstein und Berlin, sind auch die Länder der Meinung, daß der Bund allein die erforderliche Sonderhilfe zu leisten habe. Bei dieser Auslegung der Verfassung unter Interessengesichtspunkten schlägt offenbar Finanzquantität in Finanzqualität um. Soviel zur allgemeinen staatsrechtlichen Seite des Länderfinanzausgleichs.

\section{Die Elastizität des Finanzausgleichs als Verfassungproblem}

Unter den Fragen von grundsätzlicher Bedeutung wende ich mich zum Schluß noch kurz dem allgemeinen verfassungsrechtlichen Problem von S i cherung - und Revis i ons $\mathrm{klauseln}$ in der Finanzverfassung zu. Art, Ausma $B$ und Lasten der öffentlichen Aufgaben wandeln sich ununterbrochen, die Steuerkraft der Aufgabenträger nicht minder. Die Deckungsordnung der Finanzverfassung ist nie endgültig im Sinne einer Unabänderlichkeit für längere Zeit. Diese immerwährende Anpassung an den Wandel von Finanzbedarf und Finanzkraft muß in der Verfassung selbst ausdrücklich offen gehalten werden, wenn sie durch einfaches Bundesgesetz möglich sein soll. Die Relativität jeder Finanzverfassung kommt auch in Art. 107 GG zum Ausdruck, der eine Zuondnung der Deckungsmittel an Bund und Länder entsprechend ihren 
Aufgaben verlangt, und diese Aufgaben sind nie endgültig und unabänderlich. Das engere Ziel dieser Klauseln ist es, Länder und Gemeinden gegen die finanziellen Auswirkungen der künftigen Bundesgesetzgebung zu schützen, die ihnen neue Aufgaben und Lasten auferlegt.

Die rechtliche Problematik solcher Sicherungs- und Garantieklauseln besteht darin, da $B$ sie sich notwendig in so unbestimmten Begriffen, wie der Zumutbarkeit einer unausgeglichenen Mehrbelastung oder dem Erforderlichsein zusätzlicher Deckungsmittel, kristallisieren müssen. Solche im Grundsatz ebenso richtigen wie praktisch unbrauchbaren Begriffe - Herr Flume nennt sie "Pseudo-Normen" - wären möglicherweise vom Bundesverfassungsgericht auszulegen und anzuwenden, das dann im Kern Entscheidungen des Gesetzgebers überprüfen und selbst treffen müßte. Das ganze Problem würde vollends verfassungsrechtlich unlösbar, wenn entsprechend dem Beschluß des Bundesrats jedes Mehrbelastungsgesetz nur gleichzeitig mit einem Finanzdeckungsgesetz als Zustimmungsgesetz verabschiedet werden könnte. Eine solche Bestimmung würde das Gesetzgebungsverfahren der Verfassung ändern und weit über die Ermächtigung aus Art. 107 GG hinausgehen. Solche verfassungsrechtliche Junktims sind immer verhängnisvoll, weil sie das System starr und brüchig machen. In unserem Falle würden sie praktisch jedes Bundesgesetz mit Finanzfolgen zum Zustimmungsgesetz machen. Diese Zuflucht der Länder vor dem Entwicklungsgesetz des modernen Sozialstaates bei der Verfassung hat etwas Tragisches an sich.

Eine nach beiden Seiten wirkende Revisionsklausel, wie sie von der Bundesregierung und dem Bundestag vorzuschlagen ist, hat einen verständigen Sinn. Man muß sich aber auch bei ihr darüber klar sein, daß sie unter den gleichen Schwierigkeiten einer handlichen Umschreibung ihres Wirksamwerdens leidet und ihr keine automatische Rechtswirksamkeit zugunsten eines Finanzausgleichspartners beigelegt werden kann. Ihr Adressat kann aus der Natur der Sache nur der künftige Bundesgesetzgeber sein, der den Verfassungsbefehl einlöst und die Finanzfolgen auslöst. Die früheren Versuche, der Revisionsklausel eine automatische Rechtswirkung beizulegen, wie sie in \$54 des Reichsfinanzausgleichsgesetzes enthalten waren, sind praktisch gescheitert. Die Bundesregierung erklärt heute mit Recht, da $\beta$ es angesichts dieser $Z$ wangslage immer nur einen Appell an die Loyalität und Einsicht des Gesetzgebers gäbe. 
X. Schlu B bemerkungen

Damit bin ich am Schluß meines Berichts. Er wollte lediglich einen Utberblick über die besondere staatsrechtliche Problematik der Finanzverfassung im Rahmen der allgemeinen Verfassungsordnung geben. Der Versuch einer wissenschaftlichen und systematischen Betrachtung zwang mich, weiter auszuholen und von dem Grundanliegen einer Finanzverfassung überhaupt auszugehen. Ich weiß, daß viele der behandelten Fragen einer vertieften staatsrechtlichen Durchdringung fähig und bedürftig sind, und ich bin überzeugt, daß der Herr Mitberichter und die Aussprache hier wertvolle Ergänzungen bringen werden.

Läßt man das gesamte Bild der gegenwärtigen Bemühungen um eine neue und endgültigere westdeutsche Finanzverfassung auf sich wirken, so muß der Staatsrechtler davor nicht weniger erschrecken als der Finanzpolitiker. Grund dafür ist nicht die Komplexität und die technische Schwierigkeit und die Unübersichtlichkeit des Problemkreises, als vielmehr der Fehlgebrauch, den politische Interessen hier mit der Rechtsordnung höchsten Ranges, der Verfassung, immer neu versuchen. Es ist die Angst um die Erhaltung der zufälligen Besitzstände von 1949, es ist das mangelnde Vertrauen in die gestaltenden Kräfte der politischen Entwicklung, und vielleicht ist es auch ein Übermaß von Verfassungsgläubigkeit, vor der gerade wir Staatsrechtler um des Rechtes willen warnen sollten. Die faktische Kraft des Normativen ist sehr viel geringer als die normative Kraft des Faktischen. Die Flucht in die Verfassung ist ein Schwächezeichen unserer Zeit und ihr Beruf zur Verfassungsgesetzgebung ist recht gering. Wie kann man unter so vorläufigen Verhältnissen so grundsätzlich und so endgültig sein wollen! Nicolo Machiavelli schrieb 1499 in seinen discorsi: „Roms GröBe bestand darin, daß es sich nicht völlig durchordnete und lieber die Fortdauer der inneren Kämpfe und Bewegungen wählte, als eine endgültig ausgewogene Verfassung". Möchte unseren Finanzverfassungsgebern etwas von dieser römischen Größe beschieden sein. 


\title{
Leitsätze des Berichterstatters über:
}

\section{Die Finanzverfassung im Rahmen der Staatsverfassung}

\author{
I. Begriff und Wesen
}

1. Finanzverfassung im allgemeinen Sinn meint den Inbegriff von Verfassungssätzen, die sich auf die Ordnung des Geldwesens, die staatliche Haushalts-, Vermögens- und Schuldenwirtschaft sowie die Ausübung der Finanzgewalt beziehen. Im Bundesstaat ist die Aufteilung der Steuergesetzgebung und der Steuererträge ein wesentlicher Teil der Finanzverfassung, der die Entscheidungen der Staatsverfassung über das Zusammenwirken von Bund und Ländern in Gesetzgebung, Verwaltung und Rechtsprechung erst vollziehbar und lebensfähig macht.

2. Die Finanzverfassung einerseits und die Wirtschafts- und Sozialverfassung andererseits bedingen und ergänzen sich gegenseitig: Soweit diese Bereiche des Wirtschaftlichen und Sozialen überhaupt durch die Verfassung normiert werden, wird auch ihre Ordnung von den Grundentscheidungen des Verfassungsgebers getragen.

In der freiheitlich-demokratischen Grundordnung des Grundgesetzes ist die Finanzverfassung - unbeschadet ausdrücklicher Sonderregelungen und Durchbrechungen von den Grundsätzen des sozialen Rechtsstaates, der Gewaltenteilung und insbesondere von dem föderalen Prinzip beherrscht.

\section{Rechtsstaat und Finanzverfassung}

3. Das Bekenntnis der Verfassung zum sozialen Rechtsstaat verleiht den Grundfragen der Finanzordnung, insbesondere der Sicherung eines gleichbleibenden Geldwertes und der Ausübung der Finanzgewalt, einen überragenden Rang. Der Rechtsstaat ist höchst unvollkommen, wenn der staatlichen Willkür bei der Bestimmung des Geldwertes und der Ausgestaltung der Besteuerung keine Grenzen gesetzt sind.

4. Auch die Finanzgewalt findet ihre Grenzen an der Würde des Menschen und dem allgemeinen Persönlichkeitsrecht. 
Der Grundsatz der Gleichheit vor dem Gesetz erlaubt nur eine sachgerechte Verhältnismäßigkeit der Besteuerung, deren Maßstab durch die Uberzeugung aller billig und gerecht denkenden Staatsbürger bestimmt wird.

5. Das Ziel der Finanzgewalt ist notwendigerweise die entschädigungslose Fortnahme von Eigentum zur Verwirklichung der Staatszwecke. Die besonderen Schranken der Verfassung gegen enteignende Eingriffe der Staatsgewalt gelten deshalb nicht für die Finanzgewalt. Art. 14 und 15 GG verbieten keine "Enteignung" und keine „Sozialentwährung" durch Besteuerung. Der Finanzgesetzgeber ist aber an die allgemeinen Verfassungsgrenzen für die Ausübung der Staatsgewalt in der freiheitlichen Grundrechtsordnung gebunden. Der Rechtsweg gegen Finanzbefehle ist unbeschränkt (Art. 19 GG).

6. Der Schutz der Währung ist eine höchste Aufgabe jedes Rechtsstaats, weil auf ihr die ganze Rechts- und Sozialordnung beruht. Staatliche Eingriffe oder Unterlassungen, die zu wesentlichen Veränderungen des Geldwertes führen, sind mit dem Bekenntnis der Verfassung zum Rechtsstaat und vor allem zum Sozialstaat (Sparer- und Rentnerschutz!) nicht vereinbar. Sie sind verfassungswidrig, auch wenn die Währung nicht ausdrücklich durch besondere Verfassungsnormen unmittelbar oder mittelbar (institutionell) geschützt ist.

7. Gesetze, die diese Grundpficht des Staates erfüllen, z. B. Gesetze über die Stellung der Notenbank, die Haushaltsführung, die unabhängige Rechnungsprüfung, sind materiell ebenso Verfassungsrecht wie Bestimmungen der Geschäftsordnungen über eine Beschränkung der parlamentarischen Finanzinitiative oder über eine autoritäre Sonderstellung des Finanzministers. Wenn sie auch nicht die formelle Verfassungskraft des Art. 79 GG besitzen, so sind sie doch als materielles Verfassungsrecht gegenüber den sonstigen Gegenständen der einfachen Gesetzgebung im Rang herausgehoben.

Das Urteil des Bundesverfassungsgerichts vom 6. 3.1952 (Entsch. 2, 144) über die Verfassungswidrigkeit einer Selbstbeschränkung der parlamentarischen Gesetzinitiative in Finanzsachen ist in seiner Tendenz rechtsirrig. Eine solche Selbstbeschränkung der parlamentarischen Finanzinitiative entspricht auch dem Verfassungsgebot zum Ausgleich des Haushaltsplans (Art. 110 GG). 
III. Gewaltentrennung und Finanzgewalt

8. Die Finanzgewalt unterliegt dem Verfassungsgrundsatz der Gewaltenteilung (Art. 20 GG). Die Finanzverfassung kennt aber einige typische Durchbrechungen dieses Grundsatzes: Gesetzesform des Haushaltsplans und der Kreditbewilligung; als Ausnahme von der Ausnahme: weitgehendes Nothaushaltsrecht der Regierung (Art. 111 GG), Genehmigung von Haushaltsabweichungen allein durch den Finanzminister (Art. 112 GG), Zustimmungsrecht der Regierung zu Mehrausgaben gegenüber dem Voranschlag (Art. 113 GG). Die Ausnahmen vom Grundsatz der Gewaltenteilung sind aus dem Zweck der einzelnen finanzrechtlichen Institutionen und aus geschichtlichen Zusammenhängen gerechtfertigt. Der Gewaltenteilungsgrundsatz nötigt im Zweifelsfall dazu, die Ausnahmen eng und die Ausnahmen von der Ausnahme weit auszulegen.

9. Gegenüber modernen Einbrüchen der gesetzgebenden Gewalt in den Bereich der vollziehenden (nach Art des gewaltenhäufenden Parlamentsabsolutismus der Volksdemokratien) ist daran festzuhalten, daß der Haushaltsplan seiner Rechtsnatur nach nur eine Ermächtigung an die Regierung ist. Die Regierung ist nicht verpflichtet, die bewilligten Beträge für die vorgesehenen Zwecke auszugeben. Die Regierung kann Haushaltsansätze sperren oder andere Maßnahmen der Mittelbewirtschaftung nach pflichtmäßigem Ermessen allein treffen. Mitwirkungsrecht des Parlaments oder eines Parlamentsausschusses beim Vollzug des Haushaltsplans können nur durch verfassungsänderndes Gesetz begründet werden.

\section{Die Finanzgewalt im Bundesstaat}

10. Die Aufteilung der Finanzgewalt im Bundesstaat wird in einem modernen Verwaltungsstaat durch die Tatsache bestimmt, daß auch der Bundesstaat ein einheitliches Wirtschafts- und Sozialgefüge darstellt, daß sich von dem eines Einheitsstaats nicht wesenhaft unterscheidet. Das Schwergewicht der Gesetzgebung in diesem Bereich und damit überhaupt liegt beim Bund, der politisch auch für die Deckung des Finanzbedarfs der ausführenden Verwaltungsträger verantwortlich ist. Der Bund übt deshalb notuendigerweise auch ganz überwiegend die Steuergesetzgebung aus. Eine konkurrierende Finanzgesetzgebung kann es wegen der wirtschaftlichen Einheit aller Steuergegenstände nur für Steuern geben, die für die Ein- 
heit und Einheitlichkeit des Wirtschafts- und Sozialgefüges bedeutungslos sind (Art. 72 Abs. 2 Nr. 3 GG).

11. Die Zuweisung von Deckungsmitteln („Steuerertrag“) setzt eine bestimmte Aufgaben- und Lastenzuweisung voraus. Solange die Verfassung selbst darüber keine Grundsätze enthält, kann der einfache Bundesgesetzgeber die Lasten des Vollzugs der Bundesgesetze nach sachgemäßem Ermessen dem Bund oder den Ländern auferlegen. Es ist Aufgabe des Bundesgesetzgebers, für eine entsprechende Zuordnung von Deckungsmitteln zu sorgen.

Aus der verfassungsrechtlichen Unterscheidung zwischen dem Vollzug der Bundesgesetze in landeseigener Verwaltung (Art. 30,84 GG) und in weisungsgebundener Bundesauftragsverwaltung (Art. 85 GG) können keine allgemeingültigen Grundsätze für die Lastentragung gefolgert werden. Eine endgültige und verfassungskräftige Trennung der Finanzmassen von Bund und Ländern (und Gemeinden / Gemeindeverbänden) ist aus der Natur des Finanzbedarfs oder der-Deckungsmittel nicht möglich. Nur für die Lasten der Bundesauftragsverwaltung der Länder besteht eine Verfassungspflicht des Bundes zur unmittelbaren Kostentragung.

Die persönlichen und sächlichen Verwaltungskosten von Bund und Ländern als Behördenträgern sind von jedem Teil ohne gegenseitige Verwaltungskostenerstattungen zu tragen.

Weisungsfreie Landesverwaltung auf Bundeskosten (Hauptfall Art. 120 GG) widerspricht dem Grundsatz, daß eigene Verwaltung nicht für fremde Rechnung ausgeübt werden soll. „Wer befiehlt, schafft an“. Für diese Länderverwaltung besteht keine parlamentarische Kontrolle der Landtage, weil die Mittel nicht im Landeshaushalt bewilligt sind. Soweit eine solche Landesverwaltung auf Bundeskosten für einzelne Sachgebiete noch fortbesteht, hat der Bund eine unbeschränkte Finanzaufsicht mit Weisungsbefugnis; die Rechnungskontrolle obliegt für diese Länderverwaltung dem Bundestag und Bundesrat unter Mitwirkung des Bundesrechnungshofs.

12. Die überregionale Gewährleistungs- und Ausgleichspficht des Bundes (Beispiel Art. 28 Abs. 3 GG) bedeutet auch die grundsätzliche Verpflichtung des Bundes zum Ausgleich wesentlicher Unterschiede der Verwaltungsleistungen und der Steuerbelastung in den Ländern. Diese Ausgleichspflicht fließt unmittelbar aus dem Zweck der allgemeinen 
Koordinierungspflicht des Bundesstaats. Sie entspricht dem Bekenntnis der Verfassung zum Sozialstaat, dessen Objekt auch die Länder und die sonstigen Träger öffentlicher Aufgaben sind. Das differenzierende Prinzip des Bundesstaats findet seine Grenzen an den Erfordernissen eines modernen Verwaltungsstaats.

Eine Spaltung der Einkommensteuer in eine einheitliche Bundeseinkommensteuer und Landeseinkommensteuern mit unterschiedlichen Steuersätzen ist heute auch unter staatsrechtlichen Gesichtspunkten bedenklich, weil sie ungleiche Startbedingungen für den wirtschaftlichen Wettbewerb und Sozialunterschiede schafft, „für die ein sachlich einleuchtender Grund der Differenzierung sich nicht finden läßt" (BVerfG 1,10).

13. Anteile der Länder am Aufkommen der Bundessteuern in einem Uberweisungssystem sind nicht verfassungswidrig, wenn diese Anteile sich nach einem gesetzlichen Maßstab bemessen und den Ländern darauf ein Anspruch zusteht. Dagegen sind allgemeine Bedarfszuweisungen nach Schlüsselzahlen, die nicht einen bestimmten gesetzlichen Anteil an einer bestimmten Steuer darstellen, ebenso verfassungswidrig für etwaige Matrikularbeiträge der Länder an den Bund (Art. 107 Satz 3 GG).

14. Ein Steuerkraftausgleich zwischen den Ländern ist verfassungsrechtlich geboten. Die Verfassung läßt seinen Vollzug sowohl von Bundes wegen aus Bundesmitteln (väterlich, vertikal) wie auch für die Länder untereinander aus Ländermitteln (brüderlich, horizontal) zu. Dem Gedanken der bündischen Gemeinschaftshilfe entspricht ein vertikaler Finanzausgleich besser.

15. Sicherungs-(Garantie-)Klauseln zugunsten eines Partners (Länder) im Finanzausgleich widerstreiten dem ständigen Wechsel von Aufgabenlast und Finanzkraft aller Partner (Bund, Länder, Gemeinden und Gemeindeverbände).

Eine allseitige Anpassungs-(Revisions-)Klausel dagegen versteht sich aus dem Zweck des Finanzausgleichs von selbst. Sie kann aber nur den künftigen Bundesgesetzgeber verpfichten; unmittelbare Ansprüche der Partner gegeneinander, insbesondere gegen den Bund kann sie schon wegen der rechtlichen Unbestimmtheit ihrer Tatbestandsmerkmale („Zumutbarkeit einer unausgeglichenen Mehrbelastung, erforderliche zusätzliche Deckungsmittel" u. ä.) nicht begründen. Eine solche Klausel würde im Konfliktsfall das Verfassungsgericht möglicherweise in die Aufgabe des Gesetzgebers drängen. 


\section{Die Finanzverfassung im Rahmen der Staatsverfassung}

\section{Mitbericht von Professor Dr. The od or Ma u n z, München}

Herr Kollege Hettlage hat das Thema des Tages in so umfassender und gedankenreicher Art entwickelt, daB eine nochmalige volle Ausbreitung der gleichen Fragen durch mich wenig fruchtbar wäre, zumal ich in vielen Punkten mit ihm durchaus übereinstimme. Ich will aber versuchen, dem behandelten Stoff an einigen Stellen einige weitere Nuancierungen zu geben.

Seitdem der Begriff der politischen Verfassung jene sorgfältige Durchdenkung erfahren hat, die für die heutige deutsche Verfassungslehre kennzeichnend ist, ist die Finanzverfassung stets als ein Stück der Gesamtverfassung betrachtet worden. Die Formulierung: Finanzverfassung „im Rahmen" der Staatsverfassung enthält daher eine zutreffende Charakterisierung des gegenseitigen Verhältnisses. In einem etwas veränderten Sinn könnte sogar von einer Abhängigkeit (oder wie man auch zu sagen pflegt: von einer Interdependenz) der Finanzverfassung von der Staatsverfassung gesprochen werden, wenn nämlich unter Staatsverfassung die Entscheidung über den politischen Kern des staatlichen Lebens verstanden wird. Im einen wie im anderen Sinn ist die Finanzverfassung ein untrennbarer Bestandteil der Staatsverfassung. Dennoch hat jene Seite der Verfassung, die wir Finanzverfassung nennen, ihre eigenen Voraussetzungen, ihre abgesonderten Gegenstände und auch ihr besonderes Ziel.

Wenn wir von den politischen Fakten und Streitthemen ausgehen und an sie rechtliche Maßstäbe anlegen, so finden wir vorzugs we is e drei Fragenkreise für das Verfassungsrecht interessant: Die verfassungsrechtlichen Bindungen des Haushaltsrechts, das Finanzausgleichsrecht und die leitenden Steuergrundsätze. Im Haushaltsrecht konzentrieren sich die verfassungsrechtlich bedeutsamen Fragen auf das Verhältnis von Volksvertretung und Regierung und damit auf ein historisch ehrwürdiges Kampffeld um politische Grundpositionen. Im Finanzausgleichsrecht betreffen sie die Leistungsfähigkeit der Gliedstaaten im Gesamtstaat und werfen damit das Problem der Bundesstaatlichkeit auf. Bei den leitenden Steuerideen beziehen sie sich auf das Verhältnis des Bürgers zum Staat, und zwar in erster Linie auf die Rechtsstaatlichkeit 
im Bereich der Finanzverwaltung und auf die Steuerwürdigkeit. Es wird zu fragen sein, ob die Zeit gekommen ist, in allen drei Gebieten oder wenigstens in einem Teil davon aus den traditionellen Antithesen und Polemiken herauszukommen. Dazu muß an die Ursachen erinnert werden, die zu den bekannten Entgegensetzungen und Fronten geführt haben, und es muß überlegt werden, ob in der Gegenwart neue Gesichtspunkte jene Ursachen verdrängen konnten.

I. Die Kampfstellung von Volksvertretung und Regierung ${ }^{1}$ ) ist im 19. Jahrhundert das vordringlichste Anliegen und der meistbehandelte Gegenstand des Haushaltsrechts gewesen. Hier fand ein wichtiger Teil des Ringens zwischen demokratischen und autoritären Gewalten um den Einfluß auf die Staatsführung statt. Moderne Untersuchungen haben auch für das deutsche Haushaltsrecht wieder bewußt gemacht, welche Bedeutung dem Zusammenhang von Budgetrecht und Staatsverfassung besonders in England und Frankreich eingeräumt worden ist ${ }^{2}$ ). Lorenz v. Stein hatte schon im 19. Jahrhundert den Satz geschrieben, daß das Budgetrecht „Hauptausdruck und Träger der verfassungsmäßigen Freiheit überhaupt gewesen ist". Bei einer Würdigung des Haushaltsrechts ist immer wieder erörtert worden, welche entscheidenden Kräfte politischer Art auf die Begrenzungen der Regierungsmacht durch das Parlament in haushaltsrechtlicher Hinsicht eingewirkt haben. Der Haushaltsbeschluß war in überwiegender deutscher Vorstellung des 19. Jahrhunderts ${ }^{3}$ ) die Ermächtigung, nicht die Weisung der Volksvertretung an die Regierung, Ausgaben zu leisten, Zahlungsverpflichtungen einzugehen und Abgaben zu erheben. Die Bedeutung des Haushalts war in dieser Hinsicht um so größer, als der Grundsatz der Delegationsbedürftigkeit von Vollzugsakten im übrigen noch nicht generell anerkannt oder durchgeführt war, und als andere Wege zu einer Kontrolle der Exekutive noch nicht oder nur in Ansätzen vorhanden waren. In einer späteren Entwicklungsstufe aber, in der eine lückenlose Gesetzmäßigkeit und eine umfassende Kontrolle erreicht waren, war jene Ermächtigung nur eine unter vielen geworden. Es lag dann nahe zu überlegen, ob nicht der Haushaltsbeschluß mehr als eine der üblichen Delegationen ist, ob er vielleicht gar eine recht-

1) Vgl. dazu Hett la ge, DOV 1955, $2 \mathrm{ff}$.

2) Vgl. Joh a n es Heckel, Die Entwicklung des parlamentarischen Budgetrechts und seiner Ergänzungen, Handbuch d. Deutschen Staatsrechts, Band II, 1932, S. $358 \mathrm{ff}$.

3) Vgl. u. a. L a b a nd, Deutsches Staatsrecht, Band IV, 5. Aufl. 1914, S. 529, 533, 542 ff. (Gegenstimmen dortselbst S. 540, Anm. 1). liche Bindung der Exekutive darstellt, die beschlossenen Aus- 
gaben wirklich vorzunehmen. Der Streit über diese Frage ist m. E. noch nicht endgültig ausgetragen. Doch weigern sich die Regierungen heute noch, meist mit Erfolg - und sie werden darin auch vielfach von der Wissenschaft, auch von Herrn Kollegen Hettlage ${ }^{4}$, unterstützt - im Haushaltsbeschluß etwas anderes als eine Ermächtigung zu sehen. Mit dem fortschreitenden Ubergewicht der Volksvertretung wird aber immer unsicherer, wie lange diese Pasition von den Regierungen noch gehalten werden kann und ob es überhaupt noch sinnvoll ist, sie zu halten; denn heute schon kann es keinem Parlament verwehrt werden, außerhalb des Haushalts in einem speziellen Gesetz Bindungen der Regierungen zu finanziellen Aufwendungen festzulegen, zum Beispiel in einem Besoldungsgesetz, einem Fürsorgegesetz, einem Kriegsfolgenschlußgesetz u. a., dem der Haushalt dann Rechnung tragen muß. Die Positionen eines Haushalts des Staates werden bekanntlich in einem immer weiter um sich greifenden Umfang bereits vor der Haushaltsberatung durch Gesetz festgelegt, insbesondere durch Personalund Sozialausgaben. Das Gewaltenteilungsprinzip würde vergeblich beschworen werden, um die Verfassungswidrigkeit eines solchen Gesetzes zu stützen.

Allerdings ist festzustellen, da $B$ die wachsende Stärke der Volksvertretung auch Gegenwirkungen erzeugt hat. Vor allem ist erwogen und teilweise in den Verfassungstexten sogar ausdrücklich festgelegt worden, daß ihrer grundsätzlich anerkannten Macht doch von den unabweisbaren Notwendigkeiten größtmöglichster Sparsamkeit her Grenzen gezogen werden sollen und daß zu diesem Zwecke verfassungsrechtliche Hemmungen eingeschaltet werden. So erklären sich Verfassungssätze wie die, daß die Regierung oder der Finanzminister Einspruch gegen irgendwelche Ausgaben oder gegen Ausgabeerhöhungen durch das Parlament während des Haushaltsjahres erheben können, oder daß gar nur die Regierung oder der Finanzminister Vorschläge für neue Ausgaben machen dürfen. Die besondere Stellung des Finanzministers, wo sie verfassungsrechtlichen Ausdruck gefunden hat - vgl. etwa Grundgesetz Art. 112 - ist in diese Entwicklungsreihe zu stellen, ebenso das etwaige Verbot von Einnahmesenkungen und ähnlichen Maßnahmen, die einen Teil der gesetzgebenden Befugnisse dem Parlament entziehen oder auf die Regierung übertragen wollen. Solche Einschaltungen gegen die Allmacht des parlamentarischen Beschließens, die infolge der Ausgabefreudigkeit der Parlamente notwendig schienen, lassen erkennen, da $B$ sich in diesem Punkt die Gewichte verlagert

4) Hettlage, DOV 1955, 33. 
haben. Nicht mehr die Regierung erscheint als die primär aufwendige Stelle, der die Ängste der Steuerzahler, repräsentiert durch die Volksvertretung, mäßigend vor Augen gehalten werden müssen. Vielmehr ist jetzt die Regierung die Verteidigerin des ausgeglichenen Haushalts und der stabilen Währung gegenüber einer weit sorgloseren Volksvertretung. Wenn wir einen kritischen Blick auf die verfassungsmäßigen Versuche einer Rückenstärkung der sparsamen Regierung gegenüber dem gebebereiten Parlament werfen, soweit sie bereits geltendes Recht darstellen, so scheint sich zu zeigen, daß die der Regierung in die Hände gegebenen größeren Befugnisse ohne Schwierigkeiten ertragen, ja vielfach als nützlich empfunden worden sind, jedenfalls dort, wo sie in gewissem Umfang historischen Ansätzen folgen. Wo sie ohne geschichtlichen Vorgang aus bloßen Zweckmäßigkeitserwägungen in die Verfassing eingefügt werden sollen, wird die Beurteilung zu einem ähnlichen Ergebnis gelangen, wie bei sonstigen Ubernahmen anderwärts bewährter Rechtsformen in ein System, dem sie fremd sind. Die Befürchtung ist nicht von der Hand zu weisen, daB, was nicht natürlich entstanden ist, nur schwer und zögernd zur wirklichen Belebung gelangt. Im ganzen gesehen wird man die Regelungen, wie sie das Grundgesetz über die Stärkung der Regierung enthält, als vernünftig und tragbar ansprechen dürfen, und es ist unter sorgsamer Abwägung historischer und politischer Kräfte und Auffassungen eine weitere Ausreifung denkbar ${ }^{3}$.

Nun sind aber in jüngster Zeit im Haushaltsrecht der USA neue Gedanken geäußert worden, die über die altbekannten Versuche, die Macht des Parlaments durch die Weisheit der Regierung einzudämmen, weit hinausgehen und eine nochmalige Durchdenkung überkommener Rechtsformen erfordern ${ }^{6}$ ). In diesem Sinne jedenfalls möchte ich einige Gedanken von Smithies deuten, die uns Ottmar Bühler vermittelt hat. Bühler ${ }^{7}$ ) charakterisiert diesen Vorgang mit folgenden Worten: "Uber die Auffassung des Budgets als eines Kontrollsystems des Parlaments über die Regierung ist man in den USA offen-

s) Mit den verfassungmäßigen Voraussetzungen formale $r$ Art für die Reform des staatlichen Haushaltsrechts beschäftigt sich Dahlgrün, DOV 1955, 6 ff.; vgl. auch in diesem Zusammenhang die Bemerkungen von $\mathrm{D}$ a h l $\mathrm{g}$ r ü $\mathrm{n}, \mathrm{DOV} 1955,72 \mathrm{ff}$. zu Hett l a ge, DOV 1955, I ff. und 33 ff. mit Erwiderung Hettlages, DOV 1955, $74 \mathrm{f}$.

6) Vgl. S m ith ies, The budgetary prozess in the United States, New York 1955.

7) Vgl. B üh ler in einem (ungedruckten) Bericht zum Buch von Smithies an den Wissenschaftlichen Beirat des Bundesfinanzministeriums. 
bar weit hinausgekommen. Daher hat man dort in ganz anderer Weise die Hände frei für die eigentlichen wirtschaftlichen Probleme des Haushalts. Die richtigen Abwägungen bei den Bewilligungen, die richtige Zeit für die Abrufungen, die möglichist genaue Feststellung der Wirkungen des Haushalts auf die nationale Wirtschaft stehen im Vordergmund." Mit anderen Worten: der Haushalt und sein Vollzug werden als ein wirtschaftliches Phänomen ersten Ranges gewertet, demgegenüber das Funktionieren und Ineinandergreifen von Legislativ- und Exekutivorganen als durchaus nebensächlich angesehen werden. Smithies und wohl auch Bühler scheinen sogar zu hoffen, daB jene alten neuralgischen Punkte bald überhaupt unproblematisch werden könnten. Jener will das anscheinend in der Weise erreichen, daß das Budget ausschließlich als Realisierung des Regierungsprogramms gewertet wird und daher alleinige Sache des Präsidenten ist. Zwar ist es offenbar auch bei seinen Bestrebungen noch unentschieden, ob der Präsident oder der Finanzminister die Stelle sein sollen, durch die das Regierungsprogramm realisiert wird, in diesem Sinn gesehen also der Haushalt nicht nur ausgeführt, sondern sogar aufgestellt und beschlossen werden soll. Doch ist diese Frage $\mathrm{m}$. E. für uns zunächst nicht die entscheidende. Jedenfalls ist klar, was gewollt ist: unter der Erkenntnis der Einwirkung des Haushalts auf das Geschehen in der Wirtschaft und auf das Befinden der Wirtschaft soll an die Stelle politischer Spannungsfelder zwischen Verfassungsorganen die gemessene Ruhe der Sachvernunft gesetzt werden. Bei Würdigung dieser $\mathrm{Ge}-$ dankengänge ist zunächst ohne weiteres einzuräumen, daß Geldverschiebungen im Ausmaß des Bundeshaushalts (in der Bundesrepublik alljährlich fast 40 Milliarden) auf die Wirtschaft einwirken, wie kaum ein anderes normales Ereignis. Gerade in jüngster Zeit ist dies wieder augenscheinlich geworden, als bauliche Aufträge der Regierung an eine bereits in Hochkonjunktur stehende Wirtschaft abgebremst oder Steuersenkungen in dieser Situation als unzeitgemäß bezeichnet worden sind. Utber diesen zutreffenden Aspekt des neuen Gedankens braucht also kein Wort verloren zu werden.

Etwas anderes ist es jedoch, ob es gelingen kann, ja ob es wünschenswert ist, politische Spannungen durch Sachvernunft verdrängen zu wollen. Der Gegensatz von Volksvertretung und Regierung auf dem Hintergrund demokratischer oder autoritärer Wertungen beruht auf einem echten politischen Gegensatz, der durch Sieg, Niederlage oder Ausgleich gelöst werden kann,, nicht aber durch Verschieben auf die Ebene des "Sachgemäßen". Die früheren Versuche, Neutralisierungen von 
Ausschnitten aus dem politischen Geschehen zu bewirken, etwa die Wehrmacht oder das Beamtentum zu entpolitisieren, wozu nunmehr die Neutralisierung des Haushaltswesens käme, bedeuteten in Wahrheit nur ein Verlagern oder Verdecken des Kampffeldes. Mit den Fronten um wirtschaftspolitische Anschauungen und Folgerungen wird der alte Kampf zweifellos fortgesetzt werden. Versachlichung oder Entpolitisierung wären allenfalls dann zu erwarten, wenn über die wirtschaftlichen Grundsätze, nach denen die Bewilligung und der Abruf von Haushaltsmitteln erfolgen sollen, restlos Utbereinstimmung bestände. Das würde u. a. eine völlige Verbrüderung der Anhänger staatsgelenikter Wirtschaft und freier Wettbewerbswirtschaft voraussetzen. Ein solches Ereignis kann nicht als wahrscheinlich betrachtet werden. Was aber ist nützlicher, den Kampf unter der einen oder der anderen Fahne zu führen, als politischen oder als wirtschaftlichen Kampf? Schon die Frage scheint zu zeigen, daß mit dem Ruf nach Sachvernunft allein nichts Entscheidendes erreicht, jedenfalls der Kampf nicht beendet ist, und die Kräfte nicht für andere Aufgaben verfügbar geworden sind. In einem, aber für das Ganze nicht entscheidenden Punkt kann wohl den Befürwortern einer Entpolitisierung des Haushalts recht gegeben werden, daß nämlich eine Offenlegung und Betonung der wirtschaftlichen Beweggründe durchaus von Vorteil sein kann. Das führt zu dem Ergebnis, die Auseinandersetzungen um den Haushalt stärker als bisher auf wirtschaftspolitische Erwägungen zu erstrecken. Dadurch wird keine Entmachtung des die politischen Kräfte des Volkes repräsentierenden Parlaments herbeigeführt. Letzten Endes kann es sogar zu seiner Stärkung führen, wenn zum Beispiel sein Einwirken auf die so bedeutsamen $\mathrm{Ab}$ rufungen der bewilligten Beträge in den Bereich der Möglichkeiten rückt. Im ganzen gesehen eröffnen die Gedanken von Smithies weniger wegen der Meinung, der Haushalt könne als ausschließliche Sache der Exekutive angesehen werden, neue Gesichtspunkte, als vielmehr wegen der Forderung, Bewilligungen und Abrufungen von Haushaltsbeträgen stärker als bisher unter dem Blickpunkt der Einwirkung auf wirtschaftliche Vorgänge zu sehen, jedenfalls wirtschaftliche Ziele deutlicher als bisher offenzulegen. Die Hände von Volksvertretung und Regierung wenden dadurch freilich - um beim Bild zu bleiben - nur noch beschäftigter und die geistigen Anstrengungen noch größer werden als bisher.

Die Beeinflussung der Wirtschaft durch den Haushalt und überhaupt durch die Staatsfinanzgebarung führt zu der weiteren Frage, ob die Finanzverfassung des Bundes bereits 
materielle staatswirtschaftliche Grundsätze in sich birgt oder ob es möglich und sinnvoll wäre, solche Verfassungsbestandteile aufzustellen und einzufügen. Es handelt sich mit anderen Worten darum, $a b$ die geltende Verfassung bereits eine bestimmte Grundentscheidung finanzpolitischer Art getroffen hat und wie sie etwa zu den Fragekreisen „Haushalt und Konjunktur", „Haushalt und Vollbeschäftigung“, „Haushalt und Preis-Lohn-Stabilisierung " steht. $\mathrm{Zu}$ den traditionellen Bestandteilen unserer Finanzverfassung gehört allerdings schon bisher die Proklamierung des Ausgleichsprinzips, des Prinzips der Einheitlichkeit, der Vollständigkeit, der Nichtübertragbarkeit, der Scheidung in fortlaufende und einmalige Ausgaben und der Vorweg-Abdeckung von Fehlbeträgen. Sie beziehen sich teils auf die verfahrensrechtliche, teils auch auf die staatswirtschaftliche Seite des Haushaltsrechts. In letzterer Hinicht wäre eine starke Erweiterung denkbar. Freilich ist schon das Ausgleichsprinzip heute keineswegs mehr unangegriffen. Unter wirtschaftspolitischem Blickpunkt wird immer wieder die Meinung vertreten, daß ein vorübergehendes Defizit wirtschaftlich durchaus fruchtbar sein könne. Es käme nur darauf an, daß sich der Staat nicht für laufende Ausgabenzwecke verschulde. Nach der Vorstellung des Grundgesetzes müßte dagegen jeder Haushalt, der nicht ausgeglichen ist, verfassungswidrig und damit wohl unwirksam sein. Auf seiner Grundlage dürften keine Zahlungen vorgenommen werden. Es ist nicht wahrscheinlich, daß die parlamentarische und exekutive Praxis solche Folgerungen gegen sich gelten lassen würde. Vielfach ist die politische Handhabung bereits über traditionelle Programme und Terminologien des Haushaltsrechts faiktisch hinweggegangen. Wenn neue staatswirtschaftliche Grundsätze in das Verfassungsrecht eingebaut werden sollen, müßte man sich erst über sie verständigen und sie zu einer gewissen außerrechtlichen Anerkennung bringen. Erst dann wird man darüber nachdenken können, $a b$ sie in den Rang von Verfassungssätzen erhoben werden sollen. Vorläufig pflegen in den Verfassungstexten noch immer die ehrwürdigen, aber keineswegs mehr mit UTberzeugung und Sorgfalt beachteten Prinzipien des Haushaltsrechts des 19. Jahrhunderts in den überkommenen Formulierungen fortgeführt zu werden.

\section{Fin anzausgleichsrecht}

Das andere Kampffeld, auf dem verfassungsrechtliche Gegensätze neben wirtschaftspolitischen Meinungsverschiedenheiten 
ausgetragen werden, ist das der verschiedenen vertikalen und horizontalen Finanzausgleiche ${ }^{8}$ ).

Der betragsmäßige Hintergrund, auf dem sich der vertikale Finanzausgleich abspielt, ist in der Bundesrepublik bekanntlich folgender: Die allein dem Bund zufließenden Steuern erbrachten 1954 eine Summe von 19,5 Milliarden, während die ausschließlichen Ländersteuern 2,1 Milliarden einbrachten. Neben beiden steht der gemeinsame Topf für Bund und Länder, den die Einkommen- und Körperschaftsteuer mit einem Aufkommen von 12,2 Milliarden darstellt. Davon erhielt der Bund $38 \%$ oder 4,6 Milliarden, während den Ländern $62 \%$ oder 7,5 Milliarden zukamen. Insgesamt also konnten der Bund mit 24,2 Milliarden, die Länder mit 9,7 Milliarden rechnen. Es ist wohl das Erstaunlichste in dem bisher alljährlich regelmäßig aufflammenden Streit um die Bundes- und Länderanteile, daB es sich bei ihm um etwa $2 \%$ der Einkommensteuer, das ist etwa 240 Millionen im Jahr, also um weit weniger als $1 \%$ des Gesamtvolumens handelt. Es läge nahe, sowohl allen Föderalisten wie ihren Gegnern zu raten, kein weiteres Wort mehr auf diesen Streit ${ }^{\circ}$ ) zu verschwenden, sondern ihn einzustellen oder allenfalls die ärmliche Beute zu halbieren. Die Bagatelle dieses Streites hat verständlicherweise die Vermutung aufkommen lassen, daB der Bund damit auf einem verfassungsrechtlich sonst nicht vorgesehenen Weg ${ }^{10}$ ) eine mittelbare Einwirkung über die Haushalte der Länder zu gewinnen und so manche Uppigkeiten auf ein vernünftiges Maß zurückzuführen suche ${ }^{11}$ ). Damit würde ein verständliches

8) Dazu aus dem jüngsten Schrifttum z. B.: F is c h e r-M e n sh a u se $n$, DOV 1955, $261 \mathrm{ff}$;; H e n le, BayVBl. 1955, $225 \mathrm{ff}$; Hüchting, DOV 1955, $288 \mathrm{ff}$. sowie DOV 1955, $38 \mathrm{ff}$.; $\mathrm{K}$ I e in in Festschrift für Giese, 1953, S. 61 ff.; K öttg e n, DVBl. 1953, $681 \mathrm{ff}$. sowie DOV 1953, $358 \mathrm{ff}$.; W a cke, DOV 1955. $578 \mathrm{f}$; vgl. auch W a cke, Das Finanzwesen der Bundesrepublik, 1950; sodann die Referate von A u g u stin, DÖV 1953, $433 \mathrm{f}$;; N ederkorn, DOV 1953, 552 ff.; ferner - o. V. - DVBI. 1953, 432.

9) B räu e r, DƠV 1955, 585 spricht von einem ,geradezu unwürdig gewordenen Tauziehen zwischen Bund und Ländern um die Verteilungsquote"; $\mathrm{H}$ e $\mathrm{n}$ le, BayVBl. 1955, 225 mein't dank der pünktlichen Wiederholung dieses „mit planetarischer Regelmäßigkeit und trojanischem Lärm" durchgeführten Streites „möchte fast der Eindruck entstehen, es handle sich um eine Art konstitutioneller Einrichtung

10) Vgl. dazu B r äu e r, DOV 1955, 585.

11) Henle, BayVBI. 1955, 225 ist der Ansicht, angesichts der großzügigen Art, mit der sonst finanzielle Rücksichten behandelt zu werden pfiegten, ließe sich der Finanzstreit nicht ausreichend durch ein waches flnanzpolitisches Interesse erklären. Es liege 
Ziel auf einem illegitimen Pfad angesteuert werden. Für diese Deutung mag sprechen, daß im Bundesbereich gelegentlich erwogen worden ist, das Scheitern einer Einigung über den Bundesanteil zu einer Bundesexekutive besonderer Art zu benützen, deren Rechtsgrundlage in Art. 108 Abs. 4 GG zu finden wäre. Darnach kann der Bund die ordnungsgemäße Verwaltung der gemeinsamen Steuern, soweit sie dem Bund zufließen, durch Bundesbevollmächtigte überwachen lassen, die gegenüber den Mittel- und Unterbehörden ein Weisungsrecht haben. Es wird aber wohl kaum bestritten werden können, daß dieser Verfassungssatz nur das Vollstreckungsverfahren regeln will, während er eine materiellrechtliche Vorschrift über die Höhe des Bundesanteiles nicht selbst enthält, sondern voraussetzt. Ein Beschneiden allzu großer Ausgabefreudigkeit der Länder durch den Bund wird also auf diesem Wege schwerlich zu erreichen sein.

Uber einige Erkenntnisse scheinen sich indessen alle Beteiligten einig zu sein: Zunächst darüber, daß bei jeder überhaupt denkbaren Gestaltung des Finanzausgleichs zwischen Bund und Land eine Einigung über die Verteilung von Steuerquellen und Steueraufkommen nötig ist. Ein Finanzausgleich wäre selbst dann notwendig, wenn Deutschland ein Einheitsstaat wäre, und natürlich auch dann, wenn der Bund eine bundeseigene Finanzverwaltung hätte (das haben die Jahre vor 1945 und vor 1933 bewiesen). Die Intensität des Streites würde durch das eine wie das andere Faktum keineswegs gemildert, sondern nur auf eine andere rechtliche Ebene verlagert. Ferner besteht Einigkeit darüber, daß kein anderer Weg des Finanzausgleichs möglich ist, als der über eine große gemeinsame Steuer von Bund und Ländern (neben bundeseigenen und landeseigenen Steuern). Von keiner Seite ist ein anderer Weg auch nur angedeutet oder in Betracht gezogen worden ${ }^{12}$ ). Es ist auch nicht ersichtlich, inwiefern eine gemeinsame Steuer den föderativen Aufbau gefährden soll. Mit dem Bundesstaat ist nicht das "Trennsystem “ notwendig verknüpf $t^{13}$ ); es lassen sich auch andere Gestaltungen mit ihm verbinden. Im Gegenteil: eine gemeinsame Steuer ist durchaus begrüßenswert; denn sie zwingt im Verhältnis von Bund und Ländern zu beiderseitiger Rücksichtnahme und gegenseitigem Verständnis ohne

nahe, in ihm ein Symptom zu sehen, das ouf eine tieferliegende Störung, eine Art Dystonie im inneren Gefüge unseres Staates schließen ließe.

12) Vgl. He n le, BayVBl. 1955, 226.

18) Vgl. dazu Wacke, DOV 1955, 578 (mit Hinweis auf Pop i z). 
Pochen auf rechtliche therlegenheit. Schließlich ist auch nirgends geäußert worden, daß als gemeinsame Steuer eine andere als die Einkommen- und Körperschaftssteuer in Frage käme. Damit sind sich aber die streitenden Seiten schon sehr nahe gekommen. Noch keine Formel ist dafür gefunden worden, wie man die unentbehrliche Elastizität des Bundeshaushalts kombinieren kann mit einer gewissen Stabilität, die die Länder sichert, ihre Aufgaben zu erfüllen, ohne in einem ständigen finanziellen Schwebezustand zu bleiben. In diesem Punkt scheinen die planenden Finanzpolitiker von den formulierenden Verfassungsrechtlern noch nicht genügend unterstützt worden zu sein.

Die grundsätzliche Richtung, die das Grundgesetz dem Finanzausgleichsrecht zwischen Bund und Ländern gewiesen hat, ist trotz des Mißlingens einiger Sätze im ganzen doch sowohl für den Bund wie für die Länder vorteilhaft. Unbestreitbar für den Bund günstig ist das durch Art. 106 Abs. 3 GG herbeigeführte Ergebnis ${ }^{14}$ ), wonach der Bund zur Deckung seiner durch andere Einkünfte nicht gedeckten Ausgaben einen Teil der Einkommen- und Körperschaftssteuer in Anspruch nehmen darf. Die Erfahrung zeigt jedenfalls, daß sich sein Anteil von 1951 bis 1954 mehr als verdoppeln konnte, während der Länderanteil in der gleichen Zeit nur um ein Viertel anwuchs. Uberdies bedeutet die Quote des Bundes an der gemeinsamen Steuer gegenwärtig nur etwa die Hälfte seiner Gesamtsteuermasse, während die Quote der Länder an der gleichen Steuer vier Fünftel ihrer Gesamtsteuermasse ausmacht. Das Risiko der Länder bei jeder Veränderung des Anteils ist also viermal so groß als das des Bundes. Anderseits bedeutet die Regelung eine unleugbare Stärkung des Ländereinflusses, da das Bundesgesetz, das den Anteil des Bundes bestimmt, der Zustimmung des Bundesrates bedarf. Es besteht Zustimmungsrecht, nicht Zustimmungspflicht des Bundesrates. Die anderen maßgeblichen Bundesorgane können also die Notwendigkeit und die Höhe des Bundesanteiles nicht ohne Verständigung mit der Ländermehrheit bestimmen. Dadurch ist ein beruhigendes Gleichgewicht in die verfassungsrechtlichen Beziehungen zwischen Bund und Ländern auf finanziellem Gebiet geksommen, wenigstens insoferne als die Risiken verteilt und die Gemeinsamkeiten herausgehoben sind. Auch wenn der Bund nun naturgemäB versuchen wird, die Länderfront aufzugliedern (was politisch naheliegend ist), oder wenn umgekehrt die Länder bestrebt sein werden, in möglichst einheit-

14) Vgl. hierzu auch die näheren Zahlenangaben bei Henle. BayVBl. 1955, 227. 
licher Linie ihre Interessen zu wahren, muß jedenfalls in einer Art rechtlicher Waffengleichheit gerungen werden. Die $\mathrm{Zu}-$ stimmung des Bundesrates kann in keiner Weise ersetzt werden. Bundesregierung und Bundestag müssen sich letztlich mit den Ländern verständigen, ebenso wie die Länder untereinander eime Mehrheitslinie zu gewinnen suchen müssen. Kein einzelnes Land hat vermöge seiner Gliedstaatseigenschaft ein Einfluß- oder gar Einspruchsrecht. Hegemonial- oder Vetopositionen könnten, wie auch sonst im Bundesstaat, nur das Einvernehmen stören. Es ist für einen gesunden Bundesstaat charakteristisch, da $B$ ohne vertrauensvolle Verständigung kein rechtes Ergebnis zustande kommen kann und daß die Glieder dem gleichen Wagnis ausgesetzt sind wie der Gesamtstaat. Von dieser Erkenntnis aus ist es verständlich, daß im Verlaufe der jüngsten Verhandlungen zwischen Bund und Ländern über eine längerdauernde Fixierung oder gar Verselbständigung eines Bundesanteiles an der Einkommen- und Körperschaftssteuer die Länder es - jedenfalls vorerst - abgelehnt haben, auf ihre Mitbestimmung und Mitkontrolle eines künftigen verselbständigten Bundesanteiles einschließlich einer etwaigen Ergänzungsabgabe des Bundes zu verzichten. Durch einen Wegfall der Mitwirkung des Bundesrates würden kaum Verbesserungen erzielt werden; die Interessenkämpfe würden unvermindert fortdauern. Vollends würde eine einseitige Bestimmung seines Anteiles an der gemeinsamen Masse durch den Bund verfassungsrechtlich und finanzpolitisch ins Ungewisse führen. Anderseits muß es als ein legitimes Anliegen des Bundes bezeichnet werden, in gleichem Umfange Kenntnis von der Finanzwirtschaft der Länder zu erhalten, wie die Länder Kenntnis van der Finanzgebarung des Bundes bereits besitzen. Wenn dieses Anliegen nicht schon durch die Pflicht der Länder zu bundesfreundlichem Verhalten ${ }^{15}$ ) seine Erfüllung erfahren kann, müßte eine ausdrückliche Auskunftspflicht statuiert werden $\left.{ }^{16}\right)$.

15) Vgl. auch Fischer-Menshausen, DOV 1955, 262: „A uf keinem Gebiet des bundesstaatlichen Gemeinschaftslebens wird deutlicher als hier (erg.: im Gebiete der Finanzen), daß die föderative Verfassungsordnung sich nicht in der Verteilung von Kompetenzbefugnissen und der Sicherung von Freiheitsrechten erschöpft, sondern in erster Linie Verpflichtungen für alle Bundesglieder begründet ..."; vgl. in diesem Zusammenhang namentlich auch $\mathrm{K}$ le i $\mathrm{n}$ in Festschrift tüir Giese, 1953, S. $61 \mathrm{ff}$. Allgemein zur Rechtspflicht zum bundesfreundlichen Verhaiten vgl. u. a. BV erfG E. v. 21. 5. 1952 in E 1, 315 (im Anschluß an $\mathrm{S}$ mend in Festgabe für Otto Mayer, 1916, S. 261)

10) Vgl. auch Hett I a ge, DOV 1955, 37. 
Wie im Haushaltsrecht, so ist auch im Finanzausgleichsrecht das Bestreben erkennbar geworden, dadurch aus der politischen Spannung herauszukommen, daß an die Stelle politischer Auseinandersetzungen die Sachvernunft gesetzt wird. Sie soll hier darin bestehen, daß die Dauerhaftigkeit der Regelung als gewährleistet angesehen wird, wenn das Bedarfsdeckungsprinzip verwirklicht ist. Die Endgültigkeit liegt hier nicht in der Festlegung der Anteile, sondern in der Festlegung einer Regel für die Regelung ${ }^{17}$ ). Die Zauberformel hierfür, die wir der Bundestagsdrucksache 1254 entnehmen können, sollte folgendermaßen lauten: „Vom Aufkommen der Einkommen- und Körperschaftssteuer stehen dem Bund und den Ländern Anteile in dem Verhältnis zu, in dem der Steuerbedarf des Bundes nach Abzug seiner anderen Steuereinnahmen zu dem entsprechenden Steuerbedarf der Länder steht (Bedarfsverhältnisse)." Da hier ein ernster Versuch gemacht wird, die politischen Spannungen durch die Flucht in die Sachlichkeit zu ersetzen, verlohnt es sich, nachzuspüren, welcher Erfolg ihm beschieden sein kann. Die Formel geht davon aus, daß Bund und Länder gesondert die Aufgaben tragen, die sich aus der Wahmehmung der ihnen verfassungsmäßig zukommenden Aufgaben ergeben. Bei den Einnahmen haben Bund und Länder Anspruch auf gleichmäßige Deckung ihrer Ausgaben und zwar so, daß ein billiger Ausgleich erzielt, eine Belastung der Steuerpflichtigen vermieden und die Einheitlichkeit der Lebensverhältnisse im Bundesgebiet möglichst gewahrt werden. Offensichtlich bemühen sich die Urheber der Formel, die Verteilung der Einnahmen zwischen Bund und Ländern sozusagen mittels einer mathematischen Gleichung vorzunehmen, die politische Regungen und Bestrebungen von selbst ausschalten soll. In einem Rhythmus von zwei Jahren soll die Gleichung unter Zugrundelegung der gleichen Leitgedanken revidiert werden können. Indessen kann auch hier die Sachvernunft nur eine Verlagerung des Kampffeldes vornehmen. Die politischen Gegensätze bleiben bestehen und die entscheidenden Fragen ungelöst ${ }^{18}$ ). Schon der Begriff des "Bedarfs" ist kein unpolitischer Sachbegriff, sondern eine Größe des politischen Ermessens. Den öffentlichen Bedarf kann man beliebig wachsen lassen, man kann ihn aber nicht cbjektivieren. Er hat eine Tendenz ins Unermeßliche ${ }^{19}$ ), die man nur mit politischen

17) Vgl. H e n le, BayVBl. 1955, 226. 226.

18) Hierzu und zum folgenden vor allem He n l e BayVBl. 1955,

19) Vgl. auch $\mathrm{K}$ le in in Festschrift für Giese, 1953, S. $72 \mathrm{ff.}$ zum "Gesetz des steigenden Staatsbedarfs" (unter Anführung von Adolf Wagner, Gerloff und Popitz). 
Erwägungen eindämmen kann. Aber selbst wenn man den Bedarf als bestimmbar ansehen könnte, so wären die Schwierigkeiten noch keineswegs behoben. Wenn beide Partner an der Steuermasse im Verhältnis ihres Bedarfs beteiligt sein sollen, so ist eine Abwägung der einzelnen Ausgabeposten nach ihrer Bedeutung für den Staat unausweichlich. Es müßten also etwa Autobahnen mit Kliniken, Botschaftsgebäude mit Hochwasserverbauungen, Flugplätze mit Landwirtschaftsschulen nach ihrer Wichtigkeit verglichen und abgewogen werden. Ist die Steuermasse kleiner als der Gesamtbedarf, so müßte eine gleichmäßige Verminderung des beiderseitigen Bedarfs eintreten, damit der verfassungsmäßig vorgeschriebene Haushaltsausgleich in Bund und Ländern erfolgen kann (Art.110 GG). Diese Notwendigkeit gibt uns den Schlüssel dafür, daß im politischen Verhältnis von Bund und Ländern trotz des $\mathrm{Be}-$ darfsdeckungsprinzips so gut wie alles beim alten bleiben würde. Der Kampf würde dann darum gehen, welcher Bedarf zu hoch und welcher als der wichtigere zu gelten hat. Erfahrungsgemä $B$ wird dabei jeder Partner seine gegenüber dem Vorjahr etwas erhöhten Anforderungen als sehr bescheiden, die Anforderung des anderen Partners aber als überhöht bezeichnen. Zum Nachweis der Unentbehrlichkeit bestimmter Ausgaben würden lebensnotwendige politische Ziele des Gesamtstaates vorgebracht, vertragliche Pflichten nach außen oder innen behauptet oder unverrückbare soziale Mindestprogramme entwickelt werden. Es liegt auf der Hand, daß auf diesem Wege kein befriedigendes Ergebnis sichtbar wird. Die Formel, nach der eine bestimmte Steuermasse dem Gesamtstaat und den Gliedstaaten nach ihrem Bedarf zuzuteilen ist, löst die politischen Fronten nicht auf. Sie kann es schon deshalb nicht, weil das Bedarfsdeckungsprinzip in seinem Kern nichts anderes ist als eine Begriffsbestimmung des Finanzausgleichs selbst. Damit sind wir aber wieder am Anfang der Gedankenreihe angelangt. Bei diesem Rundlauf zum Ausgangspunkt bleibt überdies die verfassungsrechtliche Schwierigkeit noch unerörtert, die darin besteht, daß nach Art. 107 GG "bestimmte" Steuern zugeteilt wenden sollen, nicht ein unbestimmter Anteil, der nach erst zu findenden Maßstäben bemessen werden soll. Außerdem soll diese Verteilung der Steuern „endgültig“ erfolgen, während das Bedarfsdeckungsprinzip offensichtlich die Vorläufigkeit stabilisieren würde. Es ist freilich fraglich, ob dieses Verfassungsziel überhaupt je erreicht werden kann, ab also der Rechtssatz nicht eine Verpflichtung zu einer unmöglichen Leistung darstellt. 
Darnach möchte es also so scheinen, als ab es überhaupt keine Ruhe in diesem Bereich der Finanzverfassung geben könne. Ich fürchte in der Tat, daß es so ist und daß der Stand der größtmöglichen Ruhe und des optimalen Ausgleichs bereits erreicht ist. Es liegt im Wesen des Politischen, daß es zu keiner vollen Ruhe kommen kann. Sowohl der Bund wie die Länder sind dem Risiko des politischen Handelns und Geschehens preisgegeben, das sogar den Existenzverlust miteinschließt. Keine Sachvernunft kann sie vor diesem Risiko bewahren ${ }^{20}$ ). Bekennt man sich zu dieser Grundhaltung, so zeigen sich drei theoretisch mögliche Entwicklungswege für die Zulkunft:

Erstens die Beseitigung des einen Partners durch den anderen. Nach Lage der politischen Kräfte könnte das nur die Beseitigung der Länder durch den Bund sein, ähnlich dem Vorgang in der Sowjetzone. Es soll hier unerörtert bleiben, daß das, von der verfassungsrechtlichen Seite der Möglichkeit dieses Weges abgesehen, ein höchst beklagenswerter und folgenschwerer politischer Eingriff in die geschichtliche Fundierung des deutschen Staates wäre. Im Zusammenhang mit der Würdigung der Finanzverfassung fällt zunächst nur ins Gewicht, daß die Frage der Verteilung der Steuermasse dadurch seinem Inhalt nach nicht gefördert würde. Nur das Verfahren würde ein anderes. An die Stelle von Verhandlungen träte die einseitige Entscheidung wie in den Jahren zwischen 1933 und 1945. Ungeachtet dessen würde der politische Kampf mindestens versteckt weitergehen

Zweitens das Bestehenlassen des gegenwärtigen finanzverfassungsrechtlichen Zustandes im Verhältnis von Bund und Ländern, allenfalls mit einigen Verbesserungen, wie sie zum Beispiel die beiden Bundesgesetze vom 27. 4. 1955'21) enthalten.

20) H ettl a ge, DVBl. 1953, $716 \mathrm{f}$. befürchtet allgemein von einem „Finanzverfassungsgesetz", es führe „zur rechtsbegrifflichen Bemäntelung politischer Interessen und zu einer weiteren politischen und sachlichen Belastung des Bundesverfassungsgerichts"; die Finanzpolitik widerstrebe "ihrem Wesen nach einer handfesten rechtlichen Funktionsordnung".

21) Vgl. dazu z. B.: Fischer-M enshausen, DÖ 1955, $261 \mathrm{ff}$., der die Gesetzeswerke - als Teilstücke des gesamten geplanten Reformwerkes - als „einen bemenkenswerten Fortschritt für das finanzielle Gefüge unseres Bundesstaats" bezeichnet (261); H ü chtin g, DOV 1955, 39 stellte - vom Blickfeld des von ihm eingehend geschilderten Beratungsstandes aus - der gesamten Finanzreform eine nur teilweise günstige Prognose, meinte indes, daß sich "im Grunde" die Meinungsverschiedenheiten auf nur verhältnismäßig wenige Fragen beschränikten; vgl. auch aaO. 45; vgl. ferner $H$ ü chting in DOV 1955, 291 ff. sowie in DOV 1955, 38 gg.; vgl. auch He n le, BayVB1. 1955, 228; W. K r a u s e, DOV $1955,279 \mathrm{ff}$; K u r z welly, DOV 1955, $281 \mathrm{ff}$. 
So unhaltbar, wie er manchmal dargestellt wird, scheint dieser Zustand doch nicht zu sein. Er hat sich zwar erst sechs Jahre lang, seit Gründung der Bundesrepublik, gehalten, aber doch ohne den Beteiligten nachweisbaren oder vermeidbaren Schaden zuzufügen. $\mathrm{Ob}$ andere Wege weniger Nachteile gleichzeitig und größere Vorzüge zu bieten vermögen, ist zum mindesten bestritten. Vermutlich wird die Praxis der kommenden Jahre diesen Weg schon deshalb gehen, weil er den geringsten Widerstand verspricht ${ }^{21 a}$ ).

Drittens das unablässige Ringen um Einigung und Ausgleich zwischen Bund und Ländern, je nach Lage der wechselnden politischen Situationen unter immer erneuter Durchdenkunga9)

21a) Zwei Monate nach Enstattung des Berichts ist das Bundesgesetz zur Anderung und Ergänzung der Finanzverfassung (Finanzverfassungsgesetz) vom 23. 12. 1955 (BGBl. S. 817) verkündet worden. Darnach haben auch die Art. 106 und 107 GG eine Neufassung erhalten. Nunmehr stehen vom Aufkommen der Einkommensteuer und Körperschaftssteuer bis 31. 3. 58 dem Bund $33^{1 / 3} \mathrm{vH}$, den Ländern $66^{2} / 3 \mathrm{vH} z \mathrm{u}$. Ab 1. 4. 58 ist das Verteillungsverhältnis $35 \mathrm{vH}$ und $65 \mathrm{vH}$. Damit ist eine zwar als übergangsweise gedachte, aber doch bis auf weiteres endgültige Lösung gefunden worden. Bei wesentlicher Anderung der hauswirtschaftlichen Lage und bei Entstehen erheblicher Haushaltsfehlbeträge im Bund oder in den Ländern soll diese Verteilungsverhältnis - erstmals ab 1. 4. 58 und sodann in weiteren Abständen von je zwei Jahren - zugunsten des Bundes oder zugunsten der Länder geändert werden können. Zugunsten der Länder ist es zu ändern, wenn diesen durch Bundesgesetz zusätzliche Ausgaben auferlegt oder Einnahmen entzogen wenden. Die Anderungen des Verteilungsverhältnisses erfolgen jeweils in Form eines einfachen Zustimmungsgesetzes. Aus dem Gesetz ergibt sich deutlich, daß die Grundlinien der bisherigen Regelung fortgeführt werden. Die Erwägungen, die für das frühere Recht angestellt worden sind, können auch für die jetzige Rechtslage verwendet werden. Bemerkenswerterweise ist das Finanzverfassungsgesetz von beiden Seiten, von Bundes- wie von Landesseite, als Erfolg betrachtet worden. Die Ansichten der Presse gingen auseinander. Sicher scheint zu sein, daß eine stärkere gegenseitige Uberwachung der Haushaltsgebarung eintreten wird; denn es müssen ja jeweils von der anderen Seite die wesentliche Anderung der hauswirtschaftlichen Lage und der Grund des Entstehens erheblicher Haushaltsfehlbeträge kritisch geprüuft werden. Es zeichnet sich außerdem eine Entwicklung ab, die es immer weniger angezeigt erscheinen läßt, von einem "Sieg" des Bundes oder der Länder zu sprechen. Das wirtschaftliche Ergebnis wird ein mit steigender Intensität angesteuertes Ziel, und die Notwendigkeiten der außen- und innenpolitischen Lage machen den Bewegungsspielraum immer kleiner, innerhalb dessen das gegenwärtige Gleichgewicht geändert werden kann.

22) Es regen sich bereits Versuche zu einer ,theoretischen Grundlegung einer Disziplin der Finanzverfassungsrechtslehre", vgl. Strick rodt, JZ 1955, 129 ff. (138) sowie in JZ 1955, 469 ff.; vgl. auch $S t r i c k r o d t$, Die Finanzverfassung des Bundes als poli- 
der finanzwirtschaftlichen Gesamtsituation, wie es dem Ideal eines in sich befriedeten Bundesstaates entspricht. Das ist der mühsamste und arbeitsreichste, aber schließlich auch lohnendste Weg. Dazu müssen allerdings die maßgebenden Kräfte in Bund und Ländern ernstlich und verständnisvoll bereit sein, wie es etwa in der Schweizer Eidgenossenschaft Bund und Kantone sind und seit langem gewesen sind. Die politischen und psychologischen Voraussetzungen dazu sind jedenfalls in der Bundesrepublik auf beiden Seiten heute ungleich günstiger, als sie je in der Weimarer Zeit gewesen sind.

Das Finanzverfassungsrecht berührt nicht nur das politische und rechtliche Verhältnis von Bund und Ländern, sondern - in der Form des horizontalen Finanzausgleichs - auch die gegenseitigen Beziehungen der Länder zueinander. Das zweite der beiden genannten Finanzgesetze des Bundes von 1955 sieht sein Ziel in einer Angleichung der Finanzkraft der Länder untereinander ${ }^{24}$ ). Die stärkeren Gegensätze zwischen reichen und armen Ländern in der Bundesrepublik, die ohne die Intensivierung des horizontalen Finanzausgleichs bestehen müßten, und das dadurch bewirkte Gefälle innerhalb der Länder von West und Ost sollen mit diesem Gesetz abgeschwächt werden. Ein sehr durchdachtes System von Steuerkraftmeßzahlen und Ausgleichsmeßzahlen samt "Zahlenveredlung" liefert die Maßstäbe für die Erkenntnis, wann ein Land als finanzstark und damit als reich, oder als finanzschwach und damit als arm angesehen werden kann. $\mathrm{Da} B$ es freilich letzten Endes das Steuersystem selbst ist, das ein Land reich oder arm macht, da $B$ also keine naturgegebenen differenzierenden Merkmale vorliegen, wird dabei nicht erkannt. Die Anwendung des ausgearbeiteten Zahlensystemes auf die deutschen Länder ergibt, daß trotz aller Ausgleichsmaßnahmen, die seit Errichtung der Bundesrepublik besonders auf dem Gebiete der Kriegsfolgeschäden und des Lastenausgleichs vorgenommen worden sind, die Finanzstänke der Länder auch heute sehr unterschiedlich ist. Sie schwankt, soweit man sie zahlenmäßig ausdrücken kann, zwischen den Kennziffern 167 und 318 auf den Einwohner. Hier greift das Gesetz von 1955 ein, indem die ausgleichspflichtigen Länder $51 \%$ ihres Utberschusses an Finanz-

tisches Problem, 1951 ; ferner die Andeutungen bei $\mathrm{K} I \mathrm{l}$ i $\mathrm{n}$ in Festschrift für Giese, 1953, S. 89, K ö t $t \mathrm{~g}$ e n, DVBl. 1953, 684; in diesem Zusammenhang vgl. auch die größeren Untersuchungen z. B. von $B$ ühler in Thoma-Festschrift, 1950, S. 1 ff.; Ge r l of $f$, Die Finanzgewalt im Bundesstaat, 1948; W a cke, Das Finanzwesen der Bundesrepublik, 1950 sowie in DOV 1955, $577 \mathrm{ff}$.

24) Genaue Zahlenangaben bei Hü cht ing, DOV 1955, $230 \mathrm{ff}$.; DOV 1955, 288, $291 \mathrm{ff}$. und DOV 1955, $44 \mathrm{f}$. 
kraft gegenüber dem Bundesdurchschnitt für die ausgleichsberechtigten Länder zur Verfügung stellen. Ein so erheblicher Ausgleich hat naturgemäß weitgehende Folgen auch politischer und verfassungsrechtlicher Art. Mit dem bundesstaatlichen Staat ist er nicht wesensmäBig verbunden. In einem Bundesstaat, in dem der Gesamtstaat und alle Gliedstaaten untereinander in einem freundschaftlichen Verhältnis ohne Argwohn stehen, und die Bürger des einen Landes nicht mit Neid auf die Bürger eines anderen Landes blicken, läßt es sich unschwer ertragen, daB es reiche und arme Länder und demgemäß auch bevorzugte und benachteiligte Bürger gibt. Es kann grundsätzlich auch keine Bundesrechtspflicht auf Ausgleich anerkannt werden, allenfalls in äußersten Notfällen, etwa bei unmittelbar bedrohter Staatlichikeit des Landes. Dennoch kommt der Ausgleich des Reichtums und der Armut zwischen den Ländern in der Bundesrepublik einem politischen Interesse beider Partner entgegen. Er versetzt die Länder mit unterdurchschnittlicher Finanzkraft in die Lage, ihren Bürgern annähernd gleiche Leistungen zu gewähren wie die anderen Länder ${ }^{25}$ ), so da $\beta$ sie sich nicht mehr einem unangenehmen Druck ihrer eigenen Bürger ausgesetzt sehen, der bei engherziger Beurteilung der Lage bis zur Verneinung ihrer Existenzberechtigung reichen kann. Andererseits hat der Bund ein Interesse daran, da $\beta$ die politischen Gegensätze in Bezug auf die Bundespolitik nicht dadurch gesteigert werden, daß die Länder je nach dem Blick auf ihre Haushalte auch Fragen der Außenpolitik, der Wirtschaftspolitik, der Sozialpolitik im Bundesrat unterschiedlich beurteilen. Die Interessenlage soll von sachfremden Nebenerwägungen gereinigt und auf die Kernfragen selbst gerichtet werden. Die Anliegen beider Partner kommen sich hier im gleichen Ergebnis entgegen und so hat auch das Bundesgesetz eine Synthese gefunden, die eine weitgehende Angleichung der Länder untereinander bringt. Selbst die gebenden Länder sehen die Zweckmäßigkeit des Ausgleichs ein und begrenzen damit nicht ungern die Unruhe, die durch ihren Reichtum entsteht. So werden künftig die Länder Nordrhein-Westfalen, Baden-Württemberg, Hamburg, Bremen und Hessen Zahlungen in Höhe von jährlich etwa $450-500$ Millionen erbringen und die Länder Bayern, Niedersachsen, Schleswig-Holstein und Rheinland-Pfalz werden Empfänger dieser Zuweisung sein.

25) Vgl. dazu Fischer-Menshausen, DOV 1955, 265 (unter IV): „Ein sozialer Bundesstaat ... kann nicht zulassen, daß die Qualität der öffentlichen Verwaltungsleistungen je nach der Steuerstärke oder Steuerschwäche der einzelnen Länder gebietsweise differenziert wind ..."; vgl. z. B. auch $H$ ü $\mathrm{c}$ h $\mathrm{t}$ in $\mathbf{g}, \mathrm{DOV}$ 1955, 288. 
Wir haben seit 1955 einen durch finanziellen Rationalismus beeinflußten föderativen Aufbau, von dem vorsichtige Beurteiler meinen, daß er den Bestand und die Wirksamkeit der Länder eher festigt als gefährdet. Mit dieser Lösung dürften auch verschiedene, in den letzten Jahren behandelte Fragen des Ausgleichs in anderer Richtung (etwa die Frage der Zulässigkeit einer ländermäßigen Staffelung der Steueranteile des Bundes) überholt sein. Ich möchte diesen sogenannten „brüderlichen" Ausgleich (nach der Bezeichnung von Hettlage) vom bundesstaatlichen Gesichtspunikt den Vorzug vor dem sogenannten "väterlichen" Ausgleich geben, wenn auch selbstverständlich nicht verkannt wird, daß auch der brüderliche Ausgleich nicht durch Staatsvertrag der Länder, sondern durch Bundesgesetz zustande gekommen ist.

Ungelöst ist jedoch noch die finanzrechtliche und damit verfassungsrechtliche Stellung der Gemeinden im Gesamtstaat ${ }^{\text {2q }}$ ). Das Grundgesetz geht nicht von einem dreistufigen Bundesaufbau in Gemeinden - Länder - Bund aus, sondern von einem zweistufigen Land - Bund $\mathrm{d}^{27}$ ). Die Gemeinden behandelt es im Abschnitt „Bund und Länder“. Aber die darin enthaltene verfassungsmäßige Gewähr kommunaler Rechte vom Bund her, insbesondere die der Selbstverwaltung ${ }^{28}$ ), verbunden mit der Befugnis zur Verfassungsbeschwerde wegen Verletzung dieser Rechte an das Bundesverfassungsgericht, bringt Gemeinden und Gemeindeverbände schon jetzt in eine gewisse verfassungsrechtliche Verbindung mit dem Bund ${ }^{29}$ ), die der Zwischenschaltung der Länder ermangelt. Eine Garantie eines bestimmten Steuereinkommens oder Steueraufkommens ist darin nicht enthalten. Selbst die Realsteuern sind im Grundgesetz nicht den Kommunen unmittelbar, sondern den Ländern

20) Dazu z. B. B ühl e r im Bonnier Kommentar, 2 zu Art. 106 S. 3; Gre in ert in Recht-Staat-Wirtschaft, Bd. II (1950), S. 401 ff.; H e c k t , DOV 1955, 265 ff.; H e u n, DOV 1953, 485 ff. mit Erwiderung von August in, DOV 1953, 709 ff.; K le in in Festschrift für Giese, 1953 S. 94 ff. (mit weitteren Belegen); K öt $t$ ge n, DOV 1953, 359; R ietdorf, DOU 1953, $225 \mathrm{ff}$. mit kritischen Bemerkungen $F$ is cher-M ensh a usen, DOV 1953, $229 \mathrm{f}$.

27) Dazu z. B. B r äu er, DÓV 1955, 585 f.; $\mathrm{K}$ a i s e r (referiert von Nederkorn, DOV 1953, S. 556); Köttgen, DOV 1953, 359 (zugleich mit Hinweisen auf $B$ ü h l e r im Bonner Kommentar, Art. 107, S. 1 und v. M a n gold t, Kommentar, 1. Aufl., S. 570); oiehe ferner die Nachweise in Anm. 32.

28) In diesem Zusammenhang auch: $\mathrm{Kl}$ e in in Festschrift für Giese, 1953, S. 94 ff.; W e r n e r W e b e r, Staats- und Selbstverwaltung in der Gegenwart, 1953; vgl. z. B. auch H e ckt, DOV 1955, 266: „Die institutionelle Garantie des Art. 28 Abs. 2 GG hat... einen wesentlichen finanzpolitischen Inhalt."

2.) Dazu auch Köttgen, DOV 1953, 359. 
zugesprochen, die sie allerdings an die letzteren weitergegeben haben. Die Kommunen erstreben die sogenannte verbundene Steuerwirtschaft, und sie verstehen darunter $u$.a. die Beteiligung mit festen Sätzen am Aufkommen bestimmter Steuern und eine bundesverfassungsmäßige Zuteilung der Realsteuern an sie, an der die Länder nichts ändern könnten. Es wird von keiner Seite in Zweifel gezogen, daB es dazu einer Änderung des Grundgesetzes bedürfes0). Wenn gleichzeitig eine finanzielle Garantie für die Länder im Verhältnis zum Bund festgelegt wird, kann in einer verbundenen Steuerwirtschaft (im "Steuerverbund") keine Abschwächung des bundesstaatlichen Aufbaus der Bundesrepublik erblickt werden. Der Aufbau von unten nach oben entspricht föderativem Denken. Der Gefahr, daß die Länder zwischen Bund und Gemeinden zerrieben würden, kann durchaus vorgebeugt werden, ohne den Gemeinden die Sicherheit für ihr Wirken vorzuenthalten.

So wenig es sich rechtfertigen ließe, die gegenwärtige Verteilung der Steuerquellen und Steuererträge als unerträglich oder gar unsinnig zu bezeichnen, so wäre es auch unangebracht, die Lage, die sich bei der Verwaltung der Steuern im BundLänder-Verhältnis ergeben hat, zu dramatisieren. Die Entscheidung, da $\beta$ keine Bundesfinanzverwaltung bestehen soll, hat der Verfassunggeber des Grundgesetzes getroffen. Sie hat Verfassungsrang und wird solange fortbestehen, als sich nicht die verfassungsgesetzgebenden Organe $z u$ einer anderen Organisation entschließen. Sicher scheint zu sein, daß sich die Anhänger und Gegner einer Bundesfinanzverwaltung mit rationalen Erwägungen nicht zu überzeugen vermögen, auch nicht mit noch so umfassendem Zahlenmaterial. Ob überhaupt eine Verbilligung und Vereinfachung bewirkt würde, ist sogar unter Fachleuten bestritten und zweifelhaft. Was aber im übrigen für das Bundesfinanzministerium durch Errichtung einer Bundesfinanzverwaltung erstrebt wird, hat es doch wohl jetzt schon. Insbesondere stehen $\mathrm{ihm}$ weitestgehende rechtliche Einwirkungsmöglichkeiten in Bezug auf die Gleichmäßigkeit des Gesetzesvollzuges schon jetzt zu. Es braucht nur davon einen sachgemäßen Gebrauch zu machen, statt neue Befugnisse zu den nicht ausgenützten alten zu häufen. Die „Mischverwaltung" oder "Mitverwaltung"31), die das Grundgesetz geschaffen hat, muß sich eng an die vom Grundgesetz gestalteten Formen anschließen, wenn sie mit der Verfassung im Einklang stehen soll. Es besteht weder ein Bedürfnis noch die rechtliche Mög-

s1) Vgl. Kratzer, DOV 1950, S. 594; Köttgen, DOV 1955, S. 485; Gerner, BayVBl. 1955, 193; F ü B le i $n$, DVBl. 1956, 1.

so) Dazu näher Heck't, DÓv 1955, 226. 
lichkeit, sie zu erweitern. Das Gleiche gilt für die Bundesaufsichts- und Bundesweisungsbefugnisse auf finanzrechtlichem Gebiet. Weder die Natur der Sache noch die Erfordernisse des modernen Verwaltungsstaates können eine Änderung der gegenwärtigen Verteilung von Zuständigkeiten, Aufgaben und Aufsichtsbefugnissen ohne Verfassungsänderung rechtfertigen. Für die „Natur der Sache" als zuständigkeitsbegründendes Flement wird das Rechtsgutachten des Bundesverfassungsgerichts über ein Bundesbaugesetz zugrunde gelegt werden müssen. Auch im Bereich der Finanzverfassung müssen wir uns darnach ausrichten. Sonstige Erwägungen können Motive für den Verfassungsgesetzgeber sein, gehören aber nicht dem geltenden Recht an. Der Gedanke dagegen, daß im Verhältnis von Bund und Ländern jeder Teil die Finanzverantwortung tragen sollte, soweit ihm die Erfüllung von Aufgaben obliegt, steht durchaus im Einklang mit der Grundrichtung unserer Verfassung und mit der bundesstaatlichen Struktur der Bundesrepublik.

\section{Einfaches Finanzgesetz und Finanz- verfassungsgesetz}

Noch nicht endgültig gelöst ist eine grundsätzliche Frage des formellen Verfassungsrechts. Durch Art. 106 Abs. 3 und 4 GG ist der einfache Bundesgesetzgeber ermächtigt, Bundesanteile an Ländersteuern festzusetzen und finanzielle Ausgleiche unter den Ländern herbeizuführen. Art. 106 GG ist Verfassungsrecht im formellen Sinn, Gesetze dagegen, die die Bundesanteile festsetzen oder Ausgleichszahlungen vorschreiben, sind einfache Zustimmungsgesetze, auch wenn sie von der Grundverteilung der Steuern durch das Grundgesetz abweichen. Ähnlich verhält es sich mit Art. $107 \mathrm{GG}^{22}$ ), ${ }^{\text {s2a }}$ ).

s2) Vgl. zu den Gesetzentwürfen im Zusammenhang mit Art. 107 GG besonders: $F$ is c h er - M e $n \mathrm{sh}$ a $\mathrm{s}$ e $\mathrm{n}, \mathrm{DOV} 1955,261 \mathrm{ff}$.; vgl. auch in DOV 1952, 673 ff. sowie in DOV 1953, 229 f.; G ö r g , DOV 1955, $273 \mathrm{ff}$; He c k t, DOV 1955, $265 \mathrm{ff}$; He n le, BayVBI. 1955, 225 ff.; H et $t$ l a g e, DVBl. 1953, 713 ff. sowie FA Bd. 14, 1953, Heft 3; H e u n, DOV 1953, 485 ff.; H ü c h $t$ in $g$, DOV 1955, $41 \mathrm{f}$, auch in DOV 1953, 231; K ö t t g e n, DOV 1953, $358 \mathrm{ff}$. sowie in DVBl. 1953, 681 ff.; No l t e n i u s, Gesundung der Finanzverfasoung ..., 1953; o. V. DVBl. 1953, 432 f. (Referat); R i t d orf, DOV 1953, 225 ff.; St r i ckrodt, JZ 1955, 129 ff. (bes. 134).

32a) Durch Finanzverfassungsgesetz vor 23. 12. 1955 (BGBl. S. 817), ein Gesetz, daß nicht in den Formen der Verfassungsänderung nach Art. 79 Abs. 1 GG ergangen, sondern als einfaches $\mathrm{Zu}$ otimmungsgesetz beschlossen worden ist, haben die Art.106 und 107 GG eine neue Fassung erhalten. Anscheinend ging der Gesetzgeber davon aus, daß er im Hinblick auf die grundgesetzliche Er- 
Sein Inhalt ist formelles Verfassungsrecht. Doch ist der einfache Gesetzgeber ermächtigt, unter Abweichung von Art. 79 GG eine neue Verteilung aller der konkurrierenden Gesetzgebung unterliegenden Steuern auf Bund und Länder ${ }^{33}$ ), ssa) durch einfache Zustimmung vorzunehmen. Dieses so neugeschaffene Recht kann nach unseren bisherigen Vorstellungen vom Werden des Verfassungsrechts nicht wieder formelles Verfassungsrecht werden ${ }^{34}$ ). Nirgends sonst hat der einfache Gesetzgeber die Kraft, formelles Verfassungsrecht zu schaffen. Das kann nur der Verfassunggeber schlechthin und der Verfassungsänderungsgesetzgeber, letzterer mit qualifizierten Mehrheiten. Das Ergebnis wird künftig wohl ähnlich sein, wie im Verhältnis von Grundrechten zu vorbehaltenen Gesetzen, die von Grundrechtssätzen abweichen dürfen: ein Verfassungskern, der ja trotz Art. 106 und 107 nicht abwandelbar ist, bleibt unveränderbar bestehen; der übrige Grundgesetzinhalt in diesem Punkt ist aber nicht verfassungskräftig, und die $\mathrm{Ab}$ -

mächtigung diese Artikel durch einfaches Gesetz ändern dürfe. $\mathrm{Ob}$ die Artikel in ihrer Neufassung nunmehr formelles Verfassungsrecht geworden sind, also nur noch unter den verfassungsändernden Voraussetzungen geändert werden dürfen, scheint dahingestellt geblieben zu sein. Die Frage wird aber auftauchen, wenn etwa nicht nur das mit einfachem Gesetz zu verändernde Beteiligungsverhältnis von Bund und Ländern in Betracht kommt. Anscheinend wind bis jetzt stillschweigend die Anomalie in Kauf genommen, daß durch ein einfaches Gesetz aufgrund verfassungsrechtlicher Ermächtigung formelles Verfassungsrecht geschaffen werden kann.

s3) Auch hier sind die Gemeinden nicht erwähnt; vgl. dazu näher z. B. H e c k t, DƠV 1955, 269; K ö t t g e $n$, DOV 1953, 359; H ü c h t in g, DOV 1955, 42 ist der Ansicht, Partner des Finanzausgleichs im Sinne des Art. 107 GG seien außer Bund und Ländergesamtheit „als deren integrierende Bestandteile auch die Gesamtheit der Gemeinden" (nicht aber einzelne Länder und Gemeinden); vgl. u. a. auch Heun, DOV 1953, 486 .; M üthling (referiert von Augustin DOV 1953, 434).

ssa) Im März 1956 hat der Bundestag einen Gesetzentwurf zum „Steuerverbund" von Bund, Land und Gemeinde beschlossen. Das weitere Gesetzgebungsverfahren (Bundesrat usw.) ist noch im Gange. Nach diesem Gese'zentwurf soll den Gemeinden das Aufkommen an der Grund- und Gewerbesteuer garantiert werden und die Länder sollen verpflichtet werden, den Gemeinden einen prozentualen Anteil an dem den Ländern zufließenden Einkommen und Körperschaftssiteuerauflkommen einzuräumen. Die Höhe des prozentualen Anteils wind von Bundes wegen nicht festgelegt.

s4) $\mathrm{Zu}$ dieser sehr umstrittenen Frage vgl. vor allem: $B$ ü. h le r, Bonner Kommentar zu Art. 107, S. 1; H eckt, DOV 1953, 654 f.; Hettlage, DVBl. 1953, $713 \mathrm{ff}$.; Klein, in Festschrift für G i e se, 1953, S. $125 \mathrm{ff}$. sowie besonders in DVBl. 1954, $37 \mathrm{ff}$. (mit erschöpfenden Nachweisen); Köttge n, DVBl. 1953, 681 ff. sowie in DOV 1953, 552. 
weichungsbefugnis des einfachen Gesetzgebers ist weder einmalig noch verbrauchbar. Wollte man der durch einfaches Gesetz erfolgenden Neufassung des Art. 107 GG den Charakter von Verfassungsrecht zubilligen - wahrscheinlich wird die Verfassungspraxis dazu neigen, sobald der neue Art. 107 GG in dieser Art zustande gekommen ist - dann wird man etwa so konstruieren müssen: Der einfache Bundesgesetzgeber handelt hier noch in Fortsetzung der verfassunggebenden Kraft des Verfassunggebers, mit dessen Willen und in dessen Auftrag; seine Tätigkeit ist noch sozusagen ein Ausfluß der verfassunggebenden Gewalt. Ein Novum in der Verfassungslehre wird dennoch eine Verfassungsschöpfung auch mit dieser Begründung stets bleiben. Es würde die traditionellen Wege der Verfassunggebung bestätigen und festigen, wenn man den einfachen Gesetzgeber nur einfache Gesetze erlassen ließe $\mathrm{e}^{35}$.

IV. Steuererhebender staat und steuer$z$ ahlender Bürger

Nachdem damit das Verhältnis Regierung und Parlament, das Verhältnis Bund - Land - Gemeinde, und das Verhältnis einfaches und Verfassungsgesetz in der Schau der Finanzverfassung dargestellt worden sind, ist es förderlich, noch einen kurzen Blick auf das Verhältnis des Bürgers zum steuererhebenden und finanzgestaltenden Staat zu werfen.

Die Rechtsstaatlichkeit gibt weniger Schwierigkeiten auf als die Steuerwürdigkeit. Daß keine Steuer anders als auf Grund eines förmlichen Gesetzes erhoben werden kann unter Ausschluß des freien Ermessens der Finanzverwaltung, dünkt uns heute eine Selbstverständlichkeit. Die Einführung von Yürteparagraphen, von Rahmensätzen für Einzelbemessungen oder von Pauschsätzen wird damit nicht als unvereinbar angesehen. Eine Modifizierung des Legalitätsprinzips, das die Steuergleichheit bei der Gesetzesanwendung gewährleistet, durch das Opportunitätsprinzip kann, wie im Strafrecht, nicht als Versto $\beta$ gegen das Rechtsstaatsprinzip angesehen wenden. Die normbildende Tätigkeit der Finanzministerien ist mehr und mehr zurückgedrängt und die Ausschaltung der richterlichen Nachprüfung ist beseitigt worden. Die Hoffnung auf einen Abbau der autoritären Art unserer Steuerverwaltung, etwa durch reine Selbsteinschätzung und automatische Zahlung

35) Mit Art. 107 GG (Verfassungskraft) haben sich beschäftigt: K be i n, DVBl. 1954, 37 ff.; H e cht, DOV 1954, 173 f.; Köt t gen, DVBl. 1953, $681 \mathrm{ff}$; H e.t t l a g e, DVBI. 1953, 713 ff. (714 ff.); K ö t t g e n, DOV 1953, 358 ff. (364); H e c h t, DOV 1953, 654 . 
nach nondamerikanischem Vorbild, hat unsere Finanzverwaltung bisher in keiner Weise genährt.

Weit schwieriger ist es, Grundsätze für das materielle Steuerrecht als Verfassungsbestandteil festzulegen. Zweifelhaft ist es schon, $a b$ unser gegenwärtiges Steuersystem mit den uns allen geläufigen Einzelsteuern bereits dadurch verfassungsmäßig verankert ist, daß das Grundgesetz diese Einzelsteuern mehrfach aufzählt, oder ob darin nur eine "Wenn-Dann"-Vorschrift zu erblicken ist. Nicht minder zweifelhaft ist es, ab die Steuerwürdigkeit, zu der insbesondere die Besteuerung nach der Leistungsfähigkeit gehört, Verfassungsbestandteil geworden ist. Ich möchte letzteres bejahen, da sie die Ausprägung des Gleichheitssatzes auf steuerlichem Gebiet darstellt, indem allen ein möglichst gleiches Opfer, gemessen an ihrer wirtschaftlichen Kraft, zugemutet und auferlegt wird. Ob freilich auch noch die Pflicht zur Betriebserhaltung aus dem Gleichheitssatz hergeleitet werden kann, ist zum mindesten fraglich. Es wäre aber einer Prüfung wert, ob sie etwa aus dem Sozialstaatsprinzip gefolgert werden kann. Die Pflicht zur sozialen Ausgestaltung der Steuer durch angemessene Progression wohnt sicher diesem Prinzip inne.

Gehen wir noch einen Schritt weiter, so gelangen wir zu der bereits von Bühler angeregten Uberlegung, ob nicht die Gesamtheit unserer Finanzwirtschaft einem rationell geleiteten Unternehmerbetrieb angenähert werden soll und kann. Da tauchen dann Fragen auf wie etwa folgende: Lohnt es sich überhaupt noch, eine Aufsplitterung in fünfzig Steuern vorzunehmen und hinzunehmen? Warum sind die sogenannten indirekten Steuern noch nicht in die Umsatzsteuer eingeschmolzen? usw. Auch beim Verhältnis der leitenden Steuerideen zur Staatsverfassung taucht eine ähnliche Fragestellung auf, wie bei jener Sachvermunft, die die politischen Spannungen zwischen Regierung und Parlament ersetzen soll, oder wie beim Bedarfsdeckungsprinzip, das an die Stelle politischer Auseinandersetzungen die wirtschaftlich sozusagen von selbst gegebenen Folgerungen für das Verhältnis Bund - Länder ziehen soll: es ist der Einbau finanewirtschaftlicher Erkenntnisse als verbindlicher Ordnungsprinzipien in das Rechtssystem. Wir haben bisher im Verfassungsrecht weder die Möglichkeiten und Notwendigkeiten noch die Wirkungen eines solchen Einbaus untersucht, obschon uns der seit dreißig Jahren vor sich gehende Einbau betriebswirtschaftlicher Grundsätze in das Steuerrecht schon hellhörig hätte machen können. Bemerkenswert ist es jedenfalls, daB, wie in manchen anderen Zweigen des öffentlichen Lebens, so auch hier, wieder 
der Wunsch sichtbar wird, Erfahrungen und Erkenntnisse zu Rechtssätzen $2 u$ erheben und sie möglichst auch gleich mit Verfassungsrang auszustatten.

Die rechtliche Zementierung zeitbedingter Situationen oder wirtschaftlicher Thesen hat, im ganzen gesehen, doch wohl mehr Nachteile als Vorzüge. In der Bundesrepublik wirkt sie um so seltsamer, als immer wieder beteuert wird, das Grundgesetz sei ein Provisorium. Wenn aber die Staatsverfassung nur vorläufig ist, kann auch die Finanzverfassung in ihr nicht endgültig sein.

Selbst wenn aber einmal die gesamtdeutsche Verfassung geschaffen und damit das Provisorium überwunden sein sollte, kann für eine Finanzverfassung der Begriff „endgültig“ nie bedeuten "für immer", sondern stets nur „bis auf weiteres"; denn auch dann werden die wirtschaftlichen Verhältnisse wandelbar und auch dann wird die Finanzverfassung wie die Staatsverfassung von den politischen Verhältnissen abhängig sein. 


\section{Leitsātze des Mitberichterstatters über: \\ Die Finanzverfassung im Rahmen der Staatsverfassung}

1. Drei Fragenkreise der deutschen Finanzverfassung geben seit langer Zeit und auch in der Gegenwart wieder besonderen Anlaß zu rechtlichen Untersuchungen und politischen Auseinandersetzungen: das Recht der Haushaltsgestaltung, der bundesstaatliche Finanzausgleich und die leitenden Steuergrundsätze.

2. Gegenüber der Auffassung, daß das Staatshaushaltsrecht ein System der Kontrolle der Volksvertretung über die Regierung und damit der Begrenzung der Regierungstätigkeit begründe (sog. Legislativbudget), kann die in jüingster Zeit in den USA vertretenen Meinung, daß der Staatshaushalt die Verwirklichung des Regierungsprogramms und daher alleinige Angelegenheit der Regierung sei (sog. Exekutivbudget), für das deutsche Recht eine Bereicherung überkommener Anschauungen, aber keine grundlegende Anderung bisheriger Lehren und Praktiken bewirken.

3. Zu einer Erweiterung unserer Vorstellungen kann es auch führen, wenn die Einfügung des Staatshaushalts in den Rhythmus der Wirtschaft stärker als bisher betont wird. Unfruchtbar wäre es aber, politische und wirtschaftliche Anliegen gegeneinander auszuspielen oder etwa anzunehmen, politische Spannungen ließen sich durch wirtschaftliche Uberlegungen verdrängen.

4. Bestrebungen, die darauf abzielen, nicht nur die Befugnisse der Volksvertretung gegenüber der Regierung zu sichern, sondern auch die der Regierung gegenüber der Volksvertretung zu stärken, haben sich als realisierbar und in außerdeutschen Ländern auch als erfolgreich erwiesen. Die in dieser Richtung zielenden Rechtssätze des Grundgesetzes bedürfen allerdings noch einer stärkeren Belebung.

5. Die überkommene Auffassung, daß der Haushaltplan lediglich eine Ermächtigung für die Regierung bedeute, wird in der deutschen parlamentarischen Praxis nur noch unvollkommen eingehalten. Gegen eine Bindung der Re- 
gierung durch formelles Gesetz, Ausgaben bestimmter Art $z u$ betätigen, lassen sich aus dem Gewaltenteilungsprinzip keine überzeugenden Gesichtspunkte herleiten.

6. Die gegenwärtige deutsche Finanzverfassung enthält erst Ansätze fïr eine verfassungsrechtliche Verankerung materieller staatswirtschaftlicher Grundsätze.

7. Im Bereich des Finanzausgleichs zwischen Bund und Ländern ist ein Stand hoher Befriedung und sachgemäßen Ausgleichs bereits erreicht. Der noch andauernde Streit um die Höhe des Bundesanteils bei gewissen Steuern betrifft verhältnismäßig geringfügige Beträge.

8. Das Bedarfsdeckungsprinzip im. Finanzausgleichsrecht kann nicht eine Entpolitisierung der Beziehungen zwischen Bund und Ländern durch Sachvernunft herbeiführen.

9. Aus der Natur der Sache können keine Folgerungen dahin gezogen werden, welche Steuern dem Bund und welche den Ländern zufießen sollen. Ebensowenig kann der $\mathrm{Na}-$ tur der Sache, der „Koordinierungspflicht" des Gesamtstaates, den Erfordernissen eines „modernen Verwaltungsstaates" oder ähnlichen, im Grundgesetz nicht zum Ausdruck gekommenen allgemeinen Gesichtspunkten entnommen werden, wie die Verwaltungszuständigkeiten und die Lastentragung zwischen Bund und Ländern zu verteilen sind. Die Entscheidung dieser Fragen steht dem nach dem Grundgesetz hierfür zuständigen Gesetzgeber im Rahmen der Staatsverfassung zu.

10. Bundesaufsicht und Bundesweisungen bestehen nur für solche Materien zu Recht, für die sie dem Bund durch das Grundgesetz zugewiesen sind, und nur nach Maßgabe der darin geregelten Rechtsformen. Aus der Kostentragung des Bundes allein kann keine ungeschriebene Erweiterung dieser Materien und Rechtsformen gefolgert werden. Der Gedanke, daß im Verhältnis von Bund und Ländern jeder Teil die Finanzverantwortung soweit trägt, als ihm verfassungsmäßig die Erfüllung von Aufgaben zufällt, steht im Einklang mit der bundesstaatlichen Grundhaltung des Grundgesetzes und sollte, soweit nicht ohnehin bereits verwirklicht, Ziel weiterer Gesetze sein.

11. Eine verfassungsrechtliche Einfügung der Kommunen in den Finanzverbund von Gesamtstaat und Gliedstaaten widerspricht nicht dem bundesstaatlichen Prinzip.

12. Das Dispositionsrecht des Bundesgesetzgebers aus Art. 107 Abs. 1 GG über Teile der Finanzverfassung bewirkt nicht, daß ein vom einfachen Gesetzgeber geschaffener Finanz- 
ausgleich formelles Verfassungsrecht wird. Der im Grundgesetz enthaltene Kern des Finanzausgleichs bleibt verfassungskräftig, während der Rest auch nach Schaffung des sog. endgültigen Finanzausgleichs weiterhin der Veränderbarkeit durch Zustimmungsgesetze unterliegt.

13. Wenn eine Staatsverfassung labil ist oder gar als bloßes Provisorium angesehen wird, kann die Finanzverfassung nicht stabil und endgültig sein. Die Endgültigkeit des Finanzausgleichs in bezug auf einen Teil der Steuererträge (Art. 105 Abs. 2, Art. 107 Abs. 1 GG) kann in jedem Fall nur eine relative sein. 
3. Aussprache über:

\section{Die Finanzverfassung im Rahmen der Staatsverfassung}

St a n k a -Wien:

Wenn vor dem Jahre 1918 ein Fremder das Winterpalais des Prinzen Eugen in der Himmelpfortgasse in Wien betrat, so mußte er feststellen, daß in diesem Hause zwei Finanzministerien und daher auch zwei Finanzminister untergebracht sind. Da war nämlich erstens der k. u. k. Finanzminister, der die Ausgaben für die den beiden Staaten der österr.-ungarischen Monarchie gemeinsamen Angelegenheiten zu verwalten hatte, und zweitens der k. k. Finanzminister, der für die Finanzangelegenheiten der „im Reichsrate vertretenen Königreiche und Länder" zuständig war, wie der offizielle Titel der einen Reichshälfte hieß, seitdem der sogenannte "Ausgleich" des Jahres 1867 die Umwandlung des Einheitsstaates „Kaisertum Osterreich“ in einen zweigliedrigen Staatenverein beschlossen und durchgeführt hatte; das andere Glied, „Die Länder der ungarischen Krone" hatte ebenfalls seinen eigenen Finanzminister, den königlich ungarischen Finanzminister, der in Budapest seinen Amtssitz hatte.

Dieser Staatenverein stellte eine Personal- und Realunion dar, der nur einige Angelegenheiten zur gemeinsamen Regelung verblieben waren. Dazu gehörte neben dem gemeinsamen Organ des Staatsoberhauptes, das in der einen Reichshälfte den Titel Kaiser von Osterreich und in der anderen den eines Königs von Ungarn führte, das gemeinsame Finanzwesen, das gemeinsame Heer und die Verwaltung der auswärtigen Angelegenheiten.

Unser Blick wendet sich zunächst einmal dem sogenannten Reichsfinanzministerium zu. Seine rechtliche Stellung war nicht die eines vorgesetzten Organs der beiden anderen Finanzministerien, nämlich des k. k. Finanzministeriums und des königl. ungarischen Finanzaministeriums, sondern es war vielmehr eine Art Verrechnungsstelle zwischen den beiden anderen Finanzministerien und den anderen gemeinsamen Organen, nämlich dem Reichskriegsministerium und dem Außenministerium am Ballhausplatz. Es muß in diesem $\mathrm{Zu}$ sammenhang vor allem auf die juristische Konstruktion dieses Staatenwesens eingegangen werden, das, wie gesagt, nach 
heutiger Ansicht schon deswegen mehr einem Staatenverein als einem Bundesstaat ähnlich war, weil es keinerlei gemeinsame Gesetzgebungsorgane parlamentarischer Art hatte. Allerdings war nach der Verfassung noch immer der Kaiser und König der Gesetzgeber, wie schon aus der Proklamationsformel von damals hervorging "mit Zustimmung beider Häuser des Reichsrates finde ich (Kaiser) anzuordnen wie folgt . . .", aber materiell lag doch bereits der Schwerpunkt der Gesetzgebung beim Reichsrat, d. h. beim Abgeordnetenhaus und dem Herrenhaus bzw. bei der ungarischen Repräsentanten- und Magnatentafel. Diese waren somit die eigentlichen Gesetzesgeber eines jeden dieser beiden Staaten und es war daher eine besondere Aufgabe des Jahres 1867, gewissermaßen einen Gesetzgebungsersatz dafür zu finden, daß es keinerlei gemeinsame Gesetzgebung gab. Dies war insbesondere für das Budgetrecht notwendig, da für die gemeinsamen Ausgaben alljährlich ein Budget erstellt werden mußte. Die zu diesem Zweck von jeder der Reichshälften aus ihren parlamentarischen Körperschaften entsandten Delegierten in der Stärke von je 60 Abgeordneten, wovon $1 / 3$ dem Herrenhaus bzw. der Magnatentafel zukam und \%/s dem Abgeordnetenbzw. der Repräsentantentafel zu entnehmen war, tagten nun grundsätzlich getrennt, obwohl auch die Möglichkeit einer gemeinsamen Beratung und Abstimmung vorgesehen war. Die von diesen Delegierten gebildeten Körperschaften hießen Delegationen.

Grundsätzlich standen sich jedoch die Delegationen als Verhandlungspartner gegenüber bei der Beratung des Budgets des kormmenden Jahres, wobei vor allem das Militärbudget wichtig war. So ergaben sich für das Jahr 1913 budgetmäßig folgende Militärausgaben für die österr.-ungar. Monarchie:

für das gemeinsame Heer, einschließlich

der k.u. k. Kriegsmarine . . . . . . 582 Millionen $\mathrm{Kr}$

für die österr. Landwehr . . . . . . 75,9 Millionen $\mathrm{Kr}$

für die ungar. Landwehr (Honved) . . 87,5 Millionen $\mathrm{Kr}$, wobei ich betonen möchte, daß der Ausdruck "Landwehr" des österreichischen Rechtes sich keineswegs mit dem gleichlautenden reichsdeutschen Ausdruck deckte, sondern, daß die Landwehr (Honved) eine stehende Truppe darstellte, die sich fast nicht von dem gemeinsamen Heer unterschied, aber budgetrechtlich nicht der Delegation, sondern dem österreichischen Reichsrat (bzw. ungarischen Reichsrat) resortierte und demgemäß auch nicht verwaltungsmäßig dem Reichskriegsministerium, sondern dem $\mathrm{k}$. $\mathrm{k}$. Landesverteidigungs- bzw. dem $\mathrm{k}$. ung. Honvedministerium zugewiesen war. 
Aber kehren wir zu dem gemeinsamen Budget zurück. Ich muß noch einmal darauf hinweisen, $d a \beta$ die beiden Delegationen auf dem Wege von Verhandlungen über dieses Budget sich zu einigen hatten. $\mathrm{Da}$ jedoch die Delegationen keine $\mathrm{Ge}-$ setzgebungsorgane waren, so sah man in den sogenannten Ausgleichsgesetzen des Jahres 1867 vor, daß das gemeinsame Budget auf Grund der sogenannten Quote oder Proportion in das Budgetgesetz einer jeden der beiden Reichshälften eingebaut werden sollte. Und nun kommt das Interessante. An dem von den Delegationen beschlossene, oder besser gesagt vereinbarten gemeinsamen Budget durfte keine Änderung weder von der Regierung noch vom Parlamente vorgenommen werden, das heißt, es lag hier eine Art Weisung an Regierung und Parlament auf unveränderte Annahme des von den Delegationen beschlossenen Budgets vor.

Diesen Delegationen waren auch die drei gemeinsamen Ministerien verantwortlich. Es bestand ferner als notwendige Rechnungskontrolle ein gemeinsamer Rechnungshof. Erwähnenswert ist eine weitere Bestimmung noch, der zufolge nicht ein und dieselbe Person gleichzeitig gemeinsamer Finanzminister und Finanzminister einer der beiden Reichshälften sein durfte.

Als Groteske sei hier noch erwähnt, daß der ungarischkroatische Ausgleich, der Kroatien eine weitgehende Selbstverwaltung gewährte, den ungarischen Finanzminister als "gemeinsam" bezeichnete, was sich natürlich nur auf Angelegenheiten zwischen Ungarn und Kroatien beziehen konnte, nicht aber auf die beiden Reichshälften.

Erwähnenswert ist auch, daß man im Jahre 1878, als man nicht wußte, wie man verwaltungsmäßig Bosnien und Herzogowina eingliedern solle, man diese Gebiete dem Reichsfinanzministerium unmittelbar unterstellte.

Die österr.-ungar. Monarchie bildete grundsätzlich ein einheitliches Zollgebiet, was als Zollbündnis oder Zollunion bezeichnet wurde. Die Einhebung der Zölle erfolgte jedoch an den österreichischen Grenzen durch österreichische Zollorgane, an den ungarischen Grenzen durch ungarische Zollorgane. Zwischenzölle zwischen Ostereich und Ungarn waren verboten. Das gemeinsame Finanzministerium verfügte über keine direkten Einnahmen, denn vor allem die Zolleinnahmen erfolgten durch Organe der beiden Gliedstaaten, welche die eingelaufenen Gelder nach Abzug der Regieausgaben dem gemeinsamen Finanzministerium abzuliefern hatten. Die übrigen Einnahmen des gemeinsamen Finanzministeriums auf Grund der Delegationsbeschlüsse waren auf die beiden Reichshälften 
derartig aufgeteilt, daß die österreichische Reichshälfte $66^{46} / 49 \%$, die ungarische Reichshälfte $33^{3 / 49} \%$ der gemeinsamen Ausgaben zu tragen hatte. Die Steuergesetzgebung beider Gliedstaaten war vollkommen selbständig, während bei der Zollgesetzgebung zumindest vorgesehen war, daß sie grundsätzlich einheitlich durch übereinstimmende Gesetze der beiden Staaten erfolgen solle. So war das gemeinsame Finanzministerium ohne jede Unterbehörde, - wenn ich von der bosnischen Landesverwaltung absehe -, es hatte daher auch keinerlei Imperium. Es war, um es noch einmal zu betonen, lediglich Verrechnungsstelle.

Die im Reichsrat vertretenen Königreiche und Länder wiesen eine finanzrechtlich nicht minder bemerkenswerte Struktur auf. In den einzelnen Ländern bestand nämlich neben der eigentlichen staatlichen Verwaltung, an deren Spitze, ein vom Kaiser ernannter Statthalter (in den kleineren Ländern Landespräsident genannt), stand außerdem noch eine autonome Landesverwaltung, deren Spitze, der Landesausschuß, dem daselbst befindlichen Landtage verantwortlich war. Diese Landesverwaltung hatte naturgemä $ß$ ihr eigenes Finanzwesen.

Wichtig war ferner, daß dem Statthalter als dem Chef der politischen Verwaltung in den Ländern auch die gesamte Finanzverwaltung unterstand. So war er Chef nicht nur der sogenannten Statthalterei, sondern auch der Finanzlandesdirektion, die in kleineren Ländern, wo es nur einen Landespräsidenten gab, Finanzdirektion hieß. Allerdings wurde der Statthalter in Finanzangelegenheiten durch den Leiter der Finanzlandesdirektion - den Finanzlandesdirektor - vertreten. Mit Ausnahme der Landeshauptstädte wurde auch die Finanzverwaltung auf dem Lande unmittelbar durch die Bezirkshauptmannschaft ausgeübt, der als ausübende Finanzbehörde vor allem die Steuerämter und andere Stellen unterstanden.

Das Jahr 1918 bedeutete eine vollkommene Revolutionierung auch auf dem Gebiete der Finanzverfassung, bedingt durch die gewaltige staatsrechtliche Umwälzung dieses Jahres, die an Größe und Tiefe jedenfalls viel einschneidender war wie das gleichzeitige Ereignis im deutschen Reich. Die kleine Republik Deutschösterreich beauftragte mit dem Gesetz vom 14. November 1918 die Chefs der bisherigen autonomen Landesverwaltungen als Landesregierungschefs zugleich auch mit der Führung der Statthaltereigeschäfte. Zugleich bestimmte der $\S 4$ desselben Gesetzes, daß ein Mitglied der nunmehrigen Landesregierung als Vertreter des Landeshauptmannes mit Genehmigung des 
deutsch-österr. Staatsrates an die Spitze der Finanzverwaltung der einzelnen Länder zu treten habe. Es war die politische $\mathbf{A b}-$ sicht dieser Norm klar. Der Landeshauptmann - auch Vorstand der Finanzverwaltung - hätte einen derartig starken Machtfaktor verkörpert, daß unter Umständen dadurch weitgehende politische Komplikationen hätten entstehen können. Infolgedessen mußte man nach dem Grundsatz „divide et impera" diese Machtbefugnisse dem Landeshauptmann abnehmen.

Aber bereits 5 Wochen später wurde mit Gesetz vom 18. Dezember 1918 auch diese Einflußsphäre der Landesregierungen ausgeschaltet und die gesamte Finanzverwaltung von jeglichem Zusammenhang mit der politischen Verwaltung gelöst und dem Finanzministerium unmittelbar unterstellt. An der Spitze der Finanzdirektion trat deren leitender Beamte, welcher Rechtszustand bis heute so geblieben ist.

Viel tiefergreifend waren jedoch die Änderungen in der Steuerverfassung in jenen Tagen. In der Monarchie war der Finanzbedarf der autonomen Landesverwaltung durch $\mathrm{Zu}$ schläge tu den einzelnen Steuern gedeckt worden. Schon im Jahre 1896 wurde jedoch normiert, daß Zuschläge zur Einkommensteuer unzulässig sind. Der Zusammenbruch der Währung, der im Jahre 1917 sich bereits abzeichnete und bis in das Jahr 1922 dauerte, hatte zunächst die Folge, daß man die Landesverwaltungen durch Dotationen seitens des Bundes finanzierte und andererseits der Bund die nötigen Mittel dazu durch die Notenpresse aufbrachte. Nach der Stabilisierung der Währung ergab sich angesichts der nunmehr vollkommen geänderten staatsrechtlichen Lage die Aufgabe einer Neuordnung der Finanzverfassung. Hierbéi war zunächst zu beachten, $\mathrm{daB}$ auch ein Bundesstaat eine gewisse einheitliche Ausrichtung seines finanzpolitischen Bedarfes bedarf. Im alten Österreich waren wirtschaftspolitische Querschüsse durch die Landesregierungen dadurch unmöglich gewesen, daß im Bedarfsfalle die Regierung die Möglichkeit hatte, einen diesbezüglichen Gesetzesbeschluß eines Landtages dem Kaiser nicht vorzulegen bzw. diesen aufzufordern, die Sanktion dem Gesetz zu versagen. Zwar hat nun die österreichische Verfassung im Art. 98 ein Einspruchsrecht der Bundesregierung gegen Gesetzesbeschlüsse eines Landtages vorgesehen, aber durch einen sogenannten "Beharrungsbeschluß" könnte der Landtag diesen Einspruch zurückweisen. Es war nun klar, daß für Finanzgesetze ein anderes Verfahren notwendig ist, denn dieses 
Verfahren des Art. 98 ist ein doch allzu schwächliches. Infolgedessen hat man sich entschlossen, für Finanzfragen eine Sonderregelung zu treffen, nämlich eine Art parlamentarischen Schiedsgerichtshof einzusetzen, wenn eine derartige Streitigkeit zwischen Bundesregierung und Land entstehen sollte.

Auf einen derartigen Beharrungsbeschluß des Landtages soll im Sinne des $\$ 9$ des Finanzverfassungsgesetzes in der heutigen Fassung ein ständiger gemeinsamer Ausschuß des Nationalrates und des Bundesrates von 26 Mitgliedern die Entscheidung treffen, ob der Einspruch der Bundesregierung berechtigt ist oder nicht. Der Ausschuß hat seine Entscheidung innerhalb von 6 Wochen zu fällen. Dieser Ausschuß ist auch zuständig für die Behandlung von Gesetzesbeschlüssen der Länder wegen Aufnahme von Darlehen.

Gleichzeitig mit dem Finanzverfassungsgesetz vom 2.3.1922 wurde das Finanzausgleichsgesetz beschlossen, welches formell kein Verfassungsgesetz, sondern ein Ausführungsgesetz zum Finanzverfassungsgesetz ist. Beide Gesetze sind in den uns interessierenden Fragen im wesentlichen unverändert heute wieder in Kraft, ihre letzte Fassung und Neuredaktion erfolgte mit Bundesverfassungsgesetz vom 21. 1. 1948 und dem Bundesgesetz vom 30. 6. 1955. Hier werden folgende Abgaben unterschieden:

1. ausschließliche Bundesabgaben,

2. zwischen Bund und Ländern geteilte Abgaben,

3. ausschließliche Landes- bzw. Gemeindeabgaben und

4. Gemeindeabgaben auf Grund des freien Beschlusses.

Die geteilten Abgaben können deswegen unsere besondere Aufmerksamkeit erregen, weil hier drei Gruppen zu unterscheiden sind, und zwar: 1. solche, deren Erträge zwischen Bund, Ländern und Gemeinden geteilt werden, 2. solche, bei denen die Länder und Gemeinden Zuschlagsrechte besitzen und 3. solche, bei denen neben den Abgaben des Bundes auch noch die Lä̀nder und Gemeinden das Recht haben, die gleiche Steuerquelle zu beanspruchen.

Die Einzelheiten dieser Aufteilung möchte ich mit Ausnahme der Aufteilungssätze zwischen Bund, Ländern und Gemeinden der ersten Gruppe den Versammelten ersparen, da diese den mir gesteckten Rahmen, einen kurzen Uberblick über die $\mathrm{Zu}$ sammenhänge von Staatsverfassung und Finanzverfassung in Österreich zu vermitteln, weit übersteigen würde: 
veranlagte Einkommensteuer (Lohnsummensteuer, Kapitalertragsteuer) $\mathbf{5 0}$

Umsatzsteuer . . . . . . . . . 50

Biersteuer . . . . . . . . . . 35

Weinsteuer . . . . . . . . . 51

Mineralölsteuer . . . . . . . . 50

Grunderwerbsteuer u. Zuschläge . . 20

Erbschaftsteuer . . . . . . . . 70

Kraftfahrzeugsteuer 35

Daneben spielt die vom Finanzverfassungsgesetz gebotene Möglichkeit, daß die Länder und Gemeinden eine Steuerquelle, die der Bund abschöpft, auch ihrerseits, sei es durch Zuschläge oder durch eigene Steuersätze ausnutzen, was aber naturgemäß bei den ausschließlichen Bundesabgaben nicht sein darf, eine finanzpolitisch kaum nennenswerte Rolle.

Der Bund hat jedoch im jüngsten Finanzausgleichsgesetz, wobei er sich allerdings an frühere ähnliche Regelungen anlehnen konnte, sich für die nächsten zwei Jahre einen Betrag von 685 Millionen $S$ aus den Ertragsanteilen der Länder und Gemeinden zusichern lassen, der von den eben erwähnten $\mathrm{Ab}-$ gaben zunächst abzuziehen ist. $40 \% / 3 \%$ dieser Summe ist den Gemeinden zu nehmen, $331 / 3 \%$ Wien, das Land und Gemeinde ist, $5 \%$ Niederösterreich und $21 \%$ die übrigen Länder. Außerdem haben die Städte mit Bundespolizei pro Kopf der Bevölkerung alljährlich 20.- S für die Kosten der Polizei dem Bund abzuliefern.

Und noch ein paar Worte über die Stellung des österreichischen Rechnungshofes. Zunächst einmal budgetiert dieser, genau so wie der Verfassungs- und Verwaltungsgerichtshof; in Österreich selbständig und nicht im Rahmen eines Ministeriums, womit die Unabhängigkeit des österreichischen Rechnungshofes gegenüber sämtlichen Ministerien zum Ausdruck kommt. Der Präsident des österreichischen Rechnungshofềs hat Ministerrang. Vom Nationalrat auf Vorschlag des Hauptausschusses gewählt hat er das Recht, mit Ermächtigung dés Bundespräsidenten mit Ausnahme der hohen Beamten, die der Bundespräsident mit seiner Gegenzeichnung ernennt, gleich einem Minister seine übrigen Beamten zu ernennen. Er ist ferner nur dem Nationalrat verantwortlich und kann nur durch Nationalratsbeschluß abberufen werden. Der österreichische Rechnungshof hat die Gebarung des Bundes, der Länder, der Gemeinden und Gemeindeverbände und der Träger der Sozial- 
versicherung zu überprüfen, jedoch Gemeinden unter 20000 Einwohnern nur auf begründetes Ersuchen der zuständigen Landesregierung. Er ist ferner in Angelegenheiten der Bundesgebarung Organ des Nationalrates und in Angelegenheiten der Länder-, Gemeinden- und Gemeindeverbändegebarung Organ des Landtages.

Nicht unerwähnt sei, daß das Budgetgesetz sowie der Bundesrechnungsabschlu $B$ lediglich der Beschlußfassung bzw. Genehmigung durch den Nationalrat unterliegt, so daß der Bundesrat hierbei ausgeschaltet ist.

E r l e r-Göttingen:

Herr Hettlage hat von der Finanzgewalt und insbesondere von der Abgrenzung der Finanzgewalt gegenüber dem Begriff der Enteignung gesprochen. Mir scheinen in diesem Punkte einige Fragen, und zwar Fragen der Grenzziehung, wichtig zu sein.

Herr Hettlage hat die Finanzverfassung, - wenn ich den Leitsätzen folge -, dargestellt als den „Inbegriff von Verfassungssätzen, die sich auf die Ordnung des Geldwesens, die staatliche Haushalts-, Vermögens- und Schuldenwirtschaft sowie die Ausübung der Finanzgewalt" beziehen. Die Finanzgewalt erstreckt sich also nicht nur auf die Befriedigung des Finanzbedarfs zur Ordnung des Haushalts, sondern auch auf die Gestaltung der Schuldenwirtschaft. Sie greift damit über zu dem Bereich, in dem es sich nicht mehr um Steuern und die Deckung des Finanzbedarfs handelt, sondern um die Gestaltung und insbesondere die Verringerung der Finanzbelastung, also insbesondere auch der Schuldenbelastung des Staates.

Wenn ich Herrn Hettlage recht verstanden habe, so wird auch die Schuldenwirtschaft von jenem von ihm aufgestellten Begriff der Finanzgewalt erfaßt, als deren "Sinn und Zweck“ er ohne Einschränkung die „entschädigungslose Fortnahme von Eigentum zur Deckung des öffentlichen Finanzbedarfs und zur Gestaltung des wirtschaftlichen und sozialen Lebens" angibt.

Wir haben hier zwei Funktionen der Finanzgewalt nebeneinander: einmal die Funktion der Steuererhebung zur Deckung des $F$ in anzbedarfs, - und ich stimme Herm Hettlage durchaus $z u, d a ß$ insoweit eine Enteignungsschranke praktisch wohl kaum besteht -, zum anderen die Funktion der Gestaltung der Schuldenwirts chaft, also der Gestaltung und Verringerung der Finanzbelastung des Staates. Und innerhalb dieser zweiten Funktion allerdings, glaube ich, müssen Grenzen 
deutlich werden, durch die das Postulat, daß der Sinn und Zweck der Finanzgewalt die entschädigungslose Fortnahme von Eigentum zur Gestaltung des wirtschaftlichen und sozialen Lebens sei, eingeschränkt wird.

Vielleicht darf ich die Abgrenzungsschwierigkeit an einem Beispiel erläutern. Die Erhebung von Steuern auf der einen Seite und die Vernichtung oder Abwertung von Staatsschulden auf der anderen Seite sind selbstverständlich zwei Dinge. Aber man hat in der Praxis gesehen, daß man mit Steuern Ansprüche gegen den Staat, also Staatsschulden, wegsteuern kann. Ich denke etwa an die japanische Nachkriegsgesetzgebung, in der sämtliche Ansprüche gegen den Staat und gegen die öffentliche Verwaltung aus der Kriegszeit im Wege eines Steuergesetzes weggesteuert worden sind. In dieser Besteuerung liegt praktisch eine Enteignung der Forderungen gegen den Staat. Nach dem Gesetz wird dieser Forderungsbetrag im Wege der Steuer erhoben und mit der Forderung aufgerechnet, die damit erlischt. Wir stehen also hier auf sehr gefährlichen Zwischenstufen zwischen der Funktion der Steuererhebung für den Finanzbedarf und der Funktion der Abwertung, Umwertung und Vernichtung von Staatsschulden. Die grundsätzliche Schrankenlosigkeit des Steuereingriffs in das Vermögen droht zu einer Schrankenlosigkeit auch des Enteignungseingriffs in Forderungengegen den St a a t zu führen.

Gerade durch kürzlich ergangene Gesetze - ich denke hier insbesondere an das Kriegsfolgenschlußgesetz - sind wir auch in Deutschland in diese Problematik tief hineingeraten. Ich will nicht sprechen von staatlichen Gestaltungsmaßnahmen in Bereichen, in denen echte Forderungen gegen den Staat nicht bestanden, also insbesondere im Bereich des Kriegssachschädenausgleichs. Dort haben echte Forderungen nicht bestanden, sondern dort hat der Staat konstitutiv erst Forderungen begründet. Bei dem Flüchtlingsschädenausgleich gilt dasselbe. Die Probleme werden schon deutlicher - wie Sie alle wissen bei der Behandlung der Restitutions- und Reparationsschäden, insbesondere bei den Reparationsdemontagen im eigenen Lande. Und sie zeigen sich in voller Klarheit, wenn es sich um ganz zweifellose Forderungen handelt, wie sie etwa im Kriegsfolgenschlußgesetz umgestaltet oder vernichtet worden sind, wo auf der Grundlage und vor der Kulisse der Identität des Bundes mit dem Reich die verschiedenartigsten Forderungen gegen das Reich abgehandelt werden, von denen einige voll befriedigt werden, - so etwa aus gegenseitigen Ansprüchen, die noch nicht voll abgewickelt worden sind, und aus ding- 
lichen Ansprüchen -, andere mit 6,5 Prozent befriedigt werden, - so die aus den verbrieften Reichsschulden, - und die ganze Fülle der nicht verbrieften Reichsschulden völlig unter den Tisch gefallen ist, und zwar mit der denkwürdigen $\mathrm{Be}-$ gründung, daß es sich hier um etwa 40 Milliarden handele, und da $B$ das Feststellungsverfahren teurer sein würde als die Schattenquote, die letzten Endes dabei herausfallen würde. Das sind Begründungen, die den Juristen natürlich kitzeln, insbesondere, wenn zu gleicher Zeit bei den Auslandsschulden im wesentlichen volle Befriedigung stattfindet. Wir haben also hier die auffällige Tatsache vor uns, daß bei dieser Umwertung von alten Schulden zum Teil volle Befriedigung stattfindet, zum Teil eine Schattenquote ausgeworfen wird, zum Teil aber die durchaus als begründet anerkannten Ansprüche völlig enteignet werden.

Die Grundsatzlosigkeit der ganzen Regelung wird dadurch nicht verdeckt, da $B$ man mit einigen neuen Begriffen arbeitet, insbesondere mit dem Begriff der Katastrophenlage oder des Eingriffs, der nicht unter die traditionelle Enteignung falle, und mit der Behauptung, daß hier Schwierigkeiten der Beweisführung eine Rolle spielten.

Ich möchte auf diese Fragen nicht weiter eingehen. Es scheint mir lediglich wesentlich zu sein, darauf hinzuweisen: Außerhalb der Steuergewalt im engeren Sinne muß der Grundsatz feststehen, daß die Finanzgewalt des Staates in bereits bestehende Ansprüche nicht oder nur in einem verfassungsmäßig fest umrissenen Umfange eingreifen kann. Soweit die Finanzgewalt sich der Schuldenwirtschaft widmet, kann ihr Sinn und Zweck nicht entschädigungslose Fortnahme von Eigentum zur Deckung des öffentlichen Finanzbedarfs und zur Gestaltung des wirtschaftlichen und sozialen Lebens sein; hier muß sie vor dem Denkmal der Eigentumsgarantie stehenbleiben.

Wir ständen dann allerdings immer noch vor einem unbefriedigenden Gegensatz: auf der einen Seite sehen wir die Möglichkeit der Finanzgewalt, mit dem Mittel der Steuer einzugreifen in einem Umfang, der praktisch die Wegnahme des wesentlichen Eigentums oder doch seines Wertes bedeuten kann. Auf der anderen Seite sehen wir den starren Schutz des Eigentums durch das Institut der gesetzlich beschränkten Enteignung.

Es wäre die Frage aufzustellen: Gibt es ein drittes Gebiet $z w i s c h e n$ diesen beiden Bereichen? Was geschehen ist, insbesondere durch das Kriegsfolgenschlußgesetz, liegt auf einem solchen dritten Gebiet. Jedenfalls kann es mit unseren geläufigen Rechtsbegriffen nicht mehr erklärt werden, und 
zwar ebensowenig mit der unbeschränkten Gewalt zum Wegsteuern von Werten durch die Finanzgewalt, noch mit dem Schutz des Eigentums durch die Eigentumsgarantie.

In diesen Gesetzgebungswerken sind - wenigstens andeutungsweise - neue Forderungen aufgestellt und neue Gesichtspunkte aufgezeigt worden. Es wird die Frage zu prüfen sein: Muß man nicht bei einer Untersuchung des faktischen Gesetzgebungswerkes, das uns vorliegt, zwischen der rigorosen Möglichkeit der Fortnahme von Eigentum im Wege der Steuergewalt auf der einen Seite und dem durch das Enteignungsinstitut rechtsgeschützten Eigentum auf der anderen Seite ein wesenseigenes Institut der Möglichkeiten der Abwertung und Umwertung, vielleicht im Zusammenhang mit sozialen Krisen, wirtschaftlichen $\mathrm{Zu}-$ sammenbrüchen und sonstigen tiefgreifenden Katastrophen, finden, das ein echtes Rechtsinstitut ist? Zur Zeit ist es eine reine Aporie, in der wir stehen. Es gibt kein echtes Rechtsinstitut, das sich zwischen diesen beiden Extremen anbietet, und jedermann versucht, entweder aus der einen Richtung die Tatbestände unter die Enteignungstrage einzuordnen, oder sie aus der anderen Richtung unter dem Gesichtspunkt eines Lastenausgleichs ex gracia oder einer sozialen Umschichtung zu sehen.

Wenn man dieses dritte Rechtsinstitut nicht anerkennen will, dann muß man meines Erachtens mit völliger Deutlichkeit den Eingriff der staatlichen Finanzgewalt in begründete Ansprüche mit der Eigentumsgarantie schützen. $\mathrm{Ob}$ das angesichts der Betonung der staatlichen Leistungsfähigkeit als Anspruchsgrenze und der sozialen Angemessenheit der Entschädigung als Ausgleichsmaßstab noch möglich ist, weiß ich nicht. Denn die angeblich mangelnde Leistungsfähigkeit des Landes wird unter Umständen leicht dazu führen, daß eben doch nur Schattenquoten ausgekehrt werden, und die Frage, ob die Entschädigung angemessen ist, wird sich nach der Leistungsfähigkeit des Staates richten, deren Beurteilung dieser sich selbst vorbehält. Ein echter Enteignungsschutz wird daher gerade bei Ansprüchen gegen den Staat stets problematisch bleiben.

Es lag mir lediglich daran, auf dieses $M$ it telgebiet der Abwertung und Umwertung staatlicher Schulden aufmerksam zu machen, das bisher weder von der einen Seite noch von der anderen Seite ernstlich systematisch durchdacht und noch nirgends zu einem wirklichen Rechtsinstitut ausgebildet worden ist, obwohl es praktisch seit langem, - und heute mehr als je -, beschritten worden ist. 


\section{M e r k-Tübingen:}

Ich möchte nur einige kurze Bemerkungen machen. Zunächst möchte ich sagen, daß ich die Gestaltung des Finanzwesens im GG vom gesamtdeutschen Standpunkt aus von Anfang an als durchaus unbefriedigend betrachtet habe, insofern es dem Bunde im Vergleich mit den Ländern nicht in genügender Weise das gegeben hat, was ihm nach der Größe seiner Aufgaben zukommen sollte. Es sei hier nur erinnert an die großen Kriegsfolgelasten, wozu jetzt noch insbesondere die riesigen, in die Milliarden gehenden, Wiederaufrüstungskosten kommen. Wir verdanken diesen unbefriedigenden Zustand der Gestaltung bekanntlich vor allen Dingen dem Eingreifen der Besatzungsmächte in die Verhandlungen des Parl. Rates, der u.a. auch eine einheitliche Bundesfinanzverwaltung vorgesehen hatte, zum Zwecke der Verhinderung einer starken Finanzgewalt des Bundes. Es bleibt zu hoffen, daß bei der Gestaltung der endgültigen Verfassung durch die verfassunggebende deutsche Nationalversammlung eine befriedigendere Regelung auf dem Gebiet des Finanzwesens herauskommt, wobei die seit 1949 gemachten Erfahrungen verwertet werden können.

Den Ausführungen von Herrn Hettlage stimme ich im wesentlichen zu. Dagegen vermag ich Herrn Maunz, wenn er - soviel ich verstanden habe - sich im großen und ganzen für die Beibehaltung der bisherigen Regelung des GG ausgesprochen hat, nicht zu folgen. Wenn unter Ziff. 9 seiner Leitsätze gesagt ist, aus der Natur der Sache könnten keine Folgerungen dahin gezogen werden, welche Steuern dem Bunde, und welche den Ländern zugewiesen werden sollen, so möchte ich dazu sagen, daB mit der Natur der Sache hier allerdings nicht viel anzufangen ist; aber, geschichtlich betrachtet, ist es doch so, da $B$ in Bundesstaaten jedenfalls eine Beteiligung des Bundes bzw. Reichs an der wichtigsten unmittelbaren Steuer, der Einkommen- (und Körperschafts-)steuer, mit seinem wachsenden Finanzbedarf sich auf die Dauer nicht ausschließen läßt. Wir sehen dies in verschiedenen Bundesstaaten, so insbesondere z. B. in den Vereinigten Staaten von Amerika und in der Schweiz, wo man Bundeseinkommensteuern eingeführt hat - in der Schweiz bisher wenigstens in der Form einer außerordentlichen Kriegssteuer auf das Einkommen wie auch auf das Vermögen und einer Kriegsgewinnsteuer - . Bekkanntlich hat bei uns das Reich schon nach der RV von 1871, Art. 4, rechtlich die Befugnis zur Vorranggesetzgebung über die für seine Zwecke zu verwendenen Steuern schlechtweg gehabt, also, ohne Unterschied, ob es sich um unmittelbare (sog. direkte) oder mittelbare (indirekte) Steuern handelte; nach 
Art. 35 hatte das Reich weiter das ausschließliche Gesetzgebungsrecht über die Zölle und die fünf großen Verbrauchssteuern auf Salz, Zucker, Tabak, Bier und Branntwein vorbehaltlich der Sonderrechte der süddeutschen Länder bezüglich der Bier- und Branntweinbesteuerung. In Art. 70 in der ursprünglichen Fassung (vor 1904) war sodann zufolge der Annahme einer auf einen Antrag des Abg. Miquel zurückgehenden Bestimmung gesagt, daß, soweit die Ausgaben des Reichshaushaltsplanes durch etwaige Uberschüsse aus dem Vorjahre und die aus den Zöllen, den Verbrauchssteuern und dem Postund Telegraphenwesen fließenden Einnahmen nicht gedeckt werden, sie, "solange Reichssteuern" (d. h. unmittelbare Reichssteuern) "nicht eingeführt sind“, - nach Art einer staatenbündischen Finanzverfassung - durch die Länder mittels Matrikularbeiträgen nach dem Kopf der Bevölkerung aufgebracht werden sollen. Aber die tatsächliche Entwicklung ist dann doch so gewesen, daß sich das Reich in der Hauptsache mit den Zöllen, Verbrauchssteuern und Verkehrs- (Stempel-)steuern begnügt hat, wogegen den Ländern die bereits in ihrem Besitz befindlichen, auch erst allmählich ausgestalteten, unmittelbaren Steuern vom Einkommen und Vermögen verblieben sind. Erst langsam und zaghaft ist man seitens des Reichs infolge des Widerstands der Länder an die Erfassung von unmittelbaren Steuern herangegangen: 1906 mit der Erbschaftssteuer, die wenigstens nach der einen Auffassung des Unterschieds zwischen unmittelbaren und mittelbaren Steuern eine unmittelbare Steuer darstellt, und mit der Besteuerung der Aufsichtsratsgewinne, die als eine Sondereinkommensteuer anzusehen war, äußerlich jedoch in der Form einer Stempelsteuer erhoben wurde; dann 1913 mit dem einmaligen Wehrbeitrag und der Vermögenszuwachssteuer. Im ersten Weltkrieg trat das Unbefriedigende der Finanzverfassung des Kaiserreichs deutlich hervor. Die Einnahmen aus Zöllen und Verbrauchssteuern insbesondere gingen aus begreiflichen Gründen sehr zurück; $z$. T. mußte man, insbesondere angesichts der Absperrung zur See, froh sein, überhaupt noch etwas aus dem Auslande hereinzubekommen; aber auch der Verbrauch im Inlande ging erheblich zurück, wie z. B. beim Bier u.s.f. Das Reich war so nicht in der Lage, das zu tun, was England in vorbildlicher Weise getan hat, nämlich durch Erhöhung der Einkommensteuer - die dort eine bewegliche Steuer ist, und deren Sätze jährlich im Finanzgesetz nach Bedarf festgesetzt werden -, wie schon s. Zt. im Burenkrieg, und durch eine rechtzeitige Erfassung der Kriegsgewinne durch eine Kriegsgewinnsteuer einen erheblichen Betrag der Kriegskosten zu 
decken. Statt dessen hat man bei uns in der Hauptsache immer wieder Kriegsanleihen aufgelegt und ist $u$. a. erst spät und in unzulänglicher Weise darangegangen, auf der Grundlage der verschiedenartigen Landessteuergesetze die Kriegsgewinne zu erfassen. Gerade in solchen Krisenzeiten zeigt sich, wie notwendig es ist, daß dem Bund bzw. Oberstaat die wichtigste unmittelbare Steuer zur Verfügung steht. — In der Weimarer Zeit hat dann das Reich infolge seiner großen finanziellen Belastung nach dem verlorenen Krieg durch die sog. Erzbergersche Finanzneuordnung die Hand auf die Einkommen- (und Körperschafts-)steuer sowie die Vermögenssteuer gelegt und durch das Gesetz über die Finanzverwaltung vom 10. Sept. 1919 auch eine eigene und unmittelbare Reichsfinanzverwaltung eingeführt. - Das GG geht in wenig sinnvoller Weise davon aus, daß den Ländern in erster Reihe die Einkommen(und Körperschafts-)steuer sowie auch die Vermögenssteuer zusteht; eine Beteiligung des Bundes an der Einkommensteuer ist in Art. 106 nur unter bestimmten Voraussetzungen vorgesehen. Ich halte es hierbei insbesondere für unbefriedigend, daß die Höhe der Beteiligung des Bundes an der Einkommensteuer lediglich durch ein sog. Zustimmungsgesetz geregelt werden kann, also ein solches Gesetz an dem Widerspruch der Länder im Bundesrat scheitern kann; ich bemerke hierzu noch, da $B$ ich bei der gegenwärtigen Art der Zusammensetzung des Bundesrats überhaupt ein Gegner der sog. Zustimmungsgesetze bin. - Ich meine, dieser ewige Streit zwischen Bund und Ländern über den Anteil des Bundes an der Einkommensteuer sollte aufhören. Es müßte eine Stelle da sein, welche die endgültige Entscheidung hierüber trifft, und das kann m. E. nur der Bund, und nicht die z. T. weitgehend von Selbstsucht bestimmten und des genügenden Sinns für Einordnung in das Ganze ermangelnden Länder sein, nämlich mittels eines gewöhnlichen, sog. Einspruchsgesetzes, da die Gesamtbelange den Vorrang vor den Belangen der Länder haben müssen. Selbstverständlich müßte auch bei einer solchen Gestaltung der Bund bzw. das Reich auf die finanzielle Leistungsfähigkeit der Länder Rücksicht nehmen, wie dies ja auch in der Weimarer RV vorgeschrieben war.

Was nun die Finanzverwaltung anbelangt, so bin ich der Meinung, daß die Frage der einheitlichen Bundes- bzw. Reichsfinanzverwaltung, wie sie sich in der Weimarer Zeit durchgesetzt hatte, bei der endgültigen Verfassung noch einmal durchdacht werden sollte. Wenn Sachkenner sagen, daß infolge der Verschiedenheit der Veranlagung, der Kostspieligkeit der Aufteilung der Finanzverwaltung auf Bund und Länder usf. 
bis zu einer Milliarde DM verloren gehen, so ist das $\mathrm{m}$. $\mathrm{E}$. schlechterdings nicht zugunsten eines falsch verstandenen sog. "Föderalismus" zu verantworten. Ich kann natürlich dafür, ob diese Zahlen mehr oder weniger zutreffend sind, nicht einstehen; das bedürfte, soweit möglich, einer genaueren Nachprüfung; aber etwas Wahres wird doch wohl daran sein. Die jetzige Gestaltung der Finanzverwaltung von Bund und Ländern nach dem geltenden Finanzverwaltungsgesetz, das eine gewisse Verklammerung der Finanzverwaltung des Bundes und der Länder vorsieht, kann $\mathrm{m}$. E. nur als ein vorläufiger Notbau angesehen werden, der in der Zukunft durch eine klare und endgültige Gestaltung ersetzt werden muß.

Was weiter den Finanzausgleich anbelangt, so kann ich mich nicht für den "feind-brüderlichen" Finanzausgleich zwischen finanzstarken und finanzschwachen Ländern begeistern; das ist m. E. nur ein unvollkommener Notbehelf. Es sollte Sache des Bundes bzw. Reichs sein, seinerseits auf dem Wege der Gesetzgebung diesen Ausgleich zwischen sich und den Ländern vorzunehmen.

Zu begrüßen wäre es im übrigen im Sinne der Ziff. 11 der Leitsätze des Herrn Maunz, wenn die Gemeinden in eine unmittelbare Beziehung zum Bund, wenigstens zunächst auf dem Finanzgebiet, gebracht werden könnten, also nicht nur ein Finanzausgleich $\mathrm{zwischen} \mathrm{Bund} \mathrm{und} \mathrm{Ländern} \mathrm{stattfindet,} \mathrm{wobei}$ es den Ländern überlassen bleibt, diesen Finanzausgleich zwischen sich und den Gemeinden und zwischen diesen vorzunehmen. Ebenso stimme ich der Ziff. 12 seiner Leitsätze $z u$, wenn dort gesagt ist, da $B$ die endgültige Verteilung der Steuern zwischen Bund und Ländern i. S. des Art. 107 GG nur eines einfachen Gesetzes bedarf, es sich hier also nicht um ein Verfassungsgesetz im förmlichen Sinne des Art. 79 handelt.

Peters - Köln:

Meine Herren! Gestatten Sie zwei Bemerkungen de lege lata zu den Thesen Ziff. 4 und 9 von Herrn Hettlage.

Zunächst etwas zum Glei ch heitss a tz. Mir scheint Herr Hettlage die Bedeutung des Art. 3 GG für das Steuerrecht zu unterschätzen. Nach meinen Auseinandersetzungen mit Herrn Ipsen über die Begrenzung des Gesetzgebers durch Art. 3 werde ich gewiß nicht in den Verdacht kommen, durch eine zu weite Auslegung des Gleichheitssatzes dem Gesetzgeber in unzulässiger Weise die Hände zu binden. Gerade deshalb muß man aber $\mathrm{m}$. E. der Tendenz entgegentreten, wonach der Gesetzgeber mit dem Erlaß von Steuergesetzen wirtschaftspolitis che Ziele der verschiedensten Art erfüllen will und 
dabei entgegen dem Art. 3 GG mit einer den Gleichheitssatz verletzenden Verschiedenartigkeit an sich gleichartige Tatbestände steuerlich verschieden behandelt. Wenn beispielsweise - einer zur Zeit bestehenden Bestrebung folgend - Teilzahlungsgeschäfte beschränkt werden sollen, so mag das an sich verfassungsrechtlich zulässig sein; es geht aber nicht in der Weise, daß der Gesetzgeber für Geschäfte dieser Art die Umsatzsteuer um ein Mehrfaches erhöht. Das wäre m. E. mit dem Gleichheitssatz nicht zu vereinbaren.

Mir scheint darin auch ein Widerspruch zur These 12 von Herrn Hettlage zu liegen, die nun in entgegengesetzter Richtung m. E. zu weit geht: Es ist unter staatsrechtlichen Gesichtspunkten bedenklich, wenn man ungleiche Startbedingungen für den wirtschaftlichen Wettbewerb und soziale Unterschiede schafft, für die ein sachlich einleuchtender Grund der Differenzierung sich nicht finden läßt. Tatsächlich schaffen Steuern immer wieder verschiedene Startbedingungen, wobei oft der Grund der Art und Höhe der Steuern in erster Linie ein rein fiskalischer ist, wie z. B. beim Kaffeezoll und den besonderen Kaffeesteuern. Bereits vor mehr als $20 \mathrm{Jahren}$ hat ein Heft der Vierteljahresschrift für Finanzen und Steuern einige wertvolle Aufsätze zum Problem der Gleichheit im Steuerrecht gebracht, ohne daß damit eine abschließende Lösung gefunden worden wäre. Man darf aber m. E. die damals gewonnenen Erkenntnisse nicht außer acht lassen; auch heute noch ist, wie die Darlegungen von Herrn Hettlage zeigen, die Frage nach den durch den Gleichheitssatz dem Steuergesetzgeber gesetzten Grenzen aktuell.

Mein zweites, stärkeres Bedenken gegen Herrn Hettlages Darlegungen richtet sich gegen seine Auffassung von der Herrschaft des Gewaltenteilungsprinzips nach dem Grundgesetz. Beide Herren Referenten sind der - m. E. zutreffenden - Meinung, daß der Grundsatz der Gewaltenteilung im Finanzrecht vielfach durchbrochen sei. Nun glaubt aber Herr Hettlage zu Unrecht, daß das Gewaltenteilungsprinzip in der ihm heute gegebenen Auslegung der Lehre Montesquieus ein Fundamentalsatz unseres Verfassungsrechts und sogar eine Norm sei, die durch Art. 79 GG gegen jegliche Abänderung und Durchbrechung geschützt sei. Mit dem gleichen Recht müßte man dann eine Fülle von Maßnahmen unseres Rechtslebens, die niemand ernstlich beanstandet, für grundgesetzwidrig erklären. Wie ich in meiner Broschüre über „Die Gewaltentrennung in moderner Sicht" dargelegt habe, handelt es sich aber beim Prinzip der Gewaltenteilung lediglich um einen Baustein unserer Verfassung, nicht aber um eine Norm, von 
der nicht schon der einfache Gesetzgeber Ausnahmen zulassen dürfte (vgl. z. B. die Freiwillige Gerichtsbarkeit). Daher ist nach geltendem Verfassungsrecht ein Personalausschußgesetz zulässig, selbst wenn in dem dort vorgesehenen Personalausschuß auch Abgeordnete des Parlaments Sitz und Stimme haben. Ebensowenig ist es unzulässig, daß in einem Gesetz, auch zu im Haushaltsplan an sich bewilligten Ausgaben, die Entscheidung einer Verwaltungsbehörde an die Mitwirkung eines Parlamentsausschusses gebunden wird. Das muß aber formalgesetzlich festgelegt werden. Insoweit stimme ich Herrn Hettlage $z u$, daß eine solche Mitwirkung nicht in der Spalte „Erläuterungen“ des Haushaltsplans wirksam festgelegt werden kann; denn der Haushaltsplan als solcher, zumal in den „Erläuterungen" kann materiell kein neues Recht setzen, und das Gewaltenteilungsprinzip gilt insoweit, als es für Verwaltungshandlungen jedenfalls eine gesetzliche Vermutung zugunsten der Exekutive schafft.

Wenn aber in einem Etatstitel eine an sich unzulässige Begrenzung der Exekutive steht, auch dann kann man $\mathrm{m}$. E. nicht die Folgerung von Herrn Hettlage ziehen, daß dann der beschränkende Vermerk nichtig sei; vielmehr hat dann das Parlament der Exekutive eben die Ausgabebewilligung $\mathrm{nicht}$ erteilt. Der Etat beruht nämlich auf dem Willen des Parlaments. Wenn letzteres der Exekutive die Ausgabe nicht zur Verfügung freigestellt hat, dann kann man, falls die gesetzte Beschränkung unzulässig sein sollte, keine u n beschränkte Bewilligung als gewollt unterstellen.

Auch tatsächlich scheint mir Aufstellung und Durchführung des Haushaltsplans von Herrn Hettlage zu stark unter dem Gesichtspunkt der Gewaltenteilungslehre Montesquieus gesehen. Gewiß wird dadurch, daß der Haushalt als formelles Gesetz verabschiedet wird, der Anschein erweckt, als ob die beiden Gegenspieler Parlament und Regierung seien. Ist aber nicht in Wirklichkeit das Ganze vielmehr ein Wechselspiel zwischen Parlament und Finanzminister, da die anderen Fachminister oft genug vorher und innerlich auch später auf der Seite des Parlaments stehen. Gewöhnlich sind doch die Fachminister nicht minder ausgabefreudig als das Parlament, und es gehört zu den modernen Irrtümern, bloß die Abgeordneten als bewilligungsfreundlich hinzustellen; sie haben nur den Vorteil, daß sie dem Finanzminister gegenüber in einer stärkeren Position sind als die Ressortminister. In Wahrheit geht es hier überhaupt nicht um eine Frage der Gewaltenteilung, sondern um die finanzpolitische Tatsache, daB der Finanzminister die Verantwortung dafür hat, daß die Staatsfinanzen 
in Ordnung bleiben, während die Fachminister für ein möglichst hohes Maß der Aufgabenerfüllung innerhalb ihres Ressorts und die Abgeordneten für eine möglichst weitgehende Berücksichtigung der von ihnen selbst und von ihren Wählern, "dem Volke", für wichtig erachteten Aufgaben eintreten.

Als Ergebnis ist daher festzustellen: die Gewaltenteilung muß als Argument von Herrn Hettlage m. E. ganz ausscheiden. Rechtlich kommt sie für die Frage der Rechtmäßigkeit oder Unrechtmäßigkeit von Maßnahmen im Bereich des Finanzrechts kaum in Betracht; aber auch tatsächlich geht es viel weniger um ein Gegeneinanderstehen von Legislative und Exekutive, als es nach dem Referat den Anschein hat.

\section{W e b e r - Göttingen:}

Ich bitte Herrn Hettlage um Verzeihung, da $B$ ich aus seinem ausgezeichneten und umfassenden Referat, das mir außerordentlich viel Anregungen zu weiterem Nachdenken gegeben hat, nur einen Einzelpunkt herausgreife, nämlich Punkt 5 seiner Leitsätze. Der Punkt ist zwar schon von Herrn Erler angesprochen worden, aber ich möchte dazu noch etwas sagen.

Ich halte die Formulierung, die Herr Hettlage in diesem Punkt seiner Leitsätze gefunden hat, für bedenklich, um nicht zu sagen für gefährlich. Ich denke dabei auch daran, daß die deutsche Offentlichkeit dazu neigt, die Veröffentlichungen der Vereinigung der deutschen Staatsrechtslehrer doch mit einer gewissen gehobenen Autorität ausgestattet zu sehen. Und wenn nun in einer These zu lesen ist, die sicher nur die These des Herrn Referenten und nicht der Staatsrechtslehrervereinigung ist: "Sinn und Zweck der Finanzgewalt ist die entschädigungslose Fortnahme von Eigentum zur Deckung des öffentlichen Finanzbedarfs und zur Gestaltung des wirtschaftlichen und sozialen Lebens", so könnte das bei einer nicht durch das Filter wohlwollenden Verständnisses gereinigten Deutung zu enormen Konsequenzen führen.

Ich teile die Auffassung von Herrn Hettlage nicht, daB die Eigentumsgarantie mit der Finanzgewalt nichts $\mathrm{zu}$ tun hätte. Ich gebe freilich ohne weiteres $\mathrm{zu}$, daß, als man die Eigentumsgarantie während des 19. Jahrhunderts in unsere Verfassungen einbaute - 1789, 1848, 1850 und wann immer - man nicht daran gedacht hatte, daß gegen denjenigen, der die Steuern zu bewilligen hätte, eine besondere Sicherung eingebaut werden müsse, geschweige denn, daß diese Sicherung gerade die Eigentumsgarantie sein müsse. Aber wir erleben doch bei fast allen Grundrechten einen Bedeutungswandel, der sich aus der 
Veränderung unserer Gesamtsituation ergibt. Es muß schon auffallen, daß Herr Hettlage zwar Arbeitsfreiheit, Auslieferungsverbot, unbeschränkten Rechtsweg gegen Finanzbefehle, Freizügigkeit und Fernmeldegeheimnis für den Finanzgesetzgeber für tabu erklärt, aber die Eigentumsgarantie, dieses Kernstück unserer Grundrechte, hiervon ausnehmen will. Ich glaube nicht, da $\beta$ wir in der Sache so sehr differieren, aber dann bleibt doch, daß eben die Frage der Formulierung sehr wichtig ist.

Richtig ist, daß die En te ig n ung sklausel etwa des Art. 14 Abs. 3 GG zu unserer Frage nichts besagt. Aber die Eigentumsgarantie als solche besagt, wie mir scheint, Erhebliches zu dem Problem. Denn die Eigentumsgarantie des Art. 14 schützt ja nicht nur gegen Enteignungen oder gegen - ich will lieber sagen: Manipulationen, die sich als Enteignungen ausgeben; der Art. 14 besteht nicht nur aus einem Abs. 3, sondern der Artikel 14 garantiert zunächst einmal doch das Grundlegende, das Eigentumsinstitut als solches, nicht nur als „Rechtsinstitut", sondern als eine Fundamentalerscheinung unseres Wirtschafts- und Soziallebens und vor allem auch der Freiheitlichkeit unseres Wirtschafts- und Soziallebens. Uber die Formulierung des Satzes: „Art. 14 und Art. 15 verbieten keine ,Enteignung' und keine ,Sozialentwährung' durch Besteuerung" kann man natürlich streiten. Denn, wie gesagt, von „Enteignung“ ist hier gar nicht die Rede. Aber ich sehe doch in Art. 14 ein entscheidendes Hindernis dagegen, $c a B$, auf welchem Wege auch immer - und sei es auch auf dem Wege der Finanzgesetzgebung -, eine Konfiskation von Vermögen erfolgt und eine Sozialentwährung oder soziale Umschichtung durchgeführt wird. Ich glaube, wir können es nicht ohne Widerspruch passieren lassen, daß hier gesagt wird: Im Wege der Steuergesetzgebung, und zwar nicht nur zur Deckung des öffentlichen Finanzbedarfs, sondern auch zur Gestaltung des wirtschaftlichen und sozialen Lebens kann man sich, wenn man sich nur der Technik der Steuergesetze bedient, über alles, was sich sonst an Grenzen gesetzgeberischer Handlungsmöglichkeiten aus der Eigentumsgarantie ergibt, hinwegsetzen. Ich weiß, daß die Diskussion über diese Dinge bisher nur auf sehr schmaler Basis geführt worden ist. Ich habe in meinem Beitrag zu Art.14 GG in Band 2 des Handbuchs "Die Grundrechte" (S. 360) einmal die Literatur, die es zu diesem Punkte gibt, zusammengetragen. Ich habe als bestes Beispiel dafür ein Lehrschreiben des deutschen Episkopats gefunden, das in diesem Punkte eindeutig ist, und dann noch einige Bemerkun- 
gen von katholischen Moraltheologen, während sonst im wesentlichen etwa nur einige, allerdings sehr dezidierte Äußerungen unseres Kollegen Flume zu diesem Problem vorliegen.

Die Eigentumsgarantie bedeutet, daß das Eigentum als Grundlage einer eigenverantwortlichen Lebensgestaltung Fundament unserer Wirtschafts- und Sozialordnung sein soll, und das schließt aus, daß man auf dem Wege über eine Finanzgesetzgebung nun doch dieses Fundament unserer Wirtschaftsund Sozialordnung umstößt.

Herr Hettlage hat gesagt, man könne ja auch nicht richterlich kontrollieren, ob der Steuergesetzgeber gegen die Eigentumsgarantie verstoßen habe. Er hat also die Justiziabilität etwaiger Verstöße dieser Art gegen den verfassungsrechtlichen Eigentumsschutz bezweifelt. Ich meine jedoch sagen zu müssen, $\mathrm{daB}$ es z.B. der Normenkontrolle des Bundesverfassungsgerichts durchaus möglich sein müßte, festzustellen, wann ein Steuergesetz, etwa ein Vermögenssteuergesetz oder auch ein Einkommensteuergesetz, einen einwandfrei konfiskatorischen Charakter hat. Es gibt sicherlich Grenzzonen, wo das Bundesverfassungsgericht wird sagen müssen: Innerhalb dieses Spielraums können wir dem Gesetzgeber nicht nachrechnen, ob er etwas mehr oder weniger Zweckmäßiges oder schon Bedenkliches getan hat. Aber es gibt dann eine Linie, von wo ab der konfiskatorische Charakter oder die soziale Umschichtungsabsicht offen zutage liegt, und dann wird dieses Steuergesetz eben durch Art. 14 GG negiert.

Ich glaube ferner, daß sich in diesem Punkte doch auch etwas zur Inflation, zur Währungsabwertung sagen läßt - wenn schon nicht zu den Formen der Währungsabwertung, die sich, wie Herr Hettlage geschildert hat, in vielfältiger Weise im "gesellschaftlichen Raum" vollziehen, so doch jedenfalls etwas sagen läßt gegen eine in aller Form oder auch versteckt vom Staat inaugurierte Währungsabwertung. Ich glaube, daß Art. 14 GG, wenn er überhaupt in den Lebensbedingungen unserer heutigen Wirtschafts- und Sozialsituation eine Funktion haben soll, auch ein Hindernis bedeutet gegen solche Währungsmanipulationen, die doch im größten Stil eine Verdrängung aus der Eigentümerstellung bedeuten, nämlich gegen eine vom Staat manipulierte Inflation. Auch diese eklatante Verletzung der Eigentumsgarantie würde im übrigen verfassungsgerichtlich durchaus justitiabel sein.

Im ganzen meine ich mit aller Entschiedenheit darauf hinweisen zu müssen, daß in der Eigentumsgarantie eine unübersteigbare Grenze auch für die Finanzgewalt liegt. 
Forst h of $\mathrm{f}$-Heidelberg:

Meine sehr geehrten Herren! Das Erregende und, ich muß von mir aus sagen, Imponierende des Referats von Herrn Kollegen Hettlage besteht darin, mit aller Eindeutigkeit gezeigt zu haben, daß die Finanzverfassung ein Zentralgebiet unserer gesamten Verfassungsordnung ist.

Es ist kein Zufall, daß die Diskussion auf den Punkt gekommen ist, auf den Herr Kollege Erler und Herr Kollege Weber sie geführt haben: die Frage der Abgrenzung und überhaupt der Beziehung zwischen der Finanzhoheit und der Privateigentumsgarantie. Denn hier schlüsselt sich in der Tat die Grundentscheidung innenpolitischer Art, die wir mit der Formel vom sozialen Rechtsstaat $\mathrm{zu}$ fassen versuchen, wobei ich mehr und mehr dazu neige, nicht mehr vom Sozialstaat, sondern vom Verteilungsstaat zu sprechen, weil das präziser und eindeutiger ist und manche Verschwommenheiten vermeidet, die in dem Begriff "sozial“" liegen.

Wenn wir uns die Entscheidung, die in der Realität unserer Verfassungsordnung, wie ich glaube, jetzt angelegt ist, vergegenwärtigen, dann sehen wir auf der Eigentumsseite folgendes: Der Eigentumsschutz wird in dem Sinne verabsolutiert, das jedem einzelnen die Quote, mit der er am Volksvermögen Anteil hat, nahezu absolut garantiert wird. Das ist die innere Logik der Verwischung, die wir zwischen Enteignung, Aufopferung und Amtspflichtverletzung auf Grund der Rechtsprechung heute feststellen können.

Der Eigentumsschutz ist generell und ausnahmslos. Das heißt sub specie des Verteilungsstaates gesehen: aus dem System der Güterverteilung wird grundsätzlich nicht verteilt, sondern es wird verteilt aus dem Sozialprodukt und hinsichtlich des Sozialprodukts besteht auch der freie Auslauf der Finanzhoheit. Insofern schränke ich mich, Herr Hettlage, jetzt ein gegenüber dem, was ich vor zwei Jahren in meinem Referat über den Sozialstaat ausgeführt habe. Diese Einschränkung ist auch in der Realität der Steuerpraxis durchaus ablesbar. Wir haben hinsichtlich des Sozialprodukts Steuerstaffeln gehabt, die bis zu 100 Prozent gegangen sind, z. B. in der Körperschaftssteuer vor der Reform von 1949. Aber wir hatten und haben diese extremen Sätze nicht bei den Steuern, die in die Quote des einzelnen am Volksvermögen eingreifen, wie die Vermögenssteuer, Erbschaftssteuer usw.

Ich glaube also, hier ist die Schranke des Eigentums vor die Finanzhoheit gestellt. Es kann nicht durch eine konfiskatorische Erbschaftssteuer die Garantie des Erbrechts im Art. 14 unterwandert oder umgangen oder aufgelöst werden. Das ist nach 
Art. 19 unzulässig. Es kann auch mit der Vermögenssteuer Eigentum nicht entschädigungslos entzogen werden. Hier ist die Finanzhoheit an die Grenze der Sozialgebundenheit des Eigentums gebunden. Von diesen Erwägungen aus ist der Begriff der konfiskatorischen Steuern festlegbar. Aber bei den heute wichtigen Steuern - Einkommen-, Körperschafts-, Umsatzsteuer usw. - die sich auf das Sozialprodukt richten, ist wie ich glaube die Finanzhoheit vom Eigentumsschutz her gesehen nicht gebunden. Und das scheint mir die Logik des sozialen Rechtsstaates heute zu sein: ein absoluter Schutz des Systems der Güterverteilung in dem rigorosen Eigentumsschutz, wie ihn die Rechtsprechung hervorgebracht hat, dagegen freier Auslauf der Finanzhoheit auf das Sozialprodukt.

Merk l- Wien:

Wie gedankenreich die bisherige Diskussion gewesen ist, so hat sie doch nach meinem Eindruck den Sprühregen von Anregungen, die wir dem heutigen Bericht des Herrn Hettlage verdanken, noch lange nicht ausgeschöpft.

Eine der Erkenntnisse aus den Ausführungen des Herrn Hettlage ist für mich die, daß die Finanzverfassung ebenfalls einer der Bestandteile der Auseinandersetzung zwischen Individuum und Gemeinschaft ist. Was nützt uns etwa die überkommene rechtsstaatlich-liberale Ordnung der Freiheitsrechte und im besonderen der Freiheit der Person, der Unverletzlichkeit des Eigentums, wenn die Finanzverfassung und die Finanzpolitik alle diese Sicherungen wegzuspülen vermag.

Ich habe in einer Hinsicht den Begriff des Rechtsstaates schon auf Grund ähnlicher Erwägungen zu erweitern versucht, nämlich in meinem Beitrag zu der Festschrift „Rechtsstaat und Demokratie" für den Züricher Fachgenossen Zaccaria Giacommetti unter dem Titel "Idee und Gestalt der politischen Freiheit", Polygraphischer Verlag Zürich 1953, die große Bedeutung der Entscheidung über Krieg und Frieden für die Frage der rechtsstaatlichen Ordnung behauptet, und als Beispiel für diese Ausweitung des Rechtsstaatsbegriffs angeführt, daß die verfassungsrechtliche Ordnung der Entscheidung über Krieg und Frieden nicht weniger für die Sicherung der Person und des Eigentums, ja sogar - meiner tberzeugung nach wesentlich mehr beiträgt als alles das, was wir der liberalen Gestaltung des Rechtsstaates verdanken, und was wir gewiß nicht vermissen wollen.

Es ist unter diesen Umständen besonders bedeutsam, daß schon im Bereich der Gesetzgebung und der Regierung Siche- 
rungen angebracht werden, welche verhüten sollen, daß die Regelung der Gesetzgebung auf dem Gebiete der Rechtsprechung und Verwaltung wirkungslos gemacht wird. In dieser Hinsicht scheint mir die Lehre aus den letzten beiden Weltkriegen zu sein, daß eine Fundierung der Gesetzgebung und Regierungspolitik im Großteil der Repräsentation des Volkes, und $\mathrm{da} B$ darüber hinaus eine weitgehende Mitverantwortung, ja, sogar eine Gesamtverantwortung der an der Regierung beteiligten Parteien für die Gesetzgebung und Regierungspolitik notwendig ist.

Sie gestatten bitte, daß ich aus der Rechtslage und den Erfahrungen meiner engeren Heimat die Feststellung mache, die hierzulande, soweit ich sehe, nicht unbegreiflicherweise fast unbekannt ist, daß die österreichische Bundesverfassung eine einstimmige $\mathrm{Zustimmung}$ der Regierungsmitglieder zu sämtlichen Regierungsbeschlüssen voraussetzt, was die Folge hat, daß sich alle Regierungsparteien vollkommen klar werden müssen über die Tragweite dieser Regierungsentscheidungen und sich jeden Augenblick vor Augen halten müssen, daß sie für diese Regierungsentscheidungen mitverantwortlich gemacht werden.

Nur das Erfordernis der Einstimmigkeit der Regierungsibeschlüsse, und darüber hinaus die große Regierungsmehrheit von mehr als 90 Prozent der Mandate - es steht der sozialistischbürgerlichen Koalition nur eine kleine Opposition von 3 Kommunisten und 6 Rechtskonservativen oder Nationalen gegenüber -, und die Klarstellung innerhalb des Regierungslagers über die Strategie und Taktik der Konsolidierung des Staates, der Wiederherstellung der Unabhängigkeit, haben jene Frucht möglich gemacht, die nun nach zehnjähriger Bemühung gepflückt worden ist: Der Staatsvertrag vom 15. Mai 1955 über die Wiederherstellung eines unabhängigen Osterreich: Eine Frucht, die natürlich nicht die Folgen der nationalsozialistischen Herrschaft ausmerzen kann, die uns auch für die Zukunft mit den Folgen dieser katastrophalen Vabanquepolitik belastet, die aber doch einen Ausblick in eine hellere Zukunft eröffnet.

Die rechtstheoretische Lehre aus diesen wenigen Andeutungen ist die, daß Gesetzgebung und Regierung viel bedeutsamer sind als Verwaltung und Rechtsprechung, daB Gesetzgebung und Regierung die Bedingungen der Freiheit und der Sicherheit einer Nation schaffen müssen, und die Verwaltung und Rechtsprechung nur die letzten Folgerungen aus dieser Sicherung ziehen können. 


\section{I p s e n - Hamburg:}

Es entspricht schon meinem Altersunterschied gegenüber Herrn Weber und Herrn Forsthoff, wenn ich mich nach ihren grundsätzlichen Ausführungen wieder etwas Speziellem zuwende, was aber in ihre prinzipielle Linie paßt. Und dabei scheint es mir obzuliegen, daß meine Beiträge zu den Verhandlungen unserer Vereinigung sich in den Niederungen der Utbergangsvorschriften des Grundgesetzes bewegen. So habe ich mich in Göttingen mit dem Art. 139 beschäftigt, in Tübingen mit Art. 131. Jetzt ist Art.134 GG an der Reihe, und zwar deshalb, weil der gegenwärtige Versuch seiner Handhabung im Entwurf des Kriegsfolgenschlußgesetzes, den Herr Erler schon apostrophiert hat, das Problem exemplifiziert, das meine beiden Vorredner gestellt haben. Art. 134 GG ist bekanntlich jahrelang verstanden und exerziert worden als eine Vorschrift speziell der Auseinandersetzung zwischen Bund und Ländern, und zwar zunächst unter Mitwirkung der Besatzungsmächte, später ohne sie nach ihrem Rückzug aus dem Komplex des früheren Reichsvermögens und des preußischen Vermögens. Erst danach und jetzt ist der 5. Absatz dieser Vorschrift ins Licht gerückt worden unter dem Gesichtspunkt, Art. 134 erteile nun wohl auch den Auftrag und er gebe die Handhabe, eine Auseinandersetzung der Bundesrepublik $\mathrm{m}$ it ihren Gläubigern durchzuführen. In diesem Art. 134 Abs. 5 steht, das Nähere regele ein Bundesgesetz. Und nun prüfe man, wie diese Auseinandersetzung sich zwischen einer Güterverteilung, die unter dem Eigentumsschutz der Verfassung steht, und der Handhabung der Finanzhoheit, die an sie nicht gebunden sein soll, in dem augenblicklich erörterten Gesetzentwurf ausmacht.

Man sieht dort im Regierungsentwurf zu der Frage der Quotierung der verbrieften Reichsverbindlichkeiten, also derjenigen Ansprüche von Gläubigern, die ihr Sparkapital dem Reich zur Verfügung gestellt haben und die schon zweimal eine Abwertung erfuhren, daß der Gesetzgeber für sich in Anspruch nimmt, mit dem angeblichen Auftrag des Art. 134 Abs. 5 GG frei und ungebunden normieren zu können, lediglich gehindert durch die Erwägung, ob er nicht etwa willkürlich handelt. Das zu vermeiden, ist - so die Begründung - sein heißes Bemühen. Damit setzt er sich auseinander, und dann führen die Vorschläge der Regierung dazu, daß der Entwurf sich frei macht von der Normalumstellung von $10: 1$, die die $\mathrm{Be}-$ satzungs- und die sie bestätigende spätere deutsche Gesetzgebung allen öffentlichen Körperschaften, auch den Ländern und den Gemeinden, auferlegt hat, während der Bund seinerseits 
nun dort, wo er als Fiskus schuldet, mit den Mitteln der Finanzgewalt eine Quotierung von nur noch 6,5 Prozent vorsieht. Das ist nach meiner Meinung ein Beispiel für das Problem, das hier gestellt worden ist: ob nämlich nicht die Verfassung mit ihrer Eigentumsgewährleistung solchen Prozeduren der Finanzhoheit verfassungsmäßige Grenzen zieht, während die Regierungspraxis, einschließlich der des Bundesrats, wie wir seine Stellungnahme heute kennen, glaubt - und eben das halte ich für bedenklich -, verfassungs $\mathrm{f} r \mathrm{e} i$ operieren $\mathrm{zu}$ können, angeblich lediglich gehindert durch das Willkürverbot.

Denn dahinter sehe ich auch das allgemeinere Problem, das uns ja in der Praxis immer häufiger begegnet: ob es nicht verfassungsmäßige Bindungen gebe oder geben müsse gegenüber Versuchen des Staates, sich aus seinen fiskalischen Bindungen dadurch $\mathrm{zu}$ befreien, daß er mit hoheitlichen Mitteln der Gesetzgebung prozediert und damit das ignoriert, was er in der anderen Gestalt des Fiskus vorher an Bindungen eingegangen ist.

K r ü g e r-Hamburg:

Ich glaube, wir können dem Vorstand und den beiden Rednern sehr dankbar dafür sein, daß sie das Thema Finanzverfassung haben behandeln lassen und behandelt haben. Denn hierdurch ist man sich bewußt geworden, daß man etwas nicht gesehen hat, das zu sehen nötig gewesen wäre. Jedermann, der irgendein Unternehmen beginnt, prüft zunächst die Frage, wie er ein solches Vorhaben finanziert. Und so sollte man eigentlich auch annehmen, daß die Theorie die Frage geprüft hätte, wie das Unternehmen „Staat" zu finanzieren sei. Das gilt vor allem für diejenige Richtung, die den Staat nicht als eine Vorgegebenheit hinnimmt, sondern von einzelnen Individuen wie etwa eine Aktiengesellschaft errichten läßt. Ich kann mich nicht daran erinnern, daß A. L. Schlözer die Frage aufgeworfen hätte, wie das Kapital für diese Aktiengesellschaft aufgebracht werden soll, ob die Aktionäre eine Nachschußpflicht haben usw. usw. Die letzte große "Allgemeine Staatslehre" von Georg Jellinek enthält gleichfalls nichts von den finanziellen Problemen des Modernen Staates.

Das Übergehen eines solchen Problems ist um so erstaunlicher als die Lösung, die der Moderne Staat für es gefunden hat, nicht nur an sich höchst eigenartig ist, sondern auch den einzelnen Menschen in einer Art und Weise trifft, wie sie vorher gänzlich unbekannt war. Es ist heute hierfür das Wort "militant" gebraucht worden. Diese Kennzeichnung weist in der Tat auf wesentliches hin. Denn wahrscheinlich hängt 
dieser militante Charakter der Finanzverfassung damit zusammen, daß die Finanzfrage für den Staat in ihrer ganzen Schärfe erst durch die Notwendigkeit gestellt worden ist, große stehende Heere zu unterhalten, - eine Notwendigkeit, die ihrerseits wieder durch die neuzeitliche Außenpolitik hervorgerufen worden ist. Eben deswegen findet man diesen militanten Charakter des Finanzwesens überall, wo es moderne Staatlichkeit gibt, - und nicht etwa nur in Preußen oder seinen "Traditionsträgern".

Versucht man, die Herausbildung einer militanten Finanzverfassung geschichtlich einzuordnen, so ergibt sich abermals, daß es nicht eigentlich der Absolutismus gewesen ist, der diese Eigenart des Modernen Staates zur vollen Entfaltung gebracht hat. Denn noch bis zum Ausgang des 18. Jahrhunderts gibt es in den Lehrbüchern des Staatsrechts eine feste Reihenfolge der Finanzierungsquellen, die mit dem Ertrag der Kammergüter beginnt und die direkte Besteuerung überhaupt nur als außerordentliche Einnahmequelle kennt. Es ist auch in dieser Hinsicht wieder die Französische Revolution, die gegen die Ineffizienz des absoluten Staates aufsteht und letzten Endes in der Einkommensteuer das ergiebige und elastische Finanzierungsinstrument schafft, das, wie Cordell Hull in seinen Memoiren bemerkt hat, allein der Finanzierung eines Krieges gewachsen ist. Die militante Art der Beschaffung der Geldmittel erweist sich damit ebenso wie die gleich militante Art der Gewinnung der persönlichen Mittel durch die allgemeine Wehrpflicht als eine Hervorbringung des Liberalismus und der Demokratie, - eine Seite des 19. Jahrhunderts, die m. E bisher nicht genügend beachtet worden ist. Es mag sein, daß diese Entwicklung noch nicht einmal ihren Endpunikt erreicht hat. Denn vielleicht wird das weitere Wachstum des Finanzbedarfs den Staat eines Tages auf den Gedanken bringen, sich nicht mehr nur in Gestalt von Besteuerung an dem Einkommen seiner Bürger zu beteiligen, sondern von vornherein selbst das Einkommen zu erzielen, das seine Bürger bisher erzielt haben, und unter diesem Gesichtspunkt die Sozialisierung des produzierenden Eigentums zu betreiben.

Mit der Aufdeckung des militanten Charakters der Finanzverfassung stellt sich das Problem, wie sich eine solche Verfassung zur Rechts- und Verfassungsstaatlichkeit verhält, Leitbildern; die gerade nicht militant gemeint sind. Hier tut sich eine Antinomie auf, die nicht einmal vereinzelt ist. So sollte man sich einmal ernsthaft fragen, ob von Freiheit und vor allem von ihrer Basis im Privateigentum noch die Rede sein kann, seitdem der Staat in der Lage ist, durch Ausgabe 
von Papiergeld den Wert der Kapitalien bis auf den Nullpunkt als Grenzwert herabzudrücken. Auf diese Weise haben zwei Inflationen weite Schichten ihres Vermögens berauben können, - trotz aller verfassungsmäßigen Verbürgung der Unverletzlichkeit des Eigentums. Man braucht aber noch nicht einmal nur an solche Katastrophen zu denken. Wenn etwa Vollbeschäftigung eine Forderung ist, der sich heute kein Staat mehr entziehen kann, wenn aber Vollbeschäftigung nur durch eine schleichende Inflation zu bewirken sein sollte, dann wäre abermals der Fall eingetreten, daß zwar Verfassungs- und Rechtsstaat ein Gut gewährleisten, daß aber der Sozialstaat sich genötigt sieht, dieses Gut ohne formelle Verletzung, aber dennoch im Ergebnis mehr oder weniger weitgehend zu entwerten.

Es scheint mir in der Tat eine Notwendigkeit zu sein, die Zweiheit der Verfassungen anzuerkennen und nicht etwa über der vordergründigen Rechtsstaat-Verfassung die hintergründige Finanzverfassung zu übersehen. Das Verhältnis beider Verfassungen muB als überaus problematisch bezeichnet werden. Insbesondere wäre es eine unzulässige Vereinfachung, wenn man lediglich nach einer „Entmilitarisierung“ der Finanzverfassung rufen würde. Denn das "militante" hat sich nicht nur als die zweite wesentliche Seite von Liberalismus und Demokratie ergeben, - ohne eine effiziente Finanzverfassung könnte vor allem auch der Sozialstaat nicht bestehen.

Ma u n z-München (Schlußwort):

Es ist kaum möglich, in einem kurzen Schlußwort auf die vielgestaltigen Fragestellungen und Antworten im einzelnen einzugehen, die im Laufe des heutigen Nachmittags entwickelt worden sind, von der österreichischen Finanzorganisation über das Verhältnis von Eigentum und Finanzgewalt und dem Kriegsfolgenschlußgesetz bis zum Gleichheitssatz im Steuerrecht, der Freiheit der Person und der Gewaltenteilung. Im ganzen habe ich den Eindruck, daß in bezug auf die von uns behandelten Fragen doch mehr Einmütigkeit als Meinungsverschiedenheiten bestehen, oder ich habe jedenfalls geglaubt, sie heraushören zu dürfen. Das scheint mir auf einem Gebiet, in dem die Auffassungen der Offentlichkeit sehr entschieden aufeinanderzuprallen pflegen, doch recht beachtlich zu sein.

$\mathrm{Da}$ die Bedenken, die gegen Leitsätze vorgebracht sind, in der Hauptsache die Leitsätze des Herrn Kollegen Hettlage betreffen und ich ihm die Antwort nicht vorwegnehmen will, darf ich mich wohl darauf beschränken, noch kurz auf den 
Diskussionsbeitrag des Herrn Kollegen Merk einzugehen, der sich mit meinen eigenen Leitsätzen beschäftigt hat.

Eine Beteiligung des Bundes an der wichtigsten Steuer, der Einkommensteuer, wie sie Herr Kollege Merk gefordert hat, besteht unbestrittenermaßen bereits jetzt, so daß wir sie wohl nicht mehr zu fordern brauchen, und soweit ich unterrichtet bin, strebt auch niemand danach, diese Beteiligung irgendwie $\mathrm{zu}$ beseitigen. Es ist auch selbstverständlich, daß kein wirklicher Föderalist dem Bund die Mittel zu entziehen wünscht, die er braucht, um seine ihm vom Verfassungsgeber zugeteilten Aufgaben zu erfüllen.

Wenn Herr Kollege Merk weiterhin gesagt hat, daß die Entscheidung über die Beteiligung des Bundes an der Einkommensteuer nur der Bund treffen kann und deshalb das Zustimmungsrecht des Bundesrates beseitigt werden müsse, so darf ich u. a. darauf hinweisen, daß der Bundesrat ein Bundesorgan ist. Kein anderes Bundesorgan kann von sich sagen, daß es in höherem Maße der Bund sei als der Bundesrat. Wenn also der Bundesrat nicht zustimmt in einem Fall, in dem seine Zustimmung für die Bildung des Bundeswillens erforderlich ist, dann will der Bund keine andere Regelung. Wir sagen ja auch nicht, da $B$ die politischen Parteien ein Gesetz beschlossen haben, sondern daß der Bundestag es getan hat.

Ich habe bereits in meinem Referat angedeutet, daB die Behauptung, durch eine Bundesfinanzverwaltung würde eine Milliarde eingespart werden - eine Behauptung, die mitunter in der Presse zu lesen ist -, durchaus umstritten ist. Es stehen ihr gegenüber Behauptungen und Berechnungen völlig anderer Art. Ich glaube aber nicht, daß wir auf diese selbst unter Fachleuten umstrittene Frage der Organisationskosten weiter eingehen sollten. Die Unterschiede mit Herrn Merk in der Beurteilung dessen, was ein endgültiger Finanzausgleich ist, und wie er aussehen könnte, sind meines Erachtens im wesentlichen so, daß über sie in Ruhe gesprochen werden kann. Eine völlige Utbereinstimmung über alle Fragen kann es nirgends und niemals geben. Ich würde es schon als einen großen Gewinn ansehen, wenn wir nach den Erörterungen des heutigen Tages bei aller kritischer Stellungnahme, die man von uns selbstverständlich erwartet, weder über die Finanzgestaltungen des Grundgesetzes noch über die Vorschläge des Bundesrates zu seiner Fortentwicklung von vornherein den Stab brechen oder sie als völlig unerträglich bezeichnen würden. Ich möchte im Gegenteil meinen, daß von allen Seiten - vom Grundgesetz her, von den Bundesorganen und von den Ländern her und nicht zuletzt auch von der 
Wissenschaft her - fruchtbare Gedanken für einen weiteren Ausbau unserer Finanzverfassung entwickelt worden sind, und $\mathrm{da} \beta$ das Bemühen aller Beteiligten unüberhörbar ist, auch auf dem Gebiete der Finanzen einen für Bund und Länder und nicht minder für die Wirtschaft nützlichen Ausgleich zu finden.

Het t l a g e-Mainz:

Schlu Bwort:

Meine Herren,

ich darf unsere Aussprache mit einigen wenigen Bemerkungen zu Einzelfragen beschließen. Unter diesen ist sicherlich die wichtigste die, zu der die Herren Weber, Forsthoff, Ipsen und Krüger sich geäußert haben, nämlich die Frage nach den verfassungsrechtlichen Grenzen der Finanzgewalt und ihrem Verhältnis zur Eigentumsgarantie. Ich sagte in meinem Bericht, daß die Finanzgewalt, wie jede andere Äußerung der Staatsgewalt, dem Sittengesetz unterworfen ist, so da $B$ eine sittenwidrige Besteuerung auch eine verfassungswidrige sein würde. Ich hob hervor, daß die Finanzgewalt ihre Grenze an dem Persönlichkeitsrecht des Art. 2 GG findet. Mit diesen Feststellungen scheint mir aber für eine konkrete Entscheidung über die verfassungsrechtlichen Grenzen der Besteuerung nicht viel gewonnen zu sein. Es ist gewiß kein Zufall, daß auch die Sittenlehre sich hinsichtlich der Sittenwidrigkeit der Besteuerung sehr zurückhaltend und durchaus nur in allgemeinen und grundsätzlichen Uberlegungen äußert. Nach ihr rechtfertigt das „Ubermaß" der Besteuerung noch keineswegs den Steuerstreik. Ein Besteuerung mit dem Ziele einer konfiskatorischen und sozial-revolutionären Änderung der Einkommens- und Vermögensordnung ist nach der herrschenden Meinung nicht sittenwidrig.

Für die Rechtsfrage nach den Grenzen der Finanzgewalt können aus ihrer Begrenzung durch das Sittengesetz keine im Einzelfall brauchbaren Regeln gewonnen werden. Die Antwort darauf könnte nur aus den Bestimmungen der Verfassung selbst und ihren tragenden Grundgedanken gewonnen werden. Die beiden wichtigen hier einschlägigen Grundgedanken unserer Verfassung sind die Eigentumsgarantie in Art. 14 GG und der Gleichheitsgrundsatz in Art. 3 GG. In unmittelbarer Form ist die Eigentumsgarantie gegenüber der Finanzgewalt nicht anzuwenden, denn das Wesen der Finanzgewalt besteht eben darin, Einkommens- oder auch Vermögensteile ohne Entschädigung für Zwecke in Anspruch zu nehmen, die der souveräne Gesetzgeber bestimmt oder zuläßt. Jedoch kann nicht verkannt werden, daß die Tendenz der Eigentumsgaran- 
tie auf die Erhaltung der bestehenden Besitzordnung und auch der Einkommenschichtung gerichtet ist, denn das wohlerworbene Einkommen gehört selbstverständlich zu den geschützten Eigentumsrechten. Dabei ist die rechtliche Erscheinungsform der verschiedenen Einkommensarten unerheblich; ganz überwiegend besteht Einkommen in Forderungsrechten oder entsteht daraus. Mir scheint, daß die Vermögensrechte $\mathrm{zwar}$ nicht ausdrücklich oder institutionell durch die Eigentumsgarantie des Art.14 GG gegen entschädigungslose Wegsteuerung geschützt sind, wohl aber tendenziell. Ein sozial-revolutionäres Steuergesetz, dessen ausgesprochener Zweck die entschädigungslose Wegnahme von Vermögensrechten zwecks tibertragung an andere ist, könnte verfassungswidrig sein. Hierbei kommt es sehr auf die gesamten Umstände an. Ein solches Gesetz ist beispielsweise das Lastenausgleichsgesetz, dessen ausgesprochener Zweck eine gesellschaftgestaltende Umwälzung der Besitzordnung durch entschädigungslose Wegnahme und Ubertragung etwa des halben Volksvermögens im Laufe von 37 Jahren ist. Dieser ausschließlich gesellschaftspolitische Zweck kommt schon darin zum Ausdruck, daß die Abgaben des Lastenausgleichs nicht für den Staat, sondern für ein rechtsfähiges Sondervermögen erhoben werden, aus dem sie an die Kriegsgeschädigten neu verteilt werden. Niemand von uns wird dieses sozial-revolutionäre Gesetz, das dem Ausgleich der Kriegsfolgen dient und letztlich auch vom Gleichheitsgrundsatz gerechtfertigt wird, deshalb für verfassungswidrig halten.

Uber den $Z$ weck der Besteuerung sagt die Verfassung selbst nichts. Sie unterstellt, daß die Finanzgewalt der Deckung des Finanzbedarfes dient. Dieser Finanzbedarf ist eine subjektive, nach Art, AusmaB und Zusammensetzung von politischen Vorstellungen bestimmte Größe. Die Frage der Verfassungwidrigkeit der Besteuerung könnte sowohl wegen der Verwendungszwecke der enteigneten Werte wie auch hinsichtlich der Art und des Ausmaßes der entschädigungslosen Fortnahme gestellt werden. Ich glaube nicht, daß die Finanzgewalt durch einen verfassungswidrigen Verwendungszweck der weggenommenen Gelder ihrerseits auch verfassungswidrig werden kann. Dafür ist der Zusammenhang zwischen dem einzelnen verfassungswidrigen Verwendungszweck im Rahmen der gesamten Staatszwecke und des gesamten Finanzbedarfes zu der einzelnen Besteuerungsmaßnahme allzu mittelbar.

Eher könnte die Finanzgewalt durch die Art des Eingriffs und sein Ausma $B$ in einem bestimmten Steuergesetz oder in einem bestimmten Anwendungsfall verfassungsrechtliche $\mathrm{Be}-$ 
denken auslösen. Aber auch hier sind die Grenzen zwischen erlaubt und nicht mehr erlaubt recht unbestimmt und kaum bestimmbar. Die Wegsteuerung der höchsten Einkommen zu $90 \mathrm{vH}$ oder mehr ist wegen dieses Ausmaßes allein sicherlich noch nicht verfassungswidrig. Es müssen jeweils materielle Gesichtspunkte der Steuergerechtigkeit verletzt sein, um von einem offensichtlichen Mißbrauch der Finanzgewalt sprechen zu können, der das Steuergesetz oder den einzelnen Steuereingriff nichtig macht. Dies würde z. B. für ein Steuergesetz gelten, das nichts anderes als die wirtschaftliche Vernichtung eines einzelnen Steuerpflichtigen oder einer Gruppe von Steuerpfllichtigen bezweckt.

Mehr glaube ich zu diesem schwierigen Fragenkreis hier im Augenblick nicht sagen zu können. Sicherlich gibt es eine Grenze der Finanzgewalt, deren Ubberschreitung sie wegen Mißbrauchs der Staatsgewalt und wegen Verletzung elementarer Gerechtigkeitsvorstellungen verfassungswidrig macht. Diese Grenze allgemeingültig näher festzulegen, scheint mir unmöglich.

Das Bekenntnis zum sozialen Rechtsstaat - darin stimme ich Herrn Forsthoff und auch Herrn Krüger zu - steht in einem schwer lösbaren Spannungsverhältnis zur Eigentumsgarantie. Sozialgestaltung mit dem Mittel der Besteuerung ist ein legitimes Anliegen der Finanzgewalt im sozialen Rechtsstaat. So würde z.B. eine Erbschaftsteuer, die bei größeren Vermögen und entfernteren Verwandtschaftsgraden mehr als die Hälfte des Nachlasses, möglicherweise sogar den ganzen Nachla $\beta$ wegsteuert, nach meiner Meinung nicht verfassungswidrig sein.

Bedeutender für unser Problem als die Eigentumsgarantie scheint mir der Gleich heitssatz zu sein. Art. 3 GG setzt der Finanzgewalt qualitative und quantitative Grenzen. So halte ich z. B. den Entwurf des Kriegsfolgenschlußgesetzes für verfassungswidrig, soweit es nur die verbrieften, nicht aber die nichtverbrieften Ansprüche gegen das Reich anerkennt und mit einem bescheidenen Satz umstellt. Hier scheint es mir auf das Bestehen oder Nichtbestehen des Rechtsanspruches gegen das Reich, nicht aber darauf anzukommen, ob und wie dieser Anspruch urkundlich verbrieft ist. Die Beurkundung eines Anspruchs ist für die Beweisfrage wichtig, nicht aber für seine rechtliche Existenz.

Das Wort vom Sozialstaat und vom sozialen Rechtsstaat ist für die staatsrechtliche Auslegung erschreckend vieldeutig. Damit hat sich die Tagung unserer Vereinigung im vergangenen Jahr befaßt. Mit der Forderung nach der Verwirk- 
lichung eines sozialen Rechtsstaates können gewisse Grundbekenntnisse der Verfassung, in erster Linie die Eigentumsgarantie, mittels der Finanzgewalt auf den Kopf gestellt werden. Die Mitglieder des parlamentarischen Rates, die 1949 der Verfassung zustimmten, haben sich unter dem sozialen Rechtsstaat durchaus Verschiedenes vorgestellt. Für die einen war das sozialstaatliche Adjektiv des Rechtsstaates sicher nicht mehr als ein Tropfen $O_{1}$ zur christlichen Salbung liberaler Grundrechte. Andere haben darunter das offengehaltene Tor zu künftigen sozialreformatorischen Gesetzen verstanden. Ein legitimes Mittel zu diesem Ziel ist seit je die Anwendung der Besteuerungsgewalt. Die marxisiische Doktrin mit ihren gesellschaftsbildenden Absichten bedient sich in den letzten Jahrzehnten weit mehr der Finanzgewalt als der groben Enteignung zur Verwirklichung ihrer gesellschaftsumbildenden Absicht. Jede Steuerbegünstigung, z. B. der kleinen Einkommensempfänger oder der Kleinsparer, jede starke Progression im Steuertarif dient zugleich diesem sozialreformatorischen Ziele. Der Verwaltungsstaat bedient sich mit Vorliebe der Finanzgewalt, um den Staatshaushalt zum großen Neu- und Andersverteiler des Volkseinkommens und in gewissen Grenzen auch des Volksvermögens zu machen.

Es war das Anliegen meines Berichtes, auf diese geschichtlichen und politischen Zusammenhänge der Finanzgewalt hinzuweisen. Die verfassungsrechtliche Grundordnung erlaubt es kaum, aus dem Gedanken der freiheitlichen Demokratie oder aus dem des sozialen Rechtsstaates der Sozialgestaltung durch die Steuergesetzgebung handbare Grenzen zu setzen. 